\title{
Seizures: incidence, diagnostic aspects and the costs of epilepsy
}

Citation for published version (APA):

Kotsopoulos, I. A. W. (2002). Seizures: incidence, diagnostic aspects and the costs of epilepsy. [Doctoral Thesis, Maastricht University]. Universiteit Maastricht. https://doi.org/10.26481/dis.20020301ik

Document status and date:

Published: 01/01/2002

DOI:

10.26481/dis.20020301ik

Document Version:

Publisher's PDF, also known as Version of record

\section{Please check the document version of this publication:}

- A submitted manuscript is the version of the article upon submission and before peer-review. There can be important differences between the submitted version and the official published version of record.

People interested in the research are advised to contact the author for the final version of the publication, or visit the DOI to the publisher's website.

- The final author version and the galley proof are versions of the publication after peer review.

- The final published version features the final layout of the paper including the volume, issue and page numbers.

Link to publication

\footnotetext{
General rights rights.

- You may freely distribute the URL identifying the publication in the public portal. please follow below link for the End User Agreement:

www.umlib.nl/taverne-license

Take down policy

If you believe that this document breaches copyright please contact us at:

repository@maastrichtuniversity.nl

providing details and we will investigate your claim.
}

Copyright and moral rights for the publications made accessible in the public portal are retained by the authors and/or other copyright owners and it is a condition of accessing publications that users recognise and abide by the legal requirements associated with these

- Users may download and print one copy of any publication from the public portal for the purpose of private study or research.

- You may not further distribute the material or use it for any profit-making activity or commercial gain

If the publication is distributed under the terms of Article $25 \mathrm{fa}$ of the Dutch Copyright Act, indicated by the "Taverne" license above, 


\section{Seizures:}

Incidence, diagnostic aspects and the costs of epilepsy 
The stydy presented in this thesis was conducted at the department of Neurology of the Maastricht University Hospital and the Research Institute for Extramural and Transmural Health Care (ExTra), which participates in the Netherlands School of Primary Care Research (CaRe), acknowledged in 1995 by the Royal Netherlands Academy of Sciences (KNAW).

\section{Also financially supported by: Janssen-Cillag BV}

The publication of this thesis was financially supported by: Nationaal Epilepsie Fonds-De Macht van het Kleine, GlaxoSmithKline BV, UCB Pharma BV, Sanofi-Synthelabo BV, Astra-Zeneca BV.

ISBN: 90-5681-124-X

Printing: Unigraphic Universiteit Maastricht

O2002, I.A.W. Kotsopoulos, Maastricht, the Netherlands

All rights are reserved, whether the whole or part of the material is concerned. No part of this publication may be reproduced, stored in a retrieval system, or transmitted in any form or by any means, electronic, mechanical, photocopying, recording or otherwise, without written permission from the copyright owner. 


\section{Seizures:}

\section{Incidence, diagnostic aspects and the costs of epilepsy}

\section{PROEFSCHRIFT}

ter verkrijging van de graad van doctor aan de Universiteit Maastricht, op gezag van de Rector Magnificus,

Prof. Dr. A.C. Nieuwenhuijzen Kruseman, volgens het besluit van het College van Decanen, in het openbaar te verdedigen op vrijdag 1 maart 2002 om 14.00 uur

door

Irene Aggelik Wilhelmina Kotsopoulos 
Promotores:

Co-promotores:

Beoordelingscommissie: Prof. Dr. H.F.P. Hillen (voorzitter)

Prof. Dr. C.A. van Donselaar (Erasmus Universiteit Rotterdam)

Prof. Dr. H.L.G.J. Merkelbach
Prof. Dr. P.G. Knipschild

Dr. J.L. Severens

Prof. Dr. J.A. Knottnerus

Prof. Dr. J. Troost

Dr. M.C.T.F.M. de Krom

Dr. T. van Merode 


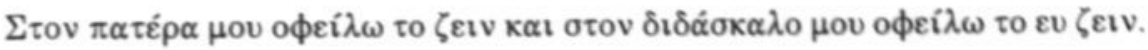





\section{Contents}

List of abbreviations

\section{Chapter 1:}

General introduction

\section{Chapter 2:}

Systematic review and meta-analysis of incidence studies of epilepsy and unprovoked seizures

\section{Chapter 3:}

The etiology of non-epileptic seizures: a systematic review

\section{Chapter 4:}

Incidence of epilepsy and unprovoked seizures: a population-based prospective study

\section{Chapter 5:}

The diagnosis of epileptic and non-epileptic seizures

\section{Chapter 6:}

Methodological issues in studies of the costs of epilepsy: a review

\section{Chapter 7:}

Estimating the costs of epilepsy: an international comparison of epilepsy cost studies

\section{Chapter 8:}

The costs of epilepsy in three different populations of patients with epilepsy

\section{Chapter 9:}

General discussion

Summary

Samenvatting

Acknowledgements 


\section{List of abbreviations}
AED
Antiepileptic drugs
$\mathrm{BU}$
Bottom Up
COI
Cost of illness
DES
Dissociative Experience Scale
DSM
Diagnostic and Statistic manual of Mental disorders
EC
Epilepsy center
GDP
Gross Domestic Product
GP
General Practice
$\mathrm{HC}$
Human Capital
ICEE
International Commission of Economic aspects of Epilepsy
ILAE International League Against Epilepsy
MMPI Minnesota Multiphasic Personality Inventory
NEH National Expenditure on Health
NES Non Epileptic Seizures
OECD Organization for Economic Cooperation and Development
PPP Purchasing Power Parities
QOLIE-31 Quality of Life in Epilepsy Inventory
TD
Top Down
UH
University Hospital 
General introduction 
An epileptic seizure is a clinical manifestation characterized by an intermittent, stereotyped, paroxysmal disturbance of consciousness, behavior, emotion, motor function, or sensation which arises because of abnormal and excessive discharges from a set of neurons in the brain $(1,2)$. According to the presence or absence of a acute precipitating insult, epileptic seizures can be categorized as provoked (acute symptomatic) or unprovoked seizures respectively. Patients who experience recurrent (two or more) unprovoked seizures obtain the diagnosis epilepsy. The time between these recurrent seizures has to be at least more than 24 hours, since multiple seizures occurring in a 24 -h period are considered a single event $(2,3)$. Epilepsy is a chronic neurological condition and one of the earliest recorded illnesses. The oldest known report of epilepsy is provided by a Babylonian tablet written in the neoAssyrian script dated between 718 and 612 B.C. (4). At this tablet is recorded that an individual with epilepsy is considered as a "possessed" person due to the "vow of the father" and by demons and ghosts who, childless themselves, looked on human children and young brides with envy and spite.

Over the years it became clear that epilepsy is not associated with any mystic, magic or religious cause but is rather a heterogeneous disorder. It results from many different cerebral disorders and physiological processes, and has a variable anatomical basis. Advances in technology and the conduct of descriptive epidemiological studies have increased the knowledge regarding the mechanisms of epileptogenesis, the natural history of epilepsy, its incidence and prevalence, and the risk factors associated with its development. In particular, the incidence studies of epilepsy indicate that the incidence of epilepsy varies considerably with age and that epilepsy is slightly more higher in males. However, these studies are difficult to interpret and compare because of methodological differences $(5,6)$.

In incidence studies, a prerequisite for a comprehensive case-ascertainment is an accurate diagnosis and classification of the cases. The diagnosis and classification of epilepsy depends highly on a meticulously obtained seizure description and on the use of ancillary tests (EEG, neuroimaging studies) $(5,7)$. The diagnosis of epileptic seizures may be hampered because these events are usually short-lived and sporadic, and occur too infrequently to be directly studied by physicians (8). In addition, different physical and psychological factors may cause paroxysmal phenomena which may be mistaken for epilepsy. As a result, these non-epileptic events may receive inappropriate, ineffective treatment often for long periods of time. The consequences of misdiagnosis are considerable: exposure to the toxicity of antiepileptic drugs, unnecessary health care costs, imposition of the lifestyle restrictions associated with epilepsy, and possible delay of appropriate psychological or other specific medical treatment (9-11). Thus, it is important to distinguish epileptic from non-epileptic seizures at an early stage of the seizure disorder.

Among the non-epileptic events, syncope and non-epileptic seizures (NES) are most often confused with epilepsy (1). The etiology of NES is probably multifactorial and involves several environmental and psychological factors (11). Early identification of the risk factors that underlie the development and maintenance of the NES would assist physicians in distinguishing epileptic from non-epileptic seizures at an early stage, and in establishing adequate treatment strategies.

In studies of the prognosis after a first unprovoked seizure, not only an accurate diagnosis and classification of seizures, but also other factors, which may influence the assessment of the outcome, have to be considered (e.g. referral patterns within the population studied, the timing of assessment for inclusion in the study, and the prevalence of a variety of potential risk factors within the population studied) (12-14). The reported estimates of the risk of recurrence vary between $40 \%$ and $52 \%$ in studies that have employed first-seizure methods (14). In general, $70-80 \%$ of the patients who developed seizures for the first time will 
eventually achieve remission, whereas the remaining $20-30 \%$ will continue to have seizures and will be classified as having chronic epilepsy (13).

Patients with chronic epilepsy differ in their pattern of service use and medical consumption from patients whose seizures are effectively controlled with regular treatment. Moreover, these patients are at greatest risk of unemployment and underemployment (15). Thus, patients with epilepsy, especially patients with poorly controlled seizures, incur significant direct and indirect costs to society. The International League Against Epilepsy (ILAE) recognized that epilepsy creates significant economic and social burdens and formed a Commission on the Economic Aspects of Epilepsy (ICEE) in 1994 (16, 17). This Commission emphasized the need to investigate the economic aspects of epilepsy in order to ensure that epilepsy care will be tailored to the needs of patients with epilepsy.

\section{Aims and outline of this thesis}

Based on these considerations, we considered in the first part of this thesis the epidemiological aspects of epilepsy (chapters 2 to 5) whereas in the second part we focused on the costs of epilepsy (chapters 6 to 8).

In summary, this thesis aims to answer the following questions:

1. What is the distribution of the incidence of unprovoked seizures and of epilepsy in different countries in relation to age, sex, etiology and seizure type?

We therefore reviewed systematically the incidence studies of unprovoked seizures and epilepsy in order to assess the methodological quality of these studies and to synthesize their results in a systematic way (chapter 2 ).

2. Which risk factors and mechanisms have been recently associated with the non-epileptic seizures?

For this purpose, we reviewed systematically the recent literature on the etiology of nonepileptic seizures with the aim to provide more insight into the recent evidence of the risk factors and mechanisms associated with NES (chapter 3).

3. How is the incidence of epilepsy and unprovoked seizures distributed in Maastricht and its surroundings in relation to age, sex, etiology and seizure type? (chapter 4)

4. Which factors are strong predictors for epileptic and non-epileptic seizures?

To answer these questions, we conducted a prospective population-based incidence study study in Maastricht and its surroundings to estimate the incidence of unprovoked seizures and epilepsy in a well-defined population and to identify predictive factors of the several seizure types with which epileptic seizures can be distinguished from non-epileptic seizure disorders more accurately (chapter 4).

5. Which items from the history, hetero-anamnesis and findings from physical examination and from diagnostic tests can assist in the early identification of patients with epileptic and non-epileptic seizures?

We therefore investigated in a prospective population-based study in Maastricht and its surroundings whether there is a cluster of diagnostic items which can differentiate patients with epileptic seizures from patients with non-epileptic seizures (chapter 5).

6. Which methodological issues have to be considered in order to make epilepsy cost studies more relevant for health policy decisions? (chapter 6)

7. What are the national and per capita estimates of the costs of epilepsy in different countries? (chapter 7)

To answer this questions, we performed a systematic review of epilepsy cost studies with the aim to assess their methodological quality and to systematically compare their direct cost estimates (chapters 6 and 7). 
8. How are the costs of epilepsy distributed in three different populations of patients with epilepsy? (chapter 8)

9. How are the direct costs in three different populations of patients with epilepsy associated with the patients' perception of their quality of life and with their seizure severity? We conducted a study of the costs of epilepsy care in three different populations of patients with epilepsy in the Netherlands (general practices, university hospital, and epilepsy center) and used cost questionnaires, cost diaries and a quality of life inventory in an attempt to answer these questions (chapter 8).

Finally, a general discussion of the findings in this thesis is presented in chapter 9 , followed by a summary of the main conclusions. 


\section{REFERENCES}

1. Chadwick D. Epilepsy. J Neurol Neurosurg Psychiatry. 1994;57(3264-277).

2. Commission on Epidemiology and Prognosis, International League Against Epilepsy. Guidelines for epidemiologic studies on epilepsy. Epilepsia. 1993;34:592-6.

3. ILAE Commission Report.The epidemiology of the epilepsies: future directions. Epilepsia. 1997; 38:614-8.

4. Wilson JVK, Reynolds EH. Translation and analysis of a cuneiform text forming part of a Babylonian treatise on epilepsy. Medical History. 1990:34:185-98.

5. Sander JW, Shorvon SD. Incidence and prevalence studies in epilepsy and their methodological problems: a review. J Neurol Neurosurg Psychiatry. 1987; 50:829-39.

6. Sander JW, Shorvon SD. Epidemiology of the epilepsies. J Neurol Neurasurg Psychiatry. 1996;61(5):433-43.

7. Jallon P, Loiseau P, Loiseau J. Newly diagnosed unprovoked epileptic seizures: presentation at diagnosis in CAROLE study. Epilepsia. 2001;42:464-75.

8. So NK, Andermann F. Differential diagnosis. In: J. Engel J, Pedley TA, eds. Epilepsy: A comprehensive textbook. Vol. 70. Philadelphia: Lippincott-Raven Publishers; 1997:791-7.

9. Nowack WJ. Epilepsy: a costly misdiagnosis. Clin Electroencephalogr. 1994;28(4):225-8.

10. Bowman ES. Nonepileptic seizures: psychiatric framework, treatment, and outcome. Neurology. 1999;53(Suppl. 2):S84-S88.

11. Krumholz A. Nonepileptic seizures:diagnosis and management. Neurology. 1999;53(Suppl. 2):S76-S83.

12. Chadwick D. Epilepsy after first seizures: risks and implications [editorial]. J Neurol Neurosurg Psychiatry. 1991;54(5):385-7.

13. Sander JW. Some aspects of prognosis in the epilepsies: a review. Epilepsia. 1993;34(6):1007-16.

14. Berg AT, Shinnar S. The risk of seizure recurence following a first unprovoked seizure: a quantative review. Neurology. 1991;41:965-72.

15. Jacoby A, Buck D, Baker G, McNamee P, Graham-Jones S, Chadwick D. Uptake and costs of care for epilepsy: Findings from a U.K. regional study. Epilepsia. 1998;39(7):776-786.

16. Beran RG, Pachtlako C. Report of the International League Against Epilepsy Commission on Economic Aspects of Epilepsy. Epilepsia. 1996;37:506-8.

17. Beran RG, Pachlatko C. Final report of the ILAE commission on economic aspects of epilepsy, 19941997. Epilepsia. 1997;38(12):1359-1362. 
14 | General introduction 
Systematic review and meta-analysis of incidence studies of epilepsy and unprovoked seizures

Authors: Kotsopoulos IAW, van Merode T, Kessels FGH, de Krom MCTFM, Knottnerus JA 


\section{Summary}

Purpose: To evaluate the methodology of incidence studies of epilepsy and unprovoked seizures and assess the value of their findings by summarizing their results.

Methods: A Medline literature search from January 1966 to December 1999 was conducted. In each selected study, key methodologic items such as case definition, and study design were evaluated. Furthermore, a quantative meta-analysis of the incidence data was performed. Results: 40 incidence studies met the inclusion criteria. There was considerable heterogeneity in study methodology and the methodological quality score was generally low. The median incidence rate of epilepsy and unprovoked seizures was 47.4 and 56 per 100,000 respectively. The age-specific incidence of epilepsy was high in those aged 60 years or older, but was highest in childhood. Males had a slightly higher incidence of epilepsy (median 50.7/100,000) than females (median 46.2/100,000) and partial seizures seemed to occur more often than generalized seizures. Developing countries had a higher incidence rate of epilepsy (median $68.7 / 100,000$ ) than industrialized countries (median 43.4/100,000). Similar results were found for unprovoked seizures. The incidence of epilepsy over time appears to decrease in children, whereas it increases in the elderly.

Conclusions: The age-specific incidence of epilepsy showed a bimodal distribution with the highest peak in childhood. No definitive conclusions could be reached for the incidence of unprovoked seizures and other specific incidence rates of epilepsy. More incidence studies with an adequate study methodology are needed to explore geographical variations and time trends of the incidence of epilepsy and unprovoked seizures. 


\section{INTRODUCTION}

Incidence studies provide important information regarding the natural history of epilepsy and its risk factors. During the last three decades, several incidence studies of epilepsy have been performed. These studies indicate that the incidence of epilepsy varies considerably with age and that epilepsy is slightly more common in males. Moreover, recent studies suggest a secular trend in the age-specific incidence, with a decline in children and an increase in elderly people $(1,2)$.

However, the available data are difficult to interpret and compare because of methodological differences $(3,4)$ and so far, the existing literature has not been reviewed systematically in order to assess the methodological quality and summarize the results of incidence studies. We performed a systematic review and a quantitative meta-analysis of incidence studies of epilepsy and unprovoked seizures (US) in order to study the effect of methodological quality on the incidence reported, on the magnitude of possible geographic differences in incidence, on the epidemiology of different types of seizures, and the possible changes of incidence over time.

\section{METHODS}

\section{Study selection}

We identified previously published incidence studies by conducting a Medline literature search from January 1966 to December 1999, using the MeSH subject headings "epidemiology", "epilep"” and "incidence". Additional relevant articles were found by tracking references. We considered studies eligible for inclusion if they recorded the incidence of epilepsy or of US and were published in English, French, German or Dutch. We excluded studies which included only acute symptomatic seizures, certain seizure patterns or epileptic syndromes such as absence epilepsy, reflex epilepsy, and Lennox-Gastaut syndrome. We also excluded studies which were restricted to selected populations (e.g. patients with gliomas or a stroke) or hospital-based studies, and studies published as a review, a letter or in abstract form only. If one study had several reports, we used the most recent and complete data for analysis.

\section{Methodological quality}

Based on earlier published proposals for reporting meta-analyses of observational studies (5), we developed a checklist (Appendix 1) to evaluate the methodological quality of all included studies. Each incidence study was scored on the following items: adequacy of case definition, type of study design, description of demography and selection criteria of the study population, type of described incidence rates, and type of epilepsy or epileptic seizure of which the incidence was defined. In accordance with the guidelines for epidemiologic studies on epilepsy of the ILAE (International League Against Epilepsy) (6, 7), we considered the items adequacy of case definition and type of study design as important quality items. The total quality score of each study is given in round numbers from 0 to 30 . Two authors (TvM and IK) independently evaluated all the incidence studies and reached a consensus with the aid of a third author (FK) in cases of disagreement. The degree of agreement was defined by using the Spearman correlation coefficient.

\section{Meta-analysis of results}

From each included study we extracted the country, year of publication, incidence rate of epilepsy or US, upper or lower age limits of the study, gender- and seizure-specific incidence 
rates, and total quality score. Furthermore, we recorded whether first attendance rates and age-adjusted or crude incidence rates were reported.

The median and ranges of the incidence rate of epilepsy and US were determined for three different age categories (children, adults, elderly) as well as by gender and seizure type. We estimated incidence rates from figures if a study did not present them in numbers and from original data if a study provided detailed demographic data (denominator) and the number of cases included (numerator). Wherever possible, we used crude incidence rates, as the methods used to adjust the results varied from study to study. Similarly, wherever possible, we used first attendance rates instead of incidence rates because first attendance rates are not subject to a selection bias, thereby giving a better representation of the size of the incident case population (3). Partial and generalized seizures were pooled, and simple partial, complex partial and secondary generalized partial seizures were combined.

We examined differences in the distribution of the several incidence rates by using the MannWhitney or the Kruskal-Wallis tests. As a sensitivity analysis, the pooling process was repeated after the successive removal of incidence studies with a low quality score. All statistical tests were two-sided, with a P-value $<0.01$ for statistical significance.

\section{RESULTS}

\section{Selected studies}

The Medline search yielded 161 English publications, eight French, one German and one Dutch (Table 1). Application of the exclusion criteria resulted in 30 incidence studies and reference tracking yielded another 10 studies. Only four studies (8-11) out of 40 were conducted earlier than 1980. Seven (12-18) of the 40 incidence studies were carried out in developing countries, and two $(19,20)$ in eastern European countries. Three studies (21-23) reported incidence rates of other diseases as well.

TABLE 1. Results of Medline search

\begin{tabular}{llc}
\hline Included & \multicolumn{1}{c}{ Excluded } & $\begin{array}{c}\text { No of selected } \\
\text { studies }\end{array}$ \\
161 English & $\begin{array}{l}\text { 14 certain seizure patterns } \\
35 \text { selected population } \\
11 \text { review }\end{array}$ & 28 \\
& 57 no incidence study & \\
& 4 letters & \\
8 French & 1 selected population & 1 \\
& 3 review & \\
1 German & 1 no incidence study & 0 \\
1 Dutch & 0 & 1 \\
\hline
\end{tabular}

\section{Methodological quality}

The quality score ranged from 6 to 30 (median 16). Table 2 shows the methodological quality scores of the 40 included studies. The interrater agreement on the scale was good $(r=0.98$, $\mathrm{P}=0.0001$ ). Most disagreement was caused by slight differences in interpretation and was easily resolved. Consensus was reached in all cases. Quality score and publication year of the study did not correlate $(r=0.20, P=0.21)$. Subgroup analysis provided similar results for industrialized and developing countries, and showed that recently published studies were not associated with a high quality score. 
TABLE 2. Methodological quality scores of the incidence studies

\begin{tabular}{lc}
\hline \multicolumn{1}{c}{ Studies } & Score \\
\hline $\begin{array}{l}\text { Sidenvall (32), Forsgren (25), Jallon (33), Beilmann } \\
\text { (19), Jallon (12) }\end{array}$ & $26-30$ \\
$\begin{array}{l}\text { Forsgren (24), Verity (34), Ellenberg (35), Hauser (2), } \\
\text { Braathen (36), Olafsson (37), Hauser (10), Annegers } \\
\text { (38), Lavados (13) }\end{array}$ & $21-25$ \\
$\begin{array}{l}\text { Doerfer (39), Granieri (40), Tsuboi (41), Kerănen (42), } \\
\text { Pavlovic (20), de Graaf (9), Blom (11), Placencia (14), }\end{array}$ & $16-20$ \\
$\begin{array}{l}\text { Tekle-Haimanot (15), Mani (16) } \\
\text { Juul-Jensen (43), Doose (44), Cockerell (1), Joensen } \\
\text { (45), Cockerell (21), Camfield (46), Rwiza (17), }\end{array}$ & $11-15$ \\
$\begin{array}{l}\text { Gissler (22), Kurtz (47), Rantala (48), Lahdorf (49), } \\
\text { Li (18) } \\
\text { vd Berg (8), lshida (50), Cavazutti (51), Okkes (23) }\end{array}$ & \\
\hline
\end{tabular}

TABLE 3. Reported incidence rates of epilepsy (/100,000/year)

\begin{tabular}{|c|c|c|c|c|c|c|}
\hline \multirow[t]{2}{*}{ Study } & \multirow{2}{*}{ Total } & \multicolumn{3}{|c|}{ Age } & \multirow{2}{*}{$\begin{array}{l}\text { Male } \\
\text { total }\end{array}$} & \multirow{2}{*}{$\begin{array}{c}\text { Female } \\
\text { total }\end{array}$} \\
\hline & & $\begin{array}{l}\text { Children } \\
(0-14 \mathrm{yr})\end{array}$ & $\begin{array}{l}\text { Adults } \\
(15-59 \mathrm{yr})\end{array}$ & $\begin{array}{l}\text { Elderly } \\
(260 \mathrm{yr})\end{array}$ & & \\
\hline Beilmann (19) & & 45.0 & & & & \\
\hline Verity (34) & & 430.0 & & & & \\
\hline Hauser (2) & 44.0 & 53.0 & 31.8 & 82.6 & 49.0 & 41.0 \\
\hline Braathen (36) & & 53.0 & & & & \\
\hline Olafsson (37) & 46.5 & 67.5 & 28.0 & 107.3 & 55.9 & 36.6 \\
\hline Hauser (10) & 48.7 & & & & 51.8 & 46.2 \\
\hline Annegers (38) & 35.5 & & & & & \\
\hline Lavados (13) & 113.0 & 124.4 & 103.4 & & 125.3 & 100.9 \\
\hline Doerfer (39) & & 52.1 & & & & \\
\hline Granieri (40) & 33.1 & & & 7.5 & 39.1 & 27.3 \\
\hline Tsuboi (41) & & 430.0 & & & & \\
\hline Kerănen (42) & 24.0 & & 23.0 & 27.0 & 31.0 & 17.0 \\
\hline Pavlovic (20) & & 650.0 & & & & \\
\hline de Graaf (9) & 32.8 & & & & & \\
\hline Blom (11) & & 82.3 & & & & \\
\hline Placencia (14) & 190.0 & 219.0 & 158.0 & 150.3 & 173.0 & 207.0 \\
\hline Tekle-Haimanot (15) & 64.0 & 86.0 & 36.0 & 20.5 & 72.0 & 57.0 \\
\hline Mani (16) & 49.3 & 61.0 & 42.0 & 23.2 & 50.7 & 47.7 \\
\hline Juul-Jensen $(43)^{\alpha}$ & 124.3 & & & & 39.0 & 28.0 \\
\hline Doose (44) & & 72.4 & & & & \\
\hline Cockerell (1) & 48.3 & 60.9 & 33.4 & 75.2 & 33.3 & 58.0 \\
\hline Joensen (45) & 42.8 & 71.5 & 29.0 & 15.0 & & \\
\hline Cockerell (21) & 23.0 & & & & & \\
\hline Camfield (46) & & 41.0 & & & & \\
\hline Rwiza (17) & 73.3 & 93.2 & 43.3 & 39.7 & 68.9 & 77.5 \\
\hline Kurtz (47) & & 840.0 & & & & \\
\hline Rantala (48) & & 130.0 & & & & \\
\hline Lahdorf (49) & & & & 87.0 & & \\
\hline $\mathrm{Li}(18)$ & 25.0 & & & & 32.0 & 19.0 \\
\hline Ishida (50) & & 145.0 & & & & \\
\hline Cavazutti (51) & & 82.0 & & & & \\
\hline Okkes (23) & 100.0 & & & & & \\
\hline Median & 47.4 & 82.2 & 34.7 & 39.7 & 50.7 & 46.2 \\
\hline
\end{tabular}

adivided the cumulative incidence reported in the study by the length of the observation period in years 


\section{Results from the incidence studies}

Table 3 and 4 summarize the results from the incidence studies. One study (22) did not provide the total incidence of the study population.

Figure 1 shows the distribution of the several incidence rates of epilepsy on a logaritmic scale. Because of the small number of incidence studies of US, we could not reasonally determine the distribution of the specific incidence rates of US.

TABLE 4. Reported incidence rates of unprovoked seizures (/100,000/year)

\begin{tabular}{|c|c|c|c|c|c|c|}
\hline \multirow[t]{2}{*}{ Study } & \multirow[t]{2}{*}{ Total } & \multicolumn{3}{|c|}{ Age } & \multirow{2}{*}{$\begin{array}{l}\text { Male } \\
\text { total }\end{array}$} & \multirow{2}{*}{$\begin{array}{r}\text { Female } \\
\text { total }\end{array}$} \\
\hline & & $\begin{array}{l}\text { Children } \\
(0-14 \mathrm{yr})\end{array}$ & $\begin{array}{l}\text { Adults } \\
(15-59 \mathrm{yr})\end{array}$ & $\begin{array}{l}\text { Elderly } \\
(\geq 60 \mathrm{yr})\end{array}$ & & \\
\hline Sidenvall (32) & & 94.7 & & & & \\
\hline Forsgren (25) & 56.0 & & 37.0 & 139.0 & 55.0 & 56.0 \\
\hline Jallon (33) & 45.6 & & & & & \\
\hline Jallon (12) & 64.1 & & & & & \\
\hline Forsgren (24) & 33.6 & & & & 38.5 & 28.7 \\
\hline Verity (34) & & 570.0 & & & & \\
\hline Ellenberg (35) & & 124.0 & & & & \\
\hline Hauser (2) & 61.0 & & & & & \\
\hline Annegers (38) & 50.9 & & & & & \\
\hline Tsuboi (41) & & 900.0 & & & & \\
\hline Juul-Jensen $(43)^{a}$ & 198.3 & & & & & \\
\hline Lahdorf (49) & & & & 104.0 & & \\
\hline vd Berg (8) & & 93.0 & & & & \\
\hline Median & 56.0 & 124.0 & 37.0 & 121.5 & 46.8 & 42.4 \\
\hline
\end{tabular}

"divided the cumulative incidence reported in the study by the length of the observation period in years

The age-specific incidence of both epilepsy and US shows a U-shaped pattern with higher rates for children and the elderly than for adults. Overall, the distribution of the age-specific incidence rates of epilepsy differed significantly $(\mathrm{P}=0.008)$. In particular, children differed significantly from the other age categories $(\mathrm{P}=0.002)$.

Furthermore, the incidence of epilepsy and US is slightly higher for males than for females. However, this difference was not significant.

In comparison with the industrialized countries (median 43.4), developing countries (median 68.7) have a higher median incidence rate of epilepsy but this difference was non-significant. Moreover, in these studies higher rates are found in children and adults than in the elderly. Generally, the median seizure-specific incidence rates are higher for partial than for generalized seizures but this difference was not significant (Table 5). The median incidence rate of partial seizures is higher in children (30) than in adults (7). Correspondingly, the median incidence rate of generalized seizures is 45.2 in children and decreases to 21 in adults. Two studies $(10,24)$ were repeated in the same area using the same methodology allowing an assesment of the incidence of epilepsy and US over time.

In the studies of Hauser et al. $(2,10)$ there was no significant difference in total incidence of epilepsy over time. However, they (2) observed significant changes in the age-specific incidence over time. The incidence in children aged less than 10 years decreased by $40 \%$ over the 10-year interval between the early study and the most recent one, whereas the incidence in the elderly population almost doubled during the same period.

Forsgren et al. (25) determined the incidence of US in adults prospectively and they found significantly higher incidence figures than a previous study (24). According to the authors (25), the most likely explanation for the increased incidence is a better case ascertainment in the latest study. 


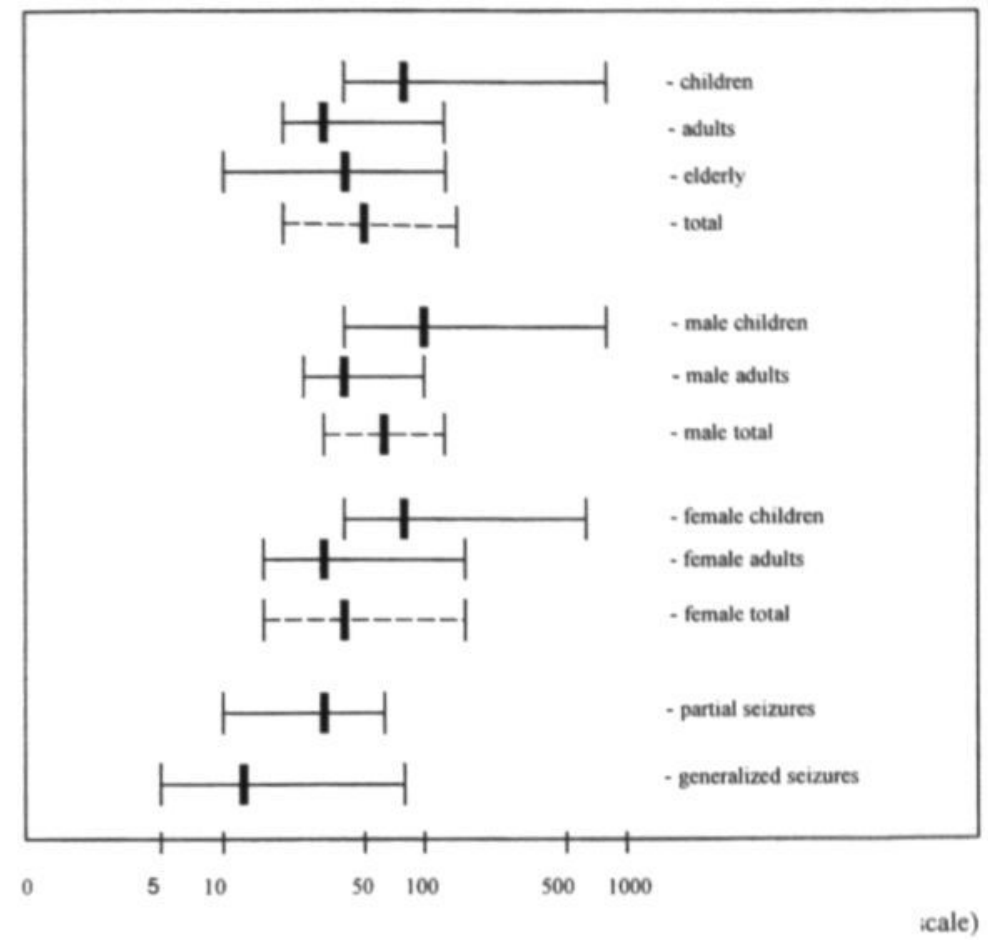

FIG. 1. Median and ranges of the incidence of epilepsy

TABLE 5. Seizure-specific incidence rates (/100,000/year)

\begin{tabular}{lcc}
\hline \multicolumn{1}{c}{ Study } & $\begin{array}{c}\text { Partial } \\
\text { total }\end{array}$ & $\begin{array}{c}\text { Generalized } \\
\text { total }\end{array}$ \\
\hline Forsgren (25) & 38.0 & \\
Forsgren (24) & 24.2 & 9.0 \\
Hauser (2) & 40.0 & 5.6 \\
Olafsson (37) & 14.4 & 32.1 \\
Hauser (10) & 30.4 & 22.0 \\
Lavados (13) & 60.8 & 43.2 \\
Granieri (40) & 10.6 & 19.6 \\
Joensen (45) & 21.9 & 16.8 \\
Rwiza (17) & 39.7 & 72.1 \\
\hline Median & 30.4 & 19.6 \\
\hline
\end{tabular}

As a sensitivity analysis, incidence studies with a quality score lower than 15,20 and 25 were removed successively, resulting in a decrease of the median incidence of epilepsy and US (from 47.6 through 46.5 to 45 , and from 58.5 through 53.4 to 50.8 respectively). Comparably, there was a decrease in the median incidence of generalized seizures (from 19.6 through 19.5 to 7.3 respectively) and in the median incidence of epilepsy for females (from 46.2 to 43.6 ), whereas the median incidence of partial seizures and the median incidence of epilepsy for 
males slightly increased (from 30.4 through 34.2 to 31.1 , and from 50.7 through 51.3 to 53.8 respectively). The median gender-specific incidence for US remained constant.

\section{DISCUSSION}

Our meta-analysis shows that the incidence studies of epilepsy and US differ considerably in their study methodology, resulting in a wide variation of the incidence rates. However, the methodological quality was generally low and despite the guidelines for epidemiological studies offered by the ILAE (7) in 1993, recently published studies did not significantly correlate with a high quality score.

\section{Epidemiology}

The incidence of epilepsy and US showed a bimodal distribution, with the highest peak in childhood. In particular, this distribution was significant for the incidence studies of epilepsy. The information from studies using selected age groups is consistent with the incidence data found in total population studies when age-specific incidence rates are evaluated. Possible causes of epilepsy in childhood are congenital, developmental, and genetic conditions $(4,26)$. The most common cause of epilepsy in the elderly population is cerebrovascular disease (4, 26, 27).

Overall, the gender-specific incidence was slightly higher for males than for females which may be the result of the higher incidence in males of definite risk factors for epilepsy (i.e. head injury, stroke, central nervous system infection). However, a similar pattern is seen when only cases with idiopathic or cryptogenic epilepsy are considered $(4,26)$.

Partial seizures seem to be the predominant seizure type in incidence studies. Studies which reported higher rates of generalized seizures may have, therefore, underreported partial seizures.

\section{Geographic differences}

The few studies that have been performed in developing countries have found higher incidence rates than in developed countries, and demonstrated a decrease of the incidence of epilepsy with age. It is likely that this different pattern of age-specific incidence of epilepsy reflects a different aetiological profile of epilepsy. In general, life expectancy in developing countries is shorter, resulting in fewer elderly people with strokes of cerebral tumours, which are common causes of epilepsy in developed countries. Furthermore, a number of specific tropical risk factors such as infections (i.e. schistomiasis, cysticercosis) and trauma (perinatal or lifelong) are associated with epilepsy, but the exact extent of this contribution is unknown (28).

\section{Changes over time}

There is some evidence that the incidence of epilepsy over time decreases in children whereas it increases in the elderly $(4,26,29)$. Several factors may be involved in this pattern, such as improved antenatal and prenatal care for children, and an increase in life expectancy in the elderly, associated with an increased risk for causes of epilepsy common in old age.

\section{Methodology of incidence studies}

Our meta-analysis of incidence data is accompanied by some limitations related to several methodological issues of the selected incidence studies.

Most of the incidence studies had a retrospective design and did not provide enough data for a further subgroup analysis of the incidence data (in separate age categories and by gender and seizure type). Furthermore, incidence studies often used different age-adjustment methods and 
defined age limits differently. However, there are studies which did define similar age limits (0-15 years for children, 16-59 years for adults and $\geq 60$ for the elderly) or whose results could be synthesized and analysed as such.

Another limitation is the issue of classification of epileptic seizures. Recent studies have classified epilepsy and epileptic seizures differently than older studies. Older studies often used the international classification of epilepsies and epileptic syndromes by the ILAE in 1989 (30). This classification appeared to be difficult to apply in retrospective studies or field surveys (4). Moreover, the extent to which an epileptic seizure is diagnosed and classified depends on a meticulously obtained seizure description and neurologic investigation $(3,4)$. A further difficulty concerns the definition of epileptic seizures. Many incidence studies did not provide thorough definitions of epilepsy and epileptic seizures, of the selection criteria and demography of the population studied, and did not fully explain their methods, introducing potential uncertainties into the results. In addition, incidence studies may differ in the inclusion of single seizures, neonatal seizures, febrile seizures and seizures in acute illness resulting in high incidence rates (3). In this meta-analysis, we have excluded the aforementioned seizures from the analysis. Moreover, in spite of the fact that non-febrile seizures can be distinguished in provoked and unprovoked seizures, a few studies, especially incidence studies in children, categorised all non-febrile seizures as US.

Taking into account all these limitations, we carried out a sensitivity analysis. This resulted in lower median incidence rates of epilepsy and US, reflecting a better case ascertainment method, classification, and definition of epileptic seizures. Hauser (26) reported that in incidence studies in France and Rochester, Minnesota, at least half of the newly occuring afebrile seizures did not fulfill the criteria for epilepsy.

\section{Recommendations}

The results of our meta-analysis were significant only for the age-specific incidence rates of epilepsy. For the other specific incidence rates of epilepsy and the incidence rates of US our findings did not reach significance, probably due to the small number of incidence studies. Similarly, our conclusions regarding the time trends of both the incidence of epilepsy and US, and the pattern of age-specific incidence of epilepsy in developing countries, cannot be definitive due to the low power of the studies. There is an urgent need for further incidence studies with appropiate methodology to document reliably the incidence of epilepsy and US worldwide, noting possible geographic differences and changes in the incidence over time. Therefore, the use of the guidelines of the $\operatorname{ILAE}(6,7)$ should be emphasized, and incidence studies should clearly state the demography of the studied population, the selection criteria and case ascertainment method. Preferably, in such studies, multiple overlapping search strategies for the identification of incident cases should be used (e.g. including review of neuroradiology reports and EEG files) to avoid selection bias by referral (31). 


\section{REFERENCES}

1. Cockerell OC, Eckle I, Goodridge DM, Sander JW, Shorvon SD. Epilepsy in a population of 6000 reexamined: secular trends in first attendance rates, prevalence, and prognosis. $J$ Neurol Neurosurg Psychiatry. 1995;58:570-6.

2. Hauser WA, Annegers JF, Kurland LT. Incidence of epilepsy and unprovoked seizures in Rochester, Minnesota: 1935-1984. Epilepsia. 1993;34:453-68.

3. Sander JW, Shorvon SD. Incidence and prevalence studies in epilepsy and their methodological problems: a review. J Neurol Neurosurg Psychiatry. 1987;50:829-39.

4. Sander JW, Shorvon SD. Epidemiology of the epilepsies. J Neurol Neurosurg Psychiatry. 1996;61(5):433-43.

5. Stroup DF, Berlin JA, Morton SC, et al. Meta-analysis of observational studies in epidemiology. JAMA. 2000;283:2008-12.

6. ILAE Commission Report. The epidemiology of the epilepsies: future directions. Epilepsia. 1997;38:614-8.

7. Commission on Epidemiology and Prognosis, International League Against Epilepsy. Guidelines for epidemiologic studies on epilepsy. Epilepsia. 1993;34:592-6.

8. Berg BJvd, Yerushalmy J. Studies on convulsive disorders in young children. Pediatr Res. 1969;3:298304.

9. Graaf ASd. Epidemiological aspects of epilepsy in Northern Norway. Epilepsia. 1974;15:291-9.

10. Hauser WA, Kurland LT. The epidemiology of epilepsy in Rochester, Minnesota, 1935 through 1967. Epilepsia. 1975;16:1-66.

11. Blom S, Heijbel J, Bergfors PG. Incidence of epilepsy in children: a follow up study three years after the first seizure. Epilepsia. 1978;19:343-50.

12. Jallon P, Smadja D, Cabre P, Mab GL, Bazin M, Group E. EPIMART: Prospective incidence study of epileptic seizures in newly referred patients in a French Carribean island (Martinique). Epilepsia. 1999;40:1103-9.

13. Lavados J, Germain L, Morales L, Campero M, Lavados P. A descriptive study of epilepsy in the district of El-Salvador, Chile, 1984-1988. Acta Neurol Scand. 1992;85:249-56.

14. Placencia M, Shorvon SD, Paredes V, et al. Epileptic seizures in an Andean region of Ecuador. Brain. 1992;115:771-82.

15. Tekle-Haimanot R, Forsgren L, Ekstedt J. Incidence of epilepsy in rural central Ethiopia. Epilepsia. 1997;38:541-46.

16. Mani KS, Rangan G, Srinivas HV, Kalyanasundaram S, Narendran S, Reddy AK. The Yelandur study: a community-based approach to epilepsy in rural South India-epidemiological aspects. Seizure. 1998;7:281-8.

17. Rwiza HT, Kilonzo GP, Haule J, et al. Prevalence and incidence of epilepsy in Ulanga, a rural Tanzanian district: a community-based study. Epilepsia. 1992;33:1051-6.

18. Li S, Schoenberg BS, Wang C, Cheng X, Zhou S, Bolis CL. Epidemiology of epilepsy in urban areas of the people's republic of China. Epilepsia. 1985;26:391-4.

19. Beilmann A, Napa A, Hämarik M, Soot A, Talvik I, Talvik T. Incidence of childhood epilepsy in Estonia. Brain and Development. 1999;21:166-74.

20. Pavlovic M, Jarebinski M, Pekmezovic T, Levic Z. Seizure disorders in preschool children in a Serbian district. Neuroepidemiology. 1998;17:105-10.

21. Cockerell OC, Goodridge DMG, Brodie D, Sander JWAS, Shorvon SD. Neurological disease in a defined population: the results of a pilot study in two general practices. Neuroepidemiology.

1996;15:73-82.

22. Gissler $\mathrm{M}$, Jărvelin $\mathrm{M}-\mathrm{R}$, Louhiala $\mathrm{P}$, Hemminki E. Boys have more health problems in childhood than girls: follow up of the 1987 Finnish birh cohort. Acta Pediatr. 1999;88:31-4.

23. Okkes IM, Lamberts $\mathrm{H}$. Verschillende frequentiecijfers van aandoeningen bij gezondheidsenquete en huisartsregistraties. Ned Tijdschr Geneeskd. 1997;141:634-9.

24. Forsgren L. Prospective incidence study and clinical characterization of seizures in newly referred adults. Epilepsia. 1990;31:292-301.

25. Forsgren L, Bucht G, Eriksson S, Bergmark L. Incidence and clinical characterization of unprovoked seizures in adults: a prospective population-based study. Epilepsia. 1996;37:224-9.

26. Hauser WA. Incidence and prevalence. In: jr JE, Pedley TA, eds. Epilepsy: A comprehensive Textbook. Philadelphia: Lippincott-Raven Publishers; 1997:47-57.

27. Stephen LJ, Brodie MJ. Epilepsy in elderly people. Lancet. 2000;355:1441-6.

28. Bittencourt PRMd, Adamolekum B, Bharucha N, et al. Epilepsy in the tropics: I. Epidemiology, socioeconomic risk factors, and etiology. Epilepsia. 1996;37:1121-7. 
29. Everitt AD, Sander JW. Incidence of epilepsy is now higher in elderly people than in children. BMJ. 1998;316:780.

30. Commission on Classification and Terminology of the International League Against Epilepsy. Proposal for revised classification of epilepsies and epileptic syndromes. Epilepsia. 1989;30:389-99.

31. Knottnerus JA. The effects of disease verification and referral on the relationship between symptoms and diseases. Med Decis Making. 1987;7:139-48.

32. Sidenvall R, Forsgren L, Blomquist HK, Heijbel J. A community-based prospective study of epileptic seizures in children. Acta Paediatr. 1993;82:60-65.

33. Jallon $\mathrm{P}$, Goumaz $\mathrm{M}$, Haenggeli $\mathrm{C}$, Morabia A. Incidence of first epileptic seizure in the canton of Geneva, Switzerland. Epilepsia. 1997;38:547-52.

34. Verity CM, Ross EM, Golding J. Epilepsy in the first 10 years of life: findings of the child health and education study. BMJ. 1992;305:857-61.

35. Ellenberg JH, Hirtz DG, Nelson KB. Age at onset of seizures in young children. Ann Neurol. 1984;15:127-34.

36. Braathen G, Theorell K. A general hospital population of childhood epilepsy. Acta Paediatr. 1995;84:1143-6.

37. Olafsson E, Hauser WA, Ludvigsson P, Gudmundsson G. Incidence of epilepsy in rural Iceland: a population-based study. Epilepsia. 1996;37:951-5.

38. Annegers JF, Dubinsky S, Coan SP, Newmark ME, Roht L. The incidence of epilepsy and unprovoked seizures in multiethnic, urban health maintenance organizations. Epilepsia. 1999;40:502-6.

39. Doerfer J, Wasser S. An epidemiologic study of febrile seizures and epilepsy in children. Epilepsy Res. 1987;1:149-51.

40. Granieri E, Rosati G, Tola R, et al. A descriptive study of epilepsy in the district of Copparo, Italy, 1964-1978. Epilepsia. 1983;24:502-14.

41. Tsuboi T. Prevalence and incidence of epilepsy in Tokyo. Epilepsia. 1988;29:103-10.

42. Keränen $\mathrm{T}$, Riekkinen $\mathrm{Pj}$, Sillanpăa $\mathrm{M}$. Incidence and prevalence of epilepsy in adults in Eastern Finland. Epilepsia. 1989;30:413-21.

43. Juul-Jensen P, Foldspang A. Natural history of epileptic seizures. Epilepsia. 1983;24:297-312.

44. Doose H, Sitepu B. Childhood epilepsy in a German city. Neuropediatrics. 1983;14:220-4.

45. Joensen P. Prevalence, incidence, and classification of epilepsy in the Faroes. Acta Neurol Scand. 1986;74:150-5.

46. Camfield CS, Camfield PR, Gordon K, Wirell E, Dooley JM. Incidence of epilepsy in childhood and adolescence: a population based study in Nova Scotia from 1977 to 1985. Epilepsia. 1996;37:19-23.

47. Kurtz Z, Tookey P, Ross E. Epilepsy in young people: 23 year follow up of the British national child development study. BMJ. 1998;316:339-42.

48. Rantala $\mathrm{H}$, Ingalsuo $\mathrm{H}$. Occurence and outcome of epilepsy in children younger than 2 years. $J$ Pediatr. 1999;135:761-4.

49. Lahdorf K, Jensen LK, Plesner AM. Epilepsy in the elderly: incidence, social function, and disability. Epilepsia. 1986;27:135-41.

50. Ishida S. Prevalence of epilepsy in Okayama prefecture: a neuroepidemiologic study. Folia Psychiatr Neurol Jpn. 1985;39:325-32.

51. Cavazzuti GB. Epidemiology of different types of epilepsy in school age children of Modena, Italy. Epilepsia. 1980;21:57-62. 
APPENDIX 1. Checklist of incidence studies*

Score

1. Definition of epilepsy, epileptic seizures

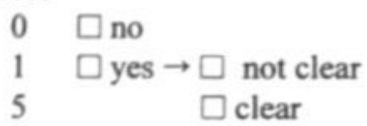

2. Type of study

$\begin{array}{cc}9 & \square \text { prospective } \\ 4 & \square \text { review of medical records } \\ & \text { and reexamination of positive cases } \\ 3 & \square \text { review of medical records } \\ 2 & \square \text { survey and reexamination of } \\ \text { positive cases } \\ 1 \quad \square \text { survey }\end{array}$

3. Study population

a. Demography

$$
\begin{aligned}
& 0 \\
& 2 \\
& \square \text { no }
\end{aligned}
$$

b. Description of selection criteria

$$
\begin{aligned}
& 0 \square \text { no } \\
& 1 \square \text { yes } \rightarrow \square \text { not clear } \\
& 3 \square \text { clear }
\end{aligned}
$$

4. Epilepsy, epileptic seizures†

$3 \square$ epilepsy

$2 \square$ certain seizures

$3 \square$ unprovoked seizures

$0 \quad \square$ epileptic seizures (provoked and unprovoked)

5. Incidence‡

$1 \square$ age adjusted incidence rates

$1 \square$ age specific incidence rates

$1 \square$ syndrome specific incidence rates

$1 \square$ sex-specific incidence rates

$1 \square$ cumulative incidence rates

$0 \quad \square$ incidence rates

$1 \square$ time trends of incidence rates

*Maximal score: 30

†Type of epilepsy or epileptic seizure of which the incidence was defined ¥Maximal score on this item: 
The etiology of non-epileptic seizures: a systematic review

Authors: Kotsopoulos IAW, van Merode T, Kessels FGH, de Krom MCTFM, Knottnerus JA 


\section{Summary}

Purpose: To provide insight into the recent evidence on risk factors and mechanisms that are associated with non-epileptic seizures (NES).

Methods: Studies on the etiology of NES were selected by a Medline literature search from January 1995 to December 1999. The methodological quality of the selected studies was evaluated. In addition, in each selected study several items which can provide evidence about the possible risk factors for NES were assessed, such as: medical history, neuropsychological testing, psychiatric assessment, reporting of possible causes and the use of control groups.

Results: 33 studies met the inclusion criteria. There was a considerable heterogeneity in study methodology, and the methodological quality score was generally low. $59 \%$ of the studies included 25 cases or less. $56 \%$ did not have any control groups and the most frequent control group consisted of patients with epilepsy $(41 \%)$. The most frequently used neuropsychological tests were the Dissociative Experience Scale (DES) (12.5\%) the Minnesota Multiphasic Personality Inventory (MMPI) (9\%) and depression scales (9\%). Conclusions: While several psychological factors may underlie the development and maintenance of NES, no definite conclusions could be reached regarding their etiology. More studies with an adequate methodology are required to identify the underlying mechanisms of NES. These studies should preferably be prospective studies in populations unselected by referral. 


\section{INTRODUCTION}

The etiology of non-epileptic seizures has been the subject of study in medical and psychiatric literature for some time. Theories regarding the causes of these seizures are probably as diverse as the phenomenology of this type of seizures.

Information about the mechanisms that underlie the onset of non-epileptic seizures (NES) may assist in the early identification of patients with NES, and is therefore of primary importance for the adequate and specific treatment of these patients, and for preventing inappropriate, ineffective, and unnecessarily costly management.

NES have been studied by neurologists as well as by psychiatrists and are considered to be psychiatric disorder which can be influenced by several environmental, and psychological factors (1). They are defined as "a sudden disruptive change in a person's behavior, which is usually time limited, and which resembles, or is mistaken for, epilepsy, but which in EEG analysis is unaccompanied by the excessive electrical discharge of brain cells which indicates true epilepsy, and is not caused by an organic disease" (2). Psychiatrists have often classified NES as a symptom of a specific psychiatric disorder by using the Diagnostic and Statistical Manual of Mental Disorders (DSM), whose most recent edition (DSM IV) was published in 1994 (3).

The purpose of our study was to review systematically the recent literature on the etiology of NES in order to provide insight into recent evidence of the risk factors and mechanisms that are associated with NES.

\section{METHODS}

\section{Study selection}

As our aim was to identify recently published studies on the etiology of NES, we searched the Medline database from January 1995 (i.e. one year after the edition of DSM IV (3)) to December 1999, using as search terms 17 synonyms for non-epileptic seizures: hysteroepilepsy, hysterical seizures, hysterical epilepsy, pseudoepilepsy, pseudoseizures, pseudoepileptic seizures, psychogenic seizures, psychoseizures, psychoepilepsy, psychogenic nonepileptic seizures, psychogenic pseudoseizures, nonconversion nonepileptic seizures, nonepileptic conversion seizures, nonepileptic attack disorder, functional seizures, simulated epilepsy and emotional seizures.

For additional relevant articles, we also searched the references of review articles and of the selected articles. Furthermore, we reviewed the abstracts produced by the literature search to identify studies which focused on the risk factors for the development of NES. Moreover, we collected indexed studies for which an abstract was not available in the Medline database, and evaluated whether they supplied information about the etiology of NES. We excluded studies published in languages other than English, studies published as a narrative overview, as a letter or in an abstract form only. If one study had several reports, we used the most recent and complete cohort for analysis.

\section{Evaluation of the selected studies}

We developed a checklist (Appendix 1) in order to evaluate the methodological quality of the selected studies and assess the information provided by these studies regarding the etiology of NES.

In each study, the methodological quality was scored on the following items: adequacy of definition, study design (a retrospective or a cross-sectional design), description of selection criteria, identification of non-epileptic seizures (with an EEG or video-EEG monitoring), and classification of the phenomenology of non-epileptic seizures (according to the epileptic 
seizures they resemble or to patterns of presentation (4). More specifically, we evaluated whether NES had also been psychiatrically diagnosed and classified as a symptom of a conversion disorder, since most of the NES can be classified as a Conversion Disorder with Seizures or Convulsions (5).

We considered that for interpreting the results of a study, a clear definition of the NES and a thorough description of the selection criteria of the patient population are needed.

In addition, we included in the checklist items which can provide evidence about the possible risk factors for NES. These items are: medical history, neuropsychological testing, psychiatric assessment, report of possible causes and use of control groups (patients with epilepsy or patients with psychiatric disorders). Furthermore, we noted the number of cases included in the empirical study and we assumed that the higher the number of cases included in a study, the higher the statistical power of the results of the study. The total quality score of each study is given in round numbers from 0 to 30 .

Two authors (IK and TM) independently evaluated all the included studies with this checklist and reached a consensus, with the aid of a third author (FK) in cases of disagreement. The degree of agreement was defined by using the Spearman correlation coefficient, a nonparametric test.

TABLE 1. Results of Medline search regarding common terms of NES

\begin{tabular}{lcc}
\hline Search term & No of studies & $\begin{array}{c}\text { No of selected } \\
\text { studies }\end{array}$ \\
Hysteroepilepsy & 0 & 0 \\
Hysterical seizures & 1 & 0 \\
Hysterical epilepsy & 0 & 0 \\
Pseudoepilepsy & 0 & 0 \\
Pseudoseizures & 55 & 18 \\
Pseudoepileptic seizures & 4 & 1 \\
Psychogenic seizures & 35 & 6 \\
Psychoseizures & 0 & 0 \\
Psychoepilepsy & 0 & 0 \\
Psychogenic non-epileptic seizures & 18 & 2 \\
Psychogenic pseudoseizures & 1 & 1 \\
Nonconversion non-epileptic seizures & 2 & 1 \\
Non-epileptic conversion seizures & 4 & 1 \\
Non-epileptic attack disorder & 6 & 3 \\
Functional seizures & 1 & 0 \\
Simulated epilepsy & 0 & 0 \\
Emotional seizures & 0 & 0 \\
\hline Total & 137 & 33 \\
\hline
\end{tabular}

\section{RESULTS}

\section{Selected studies}

Our search identified 137 articles; 33 were selected according to the defined criteria (Table 1). Excluded were 4 letters, 10 studies published in languages other than English, 15 overviews and 75 studies because they did not supply any information about the etiology of NES. It appeared that the most common terms for NES were pseudoseizures, psychogenic seizures and psychogenic non-epileptic seizures. The terms hysteroepilepsy, hysterical seizures, hysterical epilepsy, pseudoepilepsy, psychoseizures, psychoepilepsy, simulated epilepsy, and emotional seizures seemed to be abandoned, probably because of their pejorative meaning (6). These terms were commonly used in the 1960 s and 1970 s. 
Table 2 shows the basic study characteristics. Only $9(7-15)$ of the 32 studies were published before 1997.

TABLE 2. Baseline characteristics and quality score of studies of NES

\begin{tabular}{lccc}
\hline Study & Year & No of cases & Score \\
\hline Aldenkamp (27) & 1997 & 24 & 29 \\
Alper (16) & 1997 & 132 & 28 \\
Bowman (12) & 1996 & 45 & 28 \\
Ferracuti (28) & 1999 & 16 & 27 \\
Frances (29) & 1998 & 30 & 25 \\
Bowman (30) & 1999 & 58 & 24 \\
Derry (11) & 1996 & 24 & 23 \\
Jawad (14) & 1995 & 46 & 23 \\
Barry (31) & 1998 & 37 & 22 \\
Rechlin (32) & 1997 & 18 & 21 \\
Arnold (10) & 1996 & 14 & 21 \\
Alper (15) & 1995 & 91 & 21 \\
Harden (33) & 1997 & 2 & 18 \\
Blumer (13) & 1995 & 21 & 18 \\
Wyllie (34) & 1999 & 38 & 18 \\
Berkhoff (35) & 1998 & 10 & 17 \\
Krahn (9) & 1995 & 6 & 17 \\
Kalogjera (36) & 1999 & 53 & 16 \\
Ney (37) & 1998 & 5 & 16 \\
Sigurdardottir (38) & 1998 & 14 & 16 \\
Ettinger (39) & 1999 & 56 & 16 \\
Reilly (40) & 1999 & 40 & 15 \\
Griffith (41) & 1998 & 14 & 15 \\
Wood (42) & 1998 & 9 & 15 \\
Bell (43) & 1998 & 13 & 15 \\
Wolanczyk (44) & 1998 & 1 & 14 \\
Carmant (8) & 1995 & 2 & 14 \\
Breier (45) & 1998 & 25 & 12 \\
Evans (46) & 1999 & 1 & 11 \\
Kalogjera (47) & 1997 & 55 & 11 \\
Moore (17) & 1997 & 185 & 10 \\
Baker (7) & 1995 & 1 & 9 \\
\hline & & & \\
\hline
\end{tabular}

\section{Methodological quality}

The quality score ranged from 9 to 29 (median 17). The interrator agreement on the scale was good $(\mathrm{rho}=0.96, \mathrm{P}=0.0001)$. Most disagreement was caused by slight differences in interpretation and was resolved easily (Fig. 1). Consensus was reached in all cases. Quality score and publication year did not correlate $(r h o=-0.075, P=0.68)$, showing that recently published studies did not associate with a high quality score.

The majority of the studies $(62.5 \%)$ scored lower than 20 , indicating insufficient methodological quality. In particular, many studies $(47 \%)$ did not have clear selection criteria and $69 \%$ of the studies had no clear definition of NES. Only two studies diagnosed and classified NES according to the DSM criteria as well $(15,16)$. With respect to the study design, more than the half of the studies (56\%) had a cross-sectional design. Unsurprisingly, in $75 \%$ of the studies, patients with NES were identified with a video-EEG, a reliable instrument for the diagnosis of NES (1). Furthermore, only a few studies (19\%) classified the phenomenology NES and in most cases they classified them according to the epileptic seizures they resemble.

Only $41 \%$ of the studies included more than 25 cases and the maximum number of cases included in a study was 185 (17). It appeared that the more cases a study included, the higher 
the methodological quality score: a linear regression model showed that there was a significant relationship between the methodological quality score, calculated without the score of the item "number of cases", and the number of cases included in a study ( $\mathrm{P}=0.002)$.

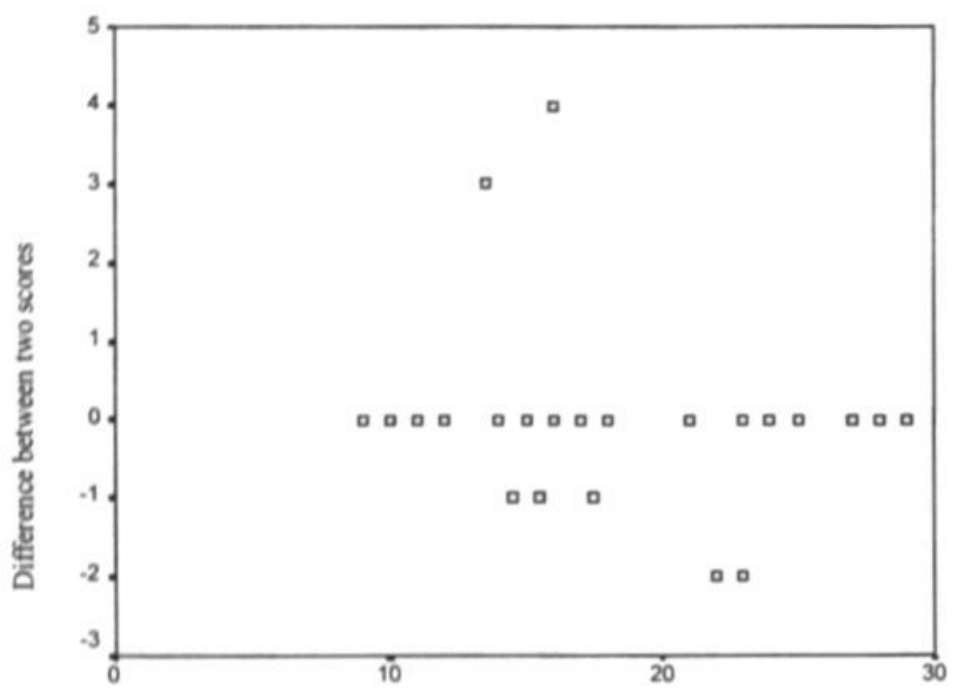

Mean of scores

FIG. 1. Interrater disagreement

\section{Etiology}

More than half of the studies reported the medical history of patients with NES, the possible causes for these seizures, and evaluated the psychological aspects of patients with nonepileptic seizures with neuropsychological tests and a psychiatric assessment. However, many studies (56\%) did not have any control groups. The most frequent control group consisted of patients with epilepsy ( $41 \%$ of the studies). Only one study used psychiatric patients as control group (14).

The most frequently used neuropsychological tests were the Dissociative Experience Scale (DES) (12.5\%), the Minnesota Multiphasic Personality Inventory (MMPI) (9\%), and depression scales ( $9 \%$ ). However, many studies $(34 \%)$ used other, less widely applied, neuropsychological tests to evaluate patients with NES, such as the Neurobehavioral Inventory (NBI), Perceived Stress Scale (PSS), Social Avoidance and Distress Scale (SADS), Halstead-Reitan Neuropsychological Test Battery, and the Family Emotional Involvement and Criticism Scale (FEICS).

Studies of NES suggested that several psychological factors may underlie the development and maintenance of these seizures, such as mood disorders (e.g. anxiety, depression), personality disorders (e.g. somatisation disorder), trauma, physical or sexual abuse, relationship problems, family dysfunctioning, and stress. 


\section{DISCUSSION}

This systematic review indicates that no definite conclusions can be drawn regarding the etiology of NES. The studies reviewed suggest that patients with NES tend to have been exposed to various types of trauma (e.g. head trauma, sexual and physical abuse) and that their families have generally disturbed patterns of communication $(1,18)$. In addition, several co-morbid psychiatric diagnoses may contribute to the development and maintenance of NES (5).

The majority of the studies reviewed had a small sample size of cases, and usually identified patients with NES in tertiary centers, which limits the value of their conclusions (19). Cases derived from tertiary centers may cause a selection bias regarding the identification of risk factors associated with NES, as these cases are often patients with long-standing NES who have been misdiagnosed with epilepsy $(1,20)$.

Although many of the reviewed studies attempted to identify precipitating events and underlying mechanisms of NES by taking an adequate neuropsychiatric history, few studies used control groups to obtain additional information regarding the risk factors for NES. The most frequent control group were patients with epilepsy, since epilepsy may coexist with NES. Up to $20 \%$ of patients identified as having NES have been reported to have epileptic seizures as well (21). In these studies, the association between possible risk factors and NES is not expressed in terms of OR (odds ratio) or RR (relative risk), probably due to the small sample sizes and the short follow-up period. Nonetheless, many patients with NES do not have epilepsy (21) and a number of psychiatric disorders may include NES in their symptoms $(1,22)$. Thus, the choice of the control group (patients with epilepsy, patients with psychiatric disorders or the general population) will depend on the purpose of the study. A study aiming at the etiology of NES generally needs a control group different from that of a study whose aim is to distinguish NES from other paroxysmal disorders (e.g. non-epileptic from epileptic seizures).

With respect to the methodological quality of the reviewed studies, this systematic review shows that studies of NES are characterized by a wide methodological heterogeneity and generally have a low methodological quality. Therefore, the quality of evidence regarding the possible risk factors for NES is low.

The definition of NES and the selection criteria of patients with NES were often unclear due to a lack of consensus regarding the terminology of NES and of standardized methods to assess patients with NES.

Patients with NES are a heterogeneous group with different symptomatology and underlying psychopathology. For instance, men may have a different phenomenology of NES from women (4), and long-standing NES are more likely to be found in patients with severe personality disorders, whereas recent-onset NES are more likely to have occurred in patients who have experienced extreme stressors (23). Consequently, it is important to identify subgroups of patients with NES. However, the studies reviewed have scarcely described and classified patients with NES.

Depending on the symptom pattern, NES can be classified either according to their pattern of presentation or to the epileptic seizures they resemble. Moreover, NES can also be diagnosed and classified into three major DSM categories: somatoform disorders (i.e. somatisation disorders, and conversion disorders associated with major or minor psychopathology), factitious disorders and malingering (1). Francis et al. (24), however, argued that the DSM IV classification lacks specificity to NES, given the heterogeneous presentation of these attacks. Similarly, Trimble (20) pointed out that a subgroup of patients with NES may have no apparent underlying neurological or psychiatric morbidity. Therefore, the DSM classification cannot be applied to these patients and their attacks will remain unclassifiable. 
Furthermore, differences in theoretical approaches taken by researchers have resulted in different neuropsychological tests and in surveys of different sets of psychopathological conditions in patients with NES. For instance, in at least one subgroup of patients, NES can be considered a dissociative phenomenon $(18,22,25)$. In these patients, dissociation acts as a central defensive mechanism to keep painful or unendurable affects out of conscious awareness. This cognitive-behavioristic theory (26) has been explored in $12.5 \%$ of the studies reviewed by applying the DES to patients with seizures. Similarly, from a psychodynamic perspective, certain personality types are associated with various diseases (24). Therefore, $9 \%$ of the studies reviewed used the MMPI to measure specific attributes of personality in patients with NES.

Such diversity in neuropsychological tests gives rise to discrepancies, as it is difficult to interpret and compare the results of the studies.

In sum, there are a number of factors which limit the value of the findings of the studies reviewed: unclear definition and selection criteria, lack of standardized methods to assess and describe patients with NES (medical history, neuropsychological tests, psychiatric assessment and classification), groups of patients selected (mostly from tertiary neurological centers), small sample size, short follow-up and lack of control groups.

Thus, there is an urgent need for further studies of NES to identify the underlying mechanisms of NES. Such studies of NES should use a transparent methodology and analysis of the data, clearly describe the definitions used, the selection criteria of the population, the way subtypes of patients with NES were identified and patients with NES were assessed, the choice of the control group and the limitations of the data. Prospective studies with a long follow-up, and a large sample size, preferably from populations not selected by referral, should be encouraged, as the studies published until now provide little evidence about the risk factors for NES. 


\section{REFERENCES}

1. Krumholz A. Nonepileptic seizures:diagnosis and management. Neurology. 1999;53(Suppl. 2):S76-S83.

2. Betts T, Boden S. Pseudoseizures (non-epileptic attack disorder). In: Trimble M, ed. Women and epilepsy. Chichester: John Wiley and Sons Ltd; 1991:237-254.

3. A.P.A., ed. Diagnostic and Statistical Manual of Mental Disorders. Washington DC: American Psychiatric Association; 1994.

4. Merode Tv, Krom MCTFMd, Knottnerus JA. Gender-related differences in non-epileptic attacks: a study of patient's cases in the literature. Seizure. 1997;6:311-315.

5. Bowman ES. Nonepileptic seizures: psychiatric framework, treatment, and outcome. Neurology. 1999;53(Suppl. 2):S84-S88.

6. Scull DA. Pseudoseizures or non-epileptic seizures (NES); 15 synonyms. J Neurol Neurosurg Psychiatry. 1997;62(2):200.

7. Baker GA, Moore P, Appleton RE. Non-epileptic attack disorders in children and adolescents: a single case study. Seizure. 1995;4:307-309.

8. Carmant L, Kramer U, Mikati MA, Riviello JJ, Helmers SL, Holmes GL. Pseudoseizure manifestations in two preschool age children. Seizure. 1995;4:147-149.

9. Krahn LE, Rummans TA, Sharbrough FW, Jowsey SG, Cascino GD. Pseudoseizures after epilepsy surgery. Psychosomatics. 1995;36(5):487-493.

10. Arnold LM, Privitera MD. Psychopathology and trauma in epileptic and psychogenic seizure patients. Psychosomatics. 1996;37(5):438-443.

11. Derry PA, McLachlan RS. The MMPI-2 as an adjunct to the diagnosis of pseudoseizures. Seizure. 1996;5:35-40.

12. Bowman ES, Markand ON. Psychodynamics and psychiatric diagnoses of pseudoseizures subjects. Am J Psychiatry. 1996;153(1):57-63.

13. Blumer D, Montouris G, Hermann B. Psychiatric morbidity in seizure patients on a neurodiagnostic monitoring unit. J Neuropsychiatry Clin Neurosci. 1995;7:445-456.

14. Jawad SS, Jamil N, Clarke EJ, Lewis A, Whitecross S, Richens A. Psychiatric morbidity and psychodynamics of patients with convulsive pseudoseizures. Seizure. 1995;4:201-206.

15. Alper K, Devinsky O, Perrine K, Vazquez B, Luciano D. Psychiatric classification of nonconversion nonepileptic seizures. Arch Neurol. 1995;532:199-201.

16. Alper K, Devinsky O, Perrine K, et al. Dissociation in epilepsy and conversion nonepileptic seizures. Epilepsia. 1997;38:991-7.

17. Moore PM, Baker GA. Non-epileptic attack disorder: a psychological perspective. Seizure. 1997;6:429434.

18. Nash JL. Pseudoseizures: an update. Compr Ther. 1995;21(9):486-491.

19. Knottnerus JA. The effect of disease verification and referral on the relationship between symptoms and diseases. Med Decis Making. 1987;7:139-48.

20. Trimble MR. Pseudoseizures. Neurol Clin. 1986;4(3):531-548.

21. Lesser RP. Psychogenic seizures. Recent advances in Epilepsy. Vol. 2. Edinburgh: Churchill Livingstone; 1985:273-296.

22. Alper K. Nonepileptic seizures. Neurol Clin. 1994;12(1):153-173.

23. Volow MR. Pseudoseizures: an overview. South Med J. 1986;79(5):600-607.

24. Francis P, Baker GA. Non-epileptic attack disorder (NEAD): a comprehensive review. Seizure. 1999;8:53-61.

25. Kuyk J, Dyck Rv, Spinhoven P. The case for a dissociative interpretation of pseudoepileptic seizures. $J$ Nerv Ment Dis. 1996;184(8):468-474.

26. Mulder OG. Management of pseudo-epileptic seizures. In: Dam M, Gram L, eds. Comprehensive Epileptology. New York: Raven Press; 1990.

27. Aldenkamp AP, Mulder OG. Behavioural mechanisms involved in pseudoepileptic seizures: a comparison between patients with seizures and patients with pseudoepileptic seizures. Seizure. 1997;6:275-282.

28. Ferracuti S, Burla F, Lazzari R. Rorschach findings for patients with pseudoseizures. Psychological Reports. 1999;85:439-444.

29. Frances PL, Baker GA, Appleton PL. Stress and avoidance in pseudoseizures: testing the assumptions. Epilepsy Res. 1998;34:241-9.

30. Bowman ES, Markand ON. The contribution of life events to pseudoseizure occurence in adults. Bull Menninger Clin. 1999;63(1):70-88.

31. Barry E, Krumholz A, Bergey GK, Chatha H, Alemayehu S, Grattan L. Nonepileptic posttraumatic seizures. Epilepsia. 1998;39(4):427-431. 
32. Rechlin T, Loew TH, Joraschky P. Pseudoseizure "status". J Psychosom Res. 1997;42(5):495-498.

33. Harden C. Pseudoseizures and dissociative disorders: a common mechanism involving traumatic experiences. Seizure. 1997;6:151-155.

34. Wyllie E, Glazer JP, Benbadis S, Kotagal P, Wolgamuth B. Psychiatric features of children and adolescents with pseudoseizures. Arch Pediatr Adolesc Med. 1999;153:244-248.

35. Berkhoff M, Brielmann RS, Radanov BP, Donatti F, Hess CW. Developmental background and outcome in patients with nonepileptic versus epileptic seizures: a controlled study. Epilepsia. 1998;39(5):463-469.

36. Kalogjera-Sackellares D, Sackellares JC. Intellectual and neuropsychological features of patients with psychogenic pseudoseizures. Psychiatry Res. 1999;86:73-84.

37. Ney GC, Barr WB, Napolitano C, Decker R, Schaul N. New-onset psychogenic seizures after surgery for epilepsy. Arch Neurol. 1998;55:726-730.

38. Sigurdardottir KR, Olafsson E. Incidence of psychogenic seizures in adults: a population-based study in Iceland. Epilepsia. 1998;39(7):749-752.

39. Ettinger AB, Devinsky O, Weisbrot DM, Goyal A, Shashikumar S. Headaches and other pain symptoms among patients with psychogenic non-epileptic seizures. Seizure. 1999;8:424-426.

40. Reilly J, Baker GA, Rhodes J, Salmon P. The association of sexual and physical abuse with somatization: characteristics of patients presenting with irritable bowel syndrome and non-epileptic attack disorder. Psychol Med. 1999:29:399-406.

41. Griffith JL, Polles A, Griffith ME. Pseudoseizures, families, and unspeakable dilemmas. Psychosomatics. 1998;39(2):144-153.

42. Wood BL, McDaniel S, Burchfiel K, Erba G. Factors distinguishing families of patients with psychogenic seizures from families of patients with epilepsy. Epilepsia. 1998;39(4):432-437.

43. Bell WL, Park YD, Thompson EA, Radtke RA. Ictal cognitive assessment of partial seizures and pseudoseizures. Arch Neurol. 1998;55:1456-1459.

44. Wolanczyk T, Brynska A. Psychogenic seizures in obsessive compulsive disorder with poor insight: a case report. Pediatr Neurol. 1998;18(1):85-86.

45. Breier J, Fuchs KL, Brookshire BL, et al. Quality of life perception in patients with intractable epilepsy or pseudoseizures. Arch Neurol. 1998;55:660-665.

46. Evans AL. Pseudoseizures as a complication of painful cervical ribs. Dev Med Child Neurol. 1999:41:840-842.

47. Kalogjera-Sackellares D, Sackellares JC. Personality profiles of patients with pseudoseizures. Seizure. 1997;6:1-7. 
APPENDIX 1. Checklist of the methodological quality of studies of non-epileptic seizures (NES)*

1. Definition

$$
\begin{array}{cll}
\text { Score } & \\
0 & 1 \square \text { no } & \\
5 & 2 \square \text { yes } & \rightarrow \square \text { clear } \\
1 & & \square \text { not clear }
\end{array}
$$

2. Number of cases in empirical study $\quad 1 \quad 1 \square 1$

$$
\begin{array}{ll}
2 & 2 \square 2-5 \\
3 & 3 \square 5-20 \\
4 & 4 \square>20
\end{array}
$$

3.Diagnosis of NES

$1 \quad 1 \square$ EEG

$2 \quad 2 \square$ Video-EEG monitoring

4. Selection criteria

$$
\begin{array}{lll}
0 & 1 \square \text { no } \\
4 & 2 \square \text { yes } \rightarrow & \square \text { consistent with definition } \\
2 & \\
& \text { not/partly consistent with } \\
\text { definition }
\end{array}
$$

5.History

$$
\begin{array}{ll}
0 & 1 \square \text { no } \\
3 & 2 \square \text { yes }
\end{array}
$$

6. Neuropsychological testing

$$
\begin{aligned}
0 \quad 1 \square \text { no } & \\
2 \quad 2 \square \text { yes } \rightarrow & \square \text { MMPI } \\
& \square \text { DES } \\
& \square \text { Depression Scales } \\
& \square \text { Anxiety Scales } \\
& \square \text { Coping Scales } \\
& \square \text { Other Scales }
\end{aligned}
$$

7. Psychiatric assessment

$$
\begin{array}{ll}
0 & 1 \square \text { no } \\
3 & 2 \square \text { yes }
\end{array}
$$

8. Cause of NES:

$$
\begin{array}{ll}
0 & 1 \square \text { no } \\
2 & 2 \square \text { yes }
\end{array}
$$

9. Classification of NES:

$$
\text { 0 } 1 \square \text { no }
$$

$2 \quad 2 \square$ yes, according to $\rightarrow \square$ imitated epileptic sz presentation

10. Type of study $\dagger$

$$
\begin{array}{ll}
1 & 1 \square \text { Retrospective } \\
1 & 2 \square \text { Cross-sectional }
\end{array}
$$

11. Control group

$$
\begin{array}{rl}
0 & 1 \square \text { no } \\
2 \quad 2 \square \text { yes } & \rightarrow \square \text { patients with epilepsy } \\
& \square \text { patients with psychiatric disorders }
\end{array}
$$

*Maximal score: 30

$\uparrow$ The literature search identified no prospective study that could be further evaluate 
38 | The etiology of NES 


\section{Incidence of epilepsy and unprovoked seizures:} a population-based prospective study 


\section{Summary}

Purpose: To estimate the incidence of unprovoked seizures (US) and epilepsy in the area of Maastricht in relation to age, sex, etiology and seizure type, and to identify predictive factors of the epileptic and non-epileptic seizures.

Methods: All patients aged $\geq 14$ years residing within certain zip-code areas at time of their first seizure or who had undiagnosed seizures before the study period were included. Patients were identified from different sources and were independently evaluated and classified by a team of neurologists. A predictive profile for the occurrence of epileptic and non-epileptic seizures was obtained by stepwise logistic regression analysis.

Results: The overall annual incidence was $55 / 100,000$ and $30 / 100,000$ for US and epilepsy respectively. The age-specific annual incidence of US and epilepsy increased with age and reached $120 / 100,000$ and $62 / 100,000$ for the $\geq 65$ years of age group respectively. In males the incidence of epilepsy and US was higher than in females and partial seizures prevailed over generalized seizures $(40$ vs. $9 / 100,000)$. The etiology was mainly cerebrovascular disease and brain tumors. Predictors for epileptic versus non-epileptic seizures of organic origin were an epileptiform EEG pattern vs. a history of hypertension or cardiovascular disease. Strong predictors for patients with seizures of non-organic origin were female sex and head injury.

Conclusions: The incidence of US and epilepsy (overall, and age-, sex-, seizure-specific) was similar to those reported by other developed countries. The predictive factors found in this study may assist in the early diagnosis of seizures. 


\section{INTRODUCTION}

Prospective population-based studies on the occurrence of epilepsy provide information regarding the incidence, natural history, associated mortality and risk factors for epilepsy. Furthermore, with these studies a more complete case ascertainment can be achieved, while excluding non-epileptic disorders, in order to investigate the distribution of epilepsy by etiology and prognosis and to determine initial treatment and management strategies. In several countries the incidence of epilepsy has been studied but only a few of these studies had a prospective population-based approach. In the Netherlands, so far, no incidence study of epilepsy has been performed.

This chapter is based on an epidemiological project of seizure disorders in Dutch adolescents and adults in the area of Maastricht. The purpose of the presented prospective populationbased study was to estimate the incidence of unprovoked seizures and epilepsy in a welldefined population in relation to age, sex, etiology and seizure type, and to compare the results with that of incidence studies in other countries. It also focused on the characteristics of the cohort with epileptic and non-epileptic seizures with the aim to identify predictive factors of the several seizure types. Thus, these factors can enable the diagnostic process of epileptic seizures.

\section{METHODS}

\section{Study population}

The study was conducted from October 1, 1998 to September 30, 2000 in Maastricht and its surroundings, which is a well circumscribed area located at the southern part of the Netherlands. Its total population on December 31,1999 was 190,860 and it is representative of the overall population of the Netherlands in terms of age, sex and ethnic structure. 83.4\% of the population were aged $\geq 14$ years old and comprised of $48.5 \%$ males and $51.5 \%$ females (Central Bureau of Statistics, the Netherlands). The health facilities in this area, which lies within the zip-code areas 6200 to 6299 , consist of 90 general practitioners, three nursing homes and one hospital, the Maastricht University Hospital.

\section{Case ascertainment}

Multiple overlapping strategies were used to identify cases. First, before the start of the study and every two months during the study, we supplied information to all general practitioners and to the physicians and nurses of the nursing homes. All general practitioners in the study area were asked to refer patients with newly diagnosed seizures directly to the investigators. Second, we asked all residents of neurology, neurologists and child neurologists to refer patients with seizure-like disorders identified at the emergency room, department of neurology or other hospital departments, and at the outpatient department of neurology. In addition, we surveyed the medical files of all the individuals who had received the diagnoses syncope, convulsion, epilepsy or attacks of unknown type during the inclusion period of the study to find patients who had not been reported through other sources. Furthermore, we regularly scrutinized all EEGs and neuroradiology reports performed during the study in order to overcome the problem of identifying patients who had not been admitted or had been miscoded on hospital discharge data. The medical files of all persons identified in this process were evaluated and, whenever possible, these patients were reexamined. All identified cases were examined in a standardized manner by one of the authors (IK) (medical history, physical and neurological examination). Blood screening tests and an ECG were performed in all cases. EEG (standard and/or sleep deprived), radiological examinations of the brain (CTs or MRIs), and video EEG were performed if indicated for a more precise diagnosis. 


\section{Inclusion and exclusion criteria}

All individuals aged $\geq 14$ years who were residents in the investigated area at the time of their first seizure were included. Included were also patients who had undiagnosed seizures before the study period and had not received any antiepileptic drugs yet. Children with seizures aged between 0 and 13 years were not included in our study since we had not the possibility to (re)examine these cases (these children are referred to pediatricians and child neurologists). Excluded were all patients who had an acute symptomatic seizure.

\section{Nursing homes}

During one year, the nurses in the nursing homes provided monthly reports of all residents with seizures and their possible cause. They also reported the age and sex of these patients and if they had been treated with antiepileptic drugs before the study period. Some of these elderly patients had not been referred to the department of Neurology and, therefore, were not examined by one of the authors and did not have any EEG or neuroradiological investigation. For reasons of confidentiality we could not define the number of these patients and we were not able to review the medical files of the reported cases in the nursing homes in order to obtain more information about their seizures and their possible etiology. Thus, for the determination of incidence, cases from nursing homes were analyzed separately from the other cases. If for these patients a known remote symptomatic cause had been reported, it was considered as the cause of the seizures; if not, the seizures were determined as unclassified.

\section{Definitions}

The seizure that led the patient to seek for medical advice (general practitioner, emergency room, or outpatient department of neurology) was defined as index seizure.

Epilepsy and epileptic syndromes were defined and classified by seizure type (partial and generalized seizures) and etiology (remote symptomatic, cryptogenic, idiopathic) according to the Commission on Classification and Terminology and the Commission on Epidemiology and Prognosis of the International League Against Epilepsy (ILAE) (1-3).

The incidence of unprovoked seizures was defined as the number of patients with a first unprovoked seizure per 100,000 inhabitants at risk per year. The incidence of epilepsy was defined as the number of new cases with epilepsy in a population at risk per 100,000 personyears. The denominator for the incidence was the number of residents aged $\geq 14$ years at the census year 1999.

\section{Diagnosis and classification of cases}

Two authors (the neurologists MdK and JL) independently evaluated all cases and classified the patient's index seizure as an epileptic seizure, a non-epileptic seizure of organic origin (e.g. syncope, benign drop attacks), or a non-epileptic seizure of non-organic origin (e.g. panic attacks, hyperventilation attacks, non-epileptic psychogenic seizures). The classification of cases was based on the clinical manifestations, EEG findings, neuroimaging findings, laboratory and ECG data acquired within six months after the index seizure. As such, for all cases there is a first diagnosis, obtained immediately after the index seizure, and a definite diagnosis obtained six months after the index seizure. For statistical analysis, only the definite diagnosis was taken into account. In cases of disagreement a consensus was reached with the aid of a third neurologist (the author JT).

The two neurologists (MdK, JL) also classified all cases with unprovoked seizures or epilepsy by seizure type and etiology according to the classification proposed by the ILAE $(1,2)$, based on the clinical description of the seizures and on data from ancillary tests. For instance, a patient with generalized seizures and focal findings on EEG or neuroimaging was classified 
as having localization-related epilepsy and secondarily generalized seizures. Patients in the category of undetermined epilepsy or unclassified seizures had no sufficient seizure description with normal or lacking EEG and neuroimaging findings. A single seizure irrespective of the EEG and neuroradiological findings was classified as an isolated seizure. This seizure could be partial, generalized or unclassified.

\section{Statistical analysis}

The percentage distribution of all incident cases was computed by seizure type and etiology. Age-specific and sex-specific incidence rates were also determined.

Furthermore, predictive factors for the diagnosis of epileptic and non-epileptic seizures were examined by means of logistic regression analysis. The following variables were entered into the predictive model: age, sex, living situation (e.g. living alone or with others), occupation (e.g. full-time, part- time, unemployed), education level (e.g. low or high), concomitant diseases (e.g. head injury, depression, cardiovascular diseases), family history of epilepsy, febrile seizures, medication (e.g. against hypertension or diabetes), provoking factors (alcohol abuse, sleep deprivation, tiredness, and stress), and findings from diagnostic procedures (EEG, CT and MRI). The variable age, which is the only continuous variable, was transformed into a categorical variable according to the age limits defined by the Central Bureau of Statistics for the general population (i.e. 14-24, 25-44, 45-64, and $\geq 65$ years). A predictive model was obtained by stepwise logistic regression retaining only the most strongly related variables. Ninety-five percent confidence intervals $(\mathrm{CI})$ for the statistically significant predictive factors were calculated. Two outcome contrasts were defined. First, the unprovoked seizures and non-epileptic seizures of organic origin were compared to the nonepileptic seizures of non-organic origin. Second, the unprovoked seizures were contrasted with the non-epileptic seizures of organic origin. In total, the first predictive model included 25 predictors for 313 cases, and the second predictive model included 22 predictors for 252 cases. As a form of sensitivity analysis and to ensure the entry of variables with coefficients different from zero, we successively used as a criterion for the inclusion of a variable the values $0.05,0.15$, and 0.20 , as recommended by Hosmer and Lemeshow (4).

\section{RESULTS}

\section{Study population}

A total of 350 cases was entered in the study. This sample consisted of $163(46.6 \%)$ men and $187(53.4 \%)$ women aged between 14 and 92 years (mean, 49 years for men and 51 years for women). In all, $71.1 \%$ of the patients were examined in a standardized manner by one of the authors (IK) whereas $28.9 \%$ of the patients were not seen by this author. This last group of patients was consisted mostly of patients who had a bad clinical condition at the time of their admittance and were usually discharged to the nursing homes directly. In a few cases, this last group of patients included patients with a known neurological disease such as brain tumor or cerebrovascular disease. These patients were often referred to the neurologists who had seen them regularly at the outpatient department of neurology.

Unprovoked seizures were diagnosed in the majority of the cases $(49.7 \%)$, followed by the non-epileptic seizures of organic origin $(22.3 \%)$, the non-epileptic seizure of non-organic origin (18\%), and the acute symptomatic seizures (7.7\%). In 8 cases $(2.3 \%)$ no definite diagnosis could be determined due to lack of data. Ninety-four (54\%) of the 174 cases with unprovoked seizures fulfilled the diagnostic criteria for epilepsy as they appeared to have had two or more recurrent unprovoked seizures.

A neuroimaging study and an EEG was conducted in most of the cases. Specifically, in 125 $(72.7 \%)$ patients with unprovoked seizures and in $74(78.7 \%)$ patients with epilepsy a CT 
TABLE 1. Age and sex-specific incidence (per 100,000/year) of unprovoked seizures (US) and epilepsy

\begin{tabular}{lcccc}
\hline Age group (yr) & \multicolumn{2}{c}{ US } & \multicolumn{2}{c}{ Epilepsy } \\
\cline { 2 - 5 } & $\mathrm{n}$ & Incidence & $\mathrm{n}$ & Incidence \\
\hline $14-24$ & 26 & 59.7 & 14 & 32.2 \\
$25-44$ & 29 & 25.3 & 16 & 13.9 \\
$45-64$ & 55 & 51.4 & 31 & 29.0 \\
265 & 64 & 119.7 & 33 & 61.7 \\
Total & 174 & 54.6 & 94 & 29.5 \\
\hline Sex & & & & \\
\hline Male & 90 & 58.3 & 47 & 30.4 \\
Female & 84 & 51.2 & 47 & 28.6 \\
\hline
\end{tabular}

scan was performed whereas in $66(38.4 \%)$ patients with unprovoked seizures and in 38 $(40.4 \%)$ patients with epilepsy a MRI was performed. Furthermore, $140(80.4 \%)$ patients with unprovoked seizures and $74(78.7 \%)$ patients with epilepsy had an EEG (standard and/or sleep deprived).

With respect to the unprovoked seizures, in $45.7 \%$ of the cases the first seizure was also the index seizure. Only $17.9 \%$ of the cases had more than five recurrent unprovoked seizures before the index seizure. In more than half of the patients $(62.4 \%)$ the first seizure had appeared in a period of less than a month whilst a few patients $(14.4 \%)$ had experienced their first seizure more than 12 months ago before admittance to the study. The duration of the index seizure was less than one minute in $6.2 \%$ of the patients, between one and five minutes in $55 \%$, between five and 15 minutes in $34.9 \%$, and more than 15 minutes in $3.1 \%$. It appeared that more than half of the patients who had seizures lasting less than one minute had experienced five of more recurrent unprovoked seizures before the index seizure $(53.1 \%)$. The nursing homes reported 16 cases with epileptic seizures, five of whom had recurrent epileptic seizures. The mean age of these patients was 78.2 years and the most frequently reported cause of their seizures was cerebrovascular disease.

TABLE 2. Age-specific incidence (per 100,000/year) of seizures

\begin{tabular}{lcccccccccc}
\hline Seizure type & \multicolumn{8}{c}{ Age groups (yr) } \\
\cline { 2 - 10 } & \multicolumn{1}{c}{$14-24$} & $25-44$ & $45-64$ & 265 & Total \\
\cline { 2 - 10 } & $\mathrm{n}$ & Incidence & $\mathrm{n}$ & Incidence & $\mathrm{n}$ & Incidence & $\mathrm{n}$ & Incidence & Incidence \\
\hline All partial & 11 & 25.3 & 15 & 13.1 & 47 & 43.9 & 54 & 101.0 & 39.9 \\
Simple partial & - & - & 2 & 1.7 & 6 & 5.6 & 8 & 14.9 & 5.0 \\
Complex partial & 2 & 4.6 & 4 & 3.5 & 4 & 3.7 & 11 & 20.6 & 6.6 \\
Secondarily generalized & 9 & 20.7 & 9 & 7.8 & 37 & 34.6 & 35 & 65.5 & 28.3 \\
All generalized & 11 & 25.3 & 8 & 6.9 & 7 & 6.5 & 2 & 3.7 & 8.8 \\
Primarily generalized & 10 & 22.3 & 8 & 6.9 & 6 & 5.6 & 2 & 3.7 & 8.2 \\
Absences & 1 & 2.3 & - & - & - & - & - & - & 0.3 \\
Atonic & - & - & - & - & 1 & 0.9 & - & - & 0.3 \\
Total & 22 & 50.6 & 23 & 20.1 & 54 & 50.5 & 56 & 104.8 & 48.7 \\
\hline
\end{tabular}

\section{Annual incidence of epilepsy and unprovoked seizures}

The overall annual incidence was 55 cases with unprovoked seizures and 30 cases with epilepsy per 100,000 person-years (Table 1). The age-specific incidence for unprovoked seizures and epilepsy increased with age and reached $120 / 100,000$ or $62 / 100,000$ for the $\geq 65$ 
age group respectively. If in this age group the cases from the nursing homes would be added then the age-specific incidence for unprovoked seizures and epilepsy would increase further to $180 / 100,000$ or $80 / 100,000$ respectively. In males the incidence of both epilepsy and unprovoked seizures was higher than in females. The age-specific distribution of the incidence of epilepsy and unprovoked seizures for both males and females was similar with the age-specific distribution of these incidences in the total population.

TABLE 3. Age-specific incidence (per 100,000/year) of epilepsy by syndrome

\begin{tabular}{|c|c|c|c|c|c|c|c|c|c|}
\hline \multirow[t]{3}{*}{ Syndrome } & \multicolumn{8}{|c|}{ Age groups (yr) } & \multirow{3}{*}{$\frac{\text { Total }}{\text { Incidence }}$} \\
\hline & \multicolumn{2}{|c|}{$14-24$} & \multicolumn{2}{|c|}{$25-44$} & \multicolumn{2}{|c|}{$45-64$} & \multicolumn{2}{|c|}{$\geq 65$} & \\
\hline & $\mathbf{n}$ & Incidence & $\mathbf{n}$ & Incidence & $\mathbf{n}$ & Incidence & $\mathbf{n}$ & Incidence & \\
\hline \multicolumn{10}{|c|}{$\begin{array}{l}\text { Localization-related } \\
\text { epilepsies }\end{array}$} \\
\hline Idiopathic & - & - & 1 & 0.9 & 1 & 0.9 & 1 & 1.9 & 0.9 \\
\hline Symptomatic & 4 & 9.2 & 3 & 2.6 & 12 & 11.2 & 27 & 50.5 & 14.4 \\
\hline Cryptogenic & 4 & 9.2 & 4 & 3.5 & 9 & 8.4 & 5 & 9.3 & 6.9 \\
\hline \multicolumn{10}{|c|}{$\begin{array}{l}\text { Generalized epilepsies } \\
\text { and syndromes }\end{array}$} \\
\hline Idiopathic & 4 & 9.2 & 2 & 1.7 & 2 & 1.9 & 2 & 3.7 & 3.1 \\
\hline Symptomatic & - & - & - & - & 1 & 0.9 & 1 & 1.9 & 0.6 \\
\hline Cryptogenic & 1 & 4.6 & 2 & 1.7 & - & - & - & - & 0.9 \\
\hline Unclassified & 4 & 9.2 & 9 & 7.8 & 7 & 6.5 & 7 & 13.9 & 8.5 \\
\hline Total & 17 & 39.1 & 21 & 18.3 & 32 & 29.9 & 43 & 80.5 & 35.5 \\
\hline
\end{tabular}

TABLE 4. Frequency of etiologic factors identified in patients with unprovoked seizures (US) and epilepsy with CT or MRI

\begin{tabular}{lcccc}
\hline Etiologic factors on CT & \multicolumn{2}{c}{ US } & \multicolumn{2}{c}{ Epilepsy } \\
\cline { 2 - 5 } & \multicolumn{2}{c}{ Frequency } & \multicolumn{2}{c}{ Frequency } \\
\cline { 2 - 5 } & $\mathrm{n}$ & $(\%)$ & $\mathrm{n}$ & $(\%)$ \\
\hline Ischemic stroke & 28 & 16.3 & 18 & 19.1 \\
Intracerebral hemorrhage & 1 & 0.6 & - & - \\
CNS tumor & 11 & 6.4 & 6 & 6.4 \\
CNS metastases & 11 & 6.4 & 8 & 8.5 \\
Others & 10 & 5.8 & 4 & 4.2 \\
\hline Etiologic factors on MRI & & & & \\
\hline Ischemic stroke & 11 & 6.4 & 7 & 7.4 \\
Intracerebral hemorrhage & 1 & 0.6 & - & - \\
CNS malformation & 1 & 0.6 & - & - \\
Mesial temporal sclerosis & 3 & 1.7 & 3 & 3.2 \\
CNS tumor & 10 & 5.8 & 6 & 6.4 \\
CNS metastases & 5 & 2.9 & 3 & 3.2 \\
Others & 20 & 11.6 & 10 & 10.6 \\
\hline CNS, central nervous system & & & & \\
\hline
\end{tabular}

CNS, central nervous system.

The total incidence of partial seizures was $40 / 100,000$ and that of generalized seizures was $9 / 100,000$. The highest incidence of generalized seizures was in the 14-24 years of age group and thereafter it decreased continuously with increasing age. In contrast, the incidence of partial seizures was highest in the $\geq 65$ age group and lowest in the 14-24 years of age group. 
The incidence of localization-related epilepsies prevailed over that of the generalized epilepsies and syndromes. The incidence of localization-related epilepsies peaked in the oldest age group. In this group of patients the incidence was highest for symptomatic epilepsy syndromes followed by cryptogenic and idiopathic localization-related epilepsies. The generalized epilepsies and syndromes were most frequent in the youngest age group. Among the generalized epilepsies and syndromes the idiopathic syndromes had the highest incidence in this age group. Only $27(16.7 \%)$ cases could not be classified according to the syndrome classification of epilepsy.

For the group of patients with unprovoked seizures it was possible to identify a predisposing cause in $35.5 \%$ or $29.6 \%$ of all the cases on the CT or MRI respectively. In comparison, for the group of patients with epilepsy a possible cause was identified in $38.3 \%$ or $30.8 \%$ of all the cases on the CT or MRI respectively (Table 4). Ischemic stroke, followed by central nervous system (CNS) tumors and metastases, were the most frequent found causes of unprovoked seizures and epilepsy. Mesial temporal sclerosis was present only in $1.7 \%$ and $3.2 \%$ of all patients with unprovoked seizures or epilepsy respectively.

TABLE 5. Prevalence and odds ratios $(O R)$ with $95 \%$ confidence intervals $(95 \% \mathrm{CI})$ of the predictive factors for the epileptic and non-epileptic seizures.

Results of the multiple logistic regression analysis.

\begin{tabular}{|c|c|c|c|c|c|}
\hline \multirow{3}{*}{$\begin{array}{l}\text { Predictors for } \\
\text { NES of non-organic } \\
\text { origin }\end{array}$} & \multirow{3}{*}{ OR $(95 \% \mathrm{Cl})$} & \multicolumn{2}{|c|}{$\begin{array}{l}\text { US and NES of organic origin } \\
\qquad n=252\end{array}$} & \multicolumn{2}{|c|}{$\begin{array}{c}\begin{array}{c}\text { NES of non-organic origin } \\
n=63\end{array} \\
.\end{array}$} \\
\hline & & \multicolumn{2}{|c|}{ Prevalence } & \multicolumn{2}{|c|}{ Prevalence } \\
\hline & & $\mathrm{n}$ & $(\%)$ & $\mathrm{n}$ & $(\%)$ \\
\hline \multicolumn{6}{|l|}{ Age groups (yr) } \\
\hline $45-64$ & $0.42(0.19-0.94)$ & 83 & 32.9 & 19 & 30 \\
\hline$\geq 65$ & $0.13(0.45-0.41)^{\alpha}$ & 85 & 33.7 & 5 & 8 \\
\hline \multicolumn{6}{|l|}{ Sex } \\
\hline Female & $2.2(1.15-4.06)$ & 131 & 51.9 & 42 & 67 \\
\hline \multicolumn{6}{|l|}{ EEG } \\
\hline $\begin{array}{l}\text { Epileptiform } \\
\text { discharges }\end{array}$ & $0.18(0.50-0.62)$ & 46 & 23 & 3 & 7 \\
\hline \multicolumn{6}{|l|}{ CT } \\
\hline abnormal & $0.13(0.31-0.59)$ & 68 & 27.3 & 2 & 3 \\
\hline $\begin{array}{l}\text { History of head } \\
\text { injury }\end{array}$ & $2.4(1.11-5.18)$ & 43 & 17 & 16 & 26 \\
\hline \multirow{3}{*}{\multicolumn{2}{|c|}{$\begin{array}{l}\text { Predictors for NES } \\
\text { of organic origin }\end{array}$}} & \multicolumn{2}{|c|}{$\begin{array}{c}\text { US } \\
n=174\end{array}$} & \multicolumn{2}{|c|}{$\begin{array}{l}\text { NES of organic origin } \\
\qquad n=78\end{array}$} \\
\hline & & \multicolumn{2}{|c|}{ Prevalence } & \multicolumn{2}{|c|}{ Prevalence } \\
\hline & & $\mathrm{n}$ & $(\%)$ & $\mathrm{n}$ & (\%) \\
\hline $\begin{array}{l}\text { History of } \\
\text { hypertension }\end{array}$ & $2.8(1.10-7.09)$ & 18 & 14 & 11 & 21 \\
\hline $\begin{array}{l}\text { History of CV } \\
\text { disease } \\
\text { EEG }\end{array}$ & $5.4(1.89-15.61)$ & 13 & 10 & 11 & 21 \\
\hline $\begin{array}{l}\text { Epileptiform } \\
\text { discharges }\end{array}$ & $0.06(0.02-0.26)$ & 43 & 31 & 3 & 5 \\
\hline
\end{tabular}

US, unprovoked seizures; NES, non-epileptic seizures; CV, cardiovascular.

${ }^{a} \mathrm{p}<0.01$

- Added after changing the significance level into $p=0.15$ or 0.20 


\section{Predictors for epileptic and non-epileptic seizures}

Table 5 shows only the predictive factors for epileptic and non-epileptic seizures that appeared to be statistically significant from the logistic regression analysis. Older age, an epileptiform EEG pattern, and an abnormal CT were more likely to appear in patients with unprovoked seizures and non-epileptic seizures of organic origin than in the group of patients with non-epileptic seizures of non-organic origin. Alternatively, the latter group was significantly associated with a history of head injury and included more females than the group of patients with seizures of somatic origin.

Furthermore, a history of hypertension and cardiovascular disease were significantly associated with non-epileptic seizures of organic origin whereas an epileptiform EEG pattern was more likely to be found in the group of patients with unprovoked seizures only.

\section{DISCUSSION}

In this prospective population-based study the total incidence of unprovoked seizures and epilepsy was calculated and certain predictive factors of the epileptic and non-epileptic seizures were identified.

In this study a strong effort was made to identify all possible cases and to avoid selection bias. Therefore, the surveillance procedure used several sources to identify cases and all cases were discussed collectively and decisions were consensus-based. In addition, in the Netherlands a patient with a seizure, even if he or she has experienced this seizure in a region outside the region of his of her residency, is likely to visit his or her general practitioner. Thus we assume that the case ascertainment was reasonably complete.

Furthermore, this study can contribute to a comprehensive characterization of seizures and epilepsy, since it is population-based. Population-based studies have the advantage to provide a representative sample to carry out unbiased evaluations of several variables of interest (5, 6).

Concerning the unprovoked seizures, it appeared that in $45.7 \%$ of the cases the first seizure was also the index seizure and in more than half of the patients $(62.4 \%)$ the first seizure had appeared in a period of less than a month before admittance to the study. Furthermore, in the majority of the cases, the duration of the index seizure varied between one and five minutes or five and 15 minutes. As expected, only in a few cases (6.2\%) the index seizure lasted less than one minute. More than half of these patients (53.1\%) had experienced five of more recurrent unprovoked seizures before the index seizure. It is likely that these patients probably experience mild seizures which may not be recognized immediately and so do not prompt a doctor's visit.

The total annual incidence of unprovoked seizure in the present study $(55 / 100,000)$ is similar to results from US American studies $(61 / 100,000)(7),(50.9 / 100,000)(8)$, from Sweden $(56 / 100,000)(9)$, and from Switzerland $(45.6 / 100,000)(10)$.

Similarly, the overall incidence of epilepsy in this study $(30 / 100,000)$ is of the same order as those documented in other population-based studies in industrialized countries: in the USA $35.5 / 100,000(8), 44 / 100,000(7)$, and $48.7 / 100,000(11)$, in the Faroes $42.8 / 100,000(12)$, in Iceland 46.5/100,000 (13), in Italy 33.1/100,000 (14), and in Finland 24/100,000 (15).

Differences in the overall incidence of unprovoked seizures and epilepsy in the several studies are, in part, due to different case ascertainment methods and due to the varying age distribution of the population across the countries.

The age-specific incidence in the present study increases with age in concordance with other studies in developed countries. This increase of age-specific incidence is found for both the unprovoked seizures and epilepsy and, in particular, most studies have reported a significant 
increase of incidence in the elderly $(9,13,16-19)$. In addition, a large prospective populationbased study in the UK has observed that most of the incident cases were recruited among the elderly $(20,21)$.

In the present study, the incidence of unprovoked seizures and epilepsy is higher for males than for females and the age-specific distribution for both males and females is similar with the age-specific distribution of these incidences in the total population. The same pattern has also been found in other incidence studies $(7,11,13-15,20,22)$.

The classification of epileptic seizures and syndromes, as it has also been stressed by other authors $(23,24)$, depends highly on the use of ancillary tests (EEG, neuroimaging studies). Berg et al. (25) demonstrated that it is possible to identify and classify a large part of the epilepsy syndromes in children accurately early in the course of the disorder depending on the quality and extent of the information available at the time of the initial diagnosis. They (25) found that two years after the initial diagnosis in only $9.8 \%$ of the cases a rectification was needed. Approximately $80 \%$ of the cases with unprovoked seizures or epilepsy in this study was evaluated with an EEG, CT or MRI. This high rate of diagnostic tests permitted a classification of epileptic seizures and syndromes in most of the cases. However, $10.9 \%$ of the epileptic seizures and $28.7 \%$ of the epilepsy syndromes remained unclassified due to the limited data. The relatively high proportion of unclassified epilepsy syndromes found in our study compared to other studies (23.3\% in the study by Manford et al. (26), $18 \%$ in the study by Zarelli et al. (27), $2.6 \%$ in the study by Loiseau et al. (28), and $1.4 \%$ for the group of patients with more than one seizure at diagnosis in the study by Jallon et al. (23)) reflects partly differences in the interpretation of the ILAE classification system. For instance, Jallon et al. (23) and Loiseau et al. (28) classified also cases after a single epileptic event whereas in our study a syndromic diagnosis was limited to the cases with epilepsy.

In the present study, the incidence of all partial seizures is markedly higher than the incidence of all generalized seizures, which corroborates with the findings from other incidence studies $(7,9,11,12,22)$. The majority of the partial seizures was secondarily generalized whilst the majority of the generalized seizures was primarily generalized. These differences in the incidence of certain seizure types reflect distribution differences across the age groups. Certain seizure types such as absences are seldom observed after midlife and some seizure types are characteristic of specific epilepsy syndromes which are more likely to occur at younger age (i.e. myoclonic seizures in patients with juvenile myoclonic epilepsy, absences in patients with juvenile absence epilepsy). Moreover, the distribution of certain seizure types and epilepsy syndromes depends on the prevalence of different etiologic factors in each age group. For example, in the present study, complex partial seizures, secondarily generalized seizures and localization-related symptomatic epilepsy occurred more often in the elderly. This is in accordance with other studies $(23,27)$ which report an increase of localizationrelated symptomatic epilepsy in the elderly. Elderly patients often have concomitant neurodegenerative, cerebrovascular, or neoplastic disease which can give rise to partial seizures $(29,30)$. Stephen et al. (30) stated that the most common cause of seizures in the elderly is cerebrovascular disease ( $49 \%$ ), followed by tumors (up to $45 \%$ ), and head injury (up to $21 \%$ ).

In most of the population-based incidence studies the proportion of cases with an identified cause ranges from $23 \%$ to $39 \%$ (31). Equally, in this study, in approximately $35 \%$ of the patients with epilepsy or epileptic seizures an underlying cause could be identified. The most common causes were cerebrovascular disease and brain tumors. These results are in keeping with the literature (32).

In the present study, we also focused on predictive factors which may discriminate patients with epileptic seizures from patients with non-epileptic seizures. As expected, the strongest predictor for patients with epileptic seizures is an epileptiform EEG pattern. Similarly, for the 
group of patients with non-epileptic seizures of organic origin, there is a high probability of a history of hypertension or cardiovascular disease which may be assumed as the underlying causes of their seizures. Furthermore, older age, which is frequently correlated with concomitant diseases, an abnormal EEG pattern and CT were more likely to appear in the group of patients with seizures of somatic origin. These items can be regarded as factors associated with several underlying causes that can give rise to seizures and result in abnormal findings on CT and EEG. Alternatively, the predictive model for the group of patients with non-epileptic seizures of non-organic origin included the factors female sex and a history of head injury. Females appear to account for a large proportion of the non-epileptic seizures of psychogenic origin, and head trauma has recently been recognized as one of the provoking factors for this type of seizures $(33,34)$. However, the reason for these findings is not entirely clear. Sociologic and cultural factors may account for the high incidence of seizures of nonorganic origin in women. In addition, head trauma may occur as a consequence of physical abuse, which may be quite common in patients with this type of seizures (34). Head trauma can also be considered as an independent factor that causes stress in susceptible individuals. Non-epileptic seizures are often misdiagnosed as epileptic seizures. Obviously, in case of a single seizure, the potential of misdiagnosis is increased. The predictive factors found in this study may assist clinicians in the diagnosis of seizures. Hence, based on certain issues such as findings from diagnostic tests (CT or EEG), they may distinguish patients with epileptic seizures from patients with non-epileptic seizures. However, it should be noted that in case a patient experiences both types of seizures (i.e. epileptic and non-epileptic seizures) probably more predictive factors are needed for an accurate diagnosis.

We conclude that the incidence of unprovoked seizures and epilepsy found in this study (overall, and age-, sex-, seizure-specific) was similar to those reported by other developed countries and that certain factors appeared to be strong predictors for the epileptic and nonepileptic seizures. These findings need to be verified by other prospective population-based studies with larger samples of patients. Moreover, these studies can provide additional predictive factors enabling an early diagnosis of the epileptic and non-epileptic seizures. 


\section{REFERENCES}

1. Commission on Classification and Terminology of the International League Against Epilepsy. Proposal for revised classification of epilepsies and epileptic syndromes. Epilepsia. 1989;30:389-99.

2. Commission on Epidemiology and Prognosis, International League Against Epilepsy. Guidelines for epidemiologic studies on epilepsy. Epilepsia. 1993;34:592-6.

3. ILAE Commission Report. The epidemiology of the epilepsies: future directions. Epilepsia. 1997:38:614-8.

4. Hosmer DW, Lemeshow S. Applied Logistic Regression New York: Academic Press; 1989.

5. Knottnerus JA, Leffers $P$. The influence of referral patterns on the characteristics of diagnostic tests. $J$ Clin Epidemiol. 1992;45:1143-54.

6. Knottnerus JA. The effects of disease verification and referral on the relationship between symptoms and diseases. Med Decis Making. 1987;7:139-48.

7. Hauser WA, Annegers JF, Kurland LT. Incidence of epilepsy and unprovoked seizures in Rochester, Minnesota: 1935-1984. Epilepsia. 1993;34:453-68.

8. Annegers JF, Dubinsky S, Coan SP, Newmark ME, Roht L. The incidence of epilepsy and unprovoked seizures in multiethnic, urban health maintenance organizations. Epilepsia. 1999;40:502-6.

9. Forsgren L, Bucht G, Eriksson S, Bergmark L. Incidence and clinical characterization of unprovoked seizures in adults: a prospective population-based study. Epilepsia. 1996;37:224-9.

10. Jallon P, Goumaz M, Haenggeli C, Morabia A. Incidence of first epileptic seizure in the canton of Geneva, Switzerland. Epilepsia. 1997;38:547-52.

11. Hauser WA, Kurland LT. The epidemiology of epilepsy in Rochester, Minnesota, 1935 through 1967. Epilepsia. 1975;16:1-66.

12. Joensen P. Prevalence, incidence, and classification of epilepsy in the Faroes. Acta Neurol Scand. 1986;74:150-5.

13. Olafsson E, Hauser WA, Ludvigsson P, Gudmundsson G. Incidence of epilepsy in rural Iceland: a population-based study. Epilepsia. 1996;37:951-5.

14. Granieri E, Rosati G, Tola R, et al. A descriptive study of epilepsy in the district of Copparo, Italy, 1964-1978. Epilepsia. 1983:24:502-14.

15. Keränen T, Riekkinen Pj. Sillanpas M. Incidence and prevalence of epilepsy in adults in Eastern Finland. Epilepsia. 1989;30:413-21.

16. Hauser WA, Annegers JF, Rocca WA. Descriptive epidemiology of epilepsy: contributions of population-based studies from Rochester, Minnesota. Mayo Clin Proc. 1996;71(6):576-86.

17. Lohdorf K, Jensen LK, Plesner AM. Epilepsy in the elderly: incidence, social function, and disability. Epilepsia. 1986;27:135-41.

18. Loiseau J, Loiseau P, Duché B, Guyot M, Dartigues JF, Aublet B. A survey of epileptic disorders in Southwest France: seizures in elderly patients. Ann Neurol. 1990;27:232-7.

19. Tallis R, Hall G, Craig I, Dean A. How common are epileptic seizures in old age? Age and ageing. 1991;20:442-8.

20. Everitt AD, Sander JW. Incidence of epilepsy is now higher in elderly people than in children. BMJ. 1998:316:780.

21. Sander JW, Hart YM, Johnson AL, Shorvon SD. National General Practice Study of Epilepsy: newly diagnosed epileptic seizures in a general population. Lancet. 1990;336(8726):1267-71.

22. Forsgren L. Prospective incidence study and clinical characterization of seizures in newly referred adults. Epilepsia. 1990;31:292-301.

23. Jallon $\mathrm{P}$, Loiseau $\mathrm{P}$, Loiseau J. Newly diagnosed unprovoked epileptic seizures: presentation at diagnosis in CAROLE study. Epilepsia. 2001;42:464-75.

24. Sander JW, Shorvon SD. Incidence and prevalence studies in epilepsy and their methodological problems: a review. J Neurol Neurosurg Psychiatry. 1987;50:829-39.

25. Berg AT, S.Shinnar, Levy SR, Testa FM, Smith-Rapaport S, Beckerman B. How well can epilepsy syndromes be identified at diagnosis? A reassessment 2 years after initial diagnosis. Epilepsia. 2000;41:1269-75.

26. Manford M, Hart YM, Sander JW, Shorvon SD. The National General Practice Study of Epilepsy. The syndromic classification of the International League Against Epilepsy applied to epilepsy in a general population. Arch Neurol. 1992;49(8):801-8.

27. Zarelli MM, Beghi E, Rocca WA, Hauser WA. Incidence of epileptic syndromes in Rochester, Minnesota: 1980-1984. Epilepsia. 1999;40:1708-14.

28. Loiseau J, Loiseau P, Guyot M, Duche B, Dartigues JF, Aublet B. Survey of seizure disorders in French southwest. I. Incidence of epileptic syndromes. Epilepsia. 1990;31:391-6. 
30. Stephen LJ, Brodie MJ. Epilepsy in elderly people. Lancet. 2000;355:1441-6.

31. Hauser WA. Incidence and prevalence. In: jr JE, Pedley TA, eds. Epilepsy: A comprehensive Textbook. Philadelphia: Lippincott-Raven Publishers; 1997:47-57.

32. Annegers JF, Rocca WA, Hauser WA. Causes of epilepsy: contributions of the Rochester epidemiology project. Mayo Clin Proc. 1996;71(6):570-5.

33. Merode Tv, Krom MCTFMd, Knottnerus JA. Gender-related differences in non-epileptic attacks: a study of patient's cases in the literature. Seizure. 1997;6:311-315.

34. Krumholz A. Nonepileptic seizures:diagnosis and management. Neurology. 1999;53(Suppl. 2):S76-S83. 
52 | Incidence of epilepsy and US 
5

The diagnosis of epileptic and non-epileptic seizures

Authors: Kotsopoulos IAW, de Krom MCTFM, Kessels FGH, Lodder J, Troost J, Twellaar M, van Merode T, Knottnerus JA 


\section{Summary}

Purpose: To define systematically a cluster of diagnostic items which can assist in the early identification of epileptic and non-epileptic seizures.

Methods: A cohort of patients aged $\geq 14$ years, suspected with a first seizure, were included in this prospective population-based study. A team of neurologists evaluated and classified all cases. Diagnostic items for epileptic and non-epileptic seizures were examined with a multiple logistic regression analysis.

Results: In total 350 cases were entered in this study. Certain distinctive features were identified for epileptic and non-epileptic seizures of organic origin (e.g. postictal confusion, an epileptiform EEG pattern, and abnormal neuroimaging findings vs. a history of hypertension, and provoking factors such as exercise and warmth). Patients with seizures of non-organic origin were characterized with items such as a history of febrile seizures, treatment by a psychologist or psychiatrist, presentiment of the seizure (e.g. feeling of choking, palpitations), a history of chronic obstructive pulmonary disease, gradual end of seizure, and memory of seizure. A separate analysis for the patients who were systematically investigated provided some additional diagnostic items for the different subgroups of patients. For instance, back arching during the seizure for the patients with seizures of non-organic origin and female sex for the patients with non-epileptic seizures of organic origin. Conclusions: A number of diagnostic items differentiating patients with epileptic from patients with non-epileptic seizures was identified. These items can improve the accuracy of the diagnosis and classification of epileptic seizures at an early stage. 


\section{INTRODUCTION}

Despite several developments in the investigation of epilepsy, including functional magnetic resonance imaging (fMRI), magnetoencephalography (MEG), and improvements in videoEEG monitoring technology, there is still no test sufficiently sensitive or specific enough to reliably diagnose epileptic seizures. As such, the diagnosis of epilepsy is mainly a clinical one. A corollary is that a correct diagnosis and classification of epileptic seizures depends highly on the extent and quality of evidence acquired at time of initial diagnosis and on additional evidence accumulated over time. However, as yet, it is not clear which items of the history and which findings of the physical examination and of diagnostic tests are of particular importance for the diagnosis of epilepsy and epileptic seizures.

Population-based studies conducted in a well-defined population have the advantage that they can contribute to a comprehensive characterization of seizures and epilepsy. They provide a representative sample to carry out unbiased evaluations of several variables of interest $(1,2)$. In this prospective population-based study, we attempted to define in a systematic way which criteria can assist in the early identification of epileptic and non-epileptic seizures and can improve the accuracy of their diagnosis and classification. For this purpose, we evaluated in a standardized manner all patients with possible epileptic seizures recruited from a well-defined population.

\section{METHODS}

\section{Study population}

The investigation was conducted as part of an ongoing prospective population-based study in Maastricht and its surroundings, which is a well circumscribed area located at the southern part of the Netherlands. This area, which lies within the zip-code area 6200 to 6299 , includes 90 general practitioners and one hospital, the Maastricht University Hospital. The baseline survey was conducted from October 1998 until October 2000 and included all patients aged $\geq$ 14 years of age suspected with a first epileptic seizure. These patients were identified through different sources (general practices, nursing homes, emergency room, hospital departments and outpatient department of neurology of the university hospital, survey of EEG and neuroradiology reports, and survey of the medical files of patients who received the diagnoses syncope, convulsion, epilepsy or attacks of unknown type during the inclusion period of the study). All patients identified in this process were evaluated and, whenever possible, were examined in a standardized manner by one of the authors (IK) (medical history, physical and neurological examination). Blood screening tests and ECG were performed in all cases. EEG (awake and/or sleep deprived), video-EEG, and neuroradiological examinations (CT or MRI) were performed if indicated for a more precise diagnosis. Excluded from this study were all patients who had an acute symptomatic seizure.

\section{Definitions}

The seizure that led the patient to seek for medical advice (general practitioner, emergency room, or department of neurology) was defined as index seizure.

Epilepsy and epileptic seizures were defined and classified according to the Commission on Classification and Terminology and the Commission on Epidemiology and Prognosis of the International League Against Epilepsy (ILAE) (3-5).

\section{Diagnosis and classification of seizures}

Two authors (the neurologists MdK and $\mathrm{JL}$ ) independently evaluated all cases and classified the patient's index seizure as an epileptic seizure, a non-epileptic seizure of organic origin 
(e.g. syncope, benign drop attacks), or a non-epileptic seizure of non-organic origin (e.g. panic attacks, hyperventilation attacks, non-epileptic psychogenic seizures). The classification of cases was based on the clinical manifestations, EEG findings, neuroimaging findings, laboratory and ECG data acquired within six months after the index seizure. As such, for all cases there is a first diagnosis, obtained immediately after the index seizure, and a definite diagnosis obtained six months after the index seizure. For statistical analysis, only the definite diagnosis was taken into account. In cases of disagreement a consensus was reached with the aid of a third neurologist (the author JT). The kappa value for the inter-observer consistency of the two neurologists (MdK, JL) was also determined.

\section{Statistical analysis}

In order to determine which cluster of items is important to establish a correct diagnosis of epileptic and non-epileptic seizures, we performed the statistical analysis in the following steps:

(1) Two groups of patients were compared with respect to age, sex, ancillary tests (laboratory tests, EEG, CT, and MRI), diagnosis and clinical characteristics of the index seizure (number of seizures before the index seizure, onset of first seizure, duration of index seizure, and seizure frequency): patients seen in a standardized manner (PS) by one of the authors (IK), and patients not seen by this author (PNS). For categorical variables, comparisons of percentages were made with the chi-square test, whereas for continuous variables, a comparison of means was performed by using the T-test. For the variable seizure frequency, which is a categorical variable with an intrinsic order (i.e. ordinal variable), also a comparison was performed by using the Mann-Whitney rank sum test.

(2) Diagnostic items for epileptic and non-epileptic seizures were examined by means of a multiple logistic regression analysis. The model contained three sets of variables (i.e. history, hetero-anamnesis, findings from physical examination and diagnostic tests), as is shown on Table 1.The variable age, which is the only continuous variable, was transformed into a categorical variable according to the age limits defined by the Central Bureau of Statistics for the general population (i.e. 14-24, 25-44, $45-64$, and $\geq 65$ years). A profile was obtained by stepwise logistic regression retaining only the most strongly related variables. Ninety-five percent confidence intervals (CI) for the statistically significant variables were calculated. Two outcome contrasts were defined. First, the unprovoked seizures and non-epileptic seizures of organic origin were compared to the non-epileptic seizures of non-organic origin. Second, the unprovoked seizures were contrasted with the non-epileptic seizures of organic origin seizures. As a form of sensitivity analysis and to ensure the entry of variables with coefficients different from zero, we successively used as a criterion for the inclusion of a variable the values $0.05,0.15$, and 0.20 , as recommended by Hosmer and Lemeshow (6).

(3) The multiple logistic regression analysis was repeated for two groups of patients separately (i.e. the PS and PNS group). In this analysis, we did not vary the significance level which was set on 0.05 .

\section{RESULTS}

\section{Study population}

A total of 350 cases was entered in the study. This sample consisted of $163(46.6 \%)$ men and $187(53.4 \%)$ women aged between 14 and 92 years (mean, 49 years for men and 51 years for women). In all, $71.1 \%$ of the patients were examined in a standardized manner by one of the authors (IK) whereas $28.9 \%$ of the patients were not seen by this author. Unprovoked seizures were diagnosed in the majority of the cases (49.7\%), followed by the non-epileptic seizures of organic origin $(22.3 \%)$, the non-epileptic seizures of non-organic origin $(18 \%)$, and the acute 
symptomatic seizures $(7.7 \%)$. In eight cases $(2.3 \%)$ no definite diagnosis could be determined due to lack of data. Ninety-four $(54 \%)$ of the 174 cases with unprovoked seizures fulfilled the diagnostic criteria for epilepsy as they appeared to have had two or more recurrent unprovoked seizures. The kappa value for the inter-rater agreement was good $(0.93$, $\mathrm{p}<0.0001$ ).

Table 2 shows the baseline characteristics of the patients with unprovoked seizures, with nonepileptic seizures of organic origin, and with non-epileptic seizures of non-organic origin. In contrast with the group of patients with unprovoked seizures, the two groups of patients with non-epileptic seizures are characterized with a greater proportion of females than males.

TABLE 1. Variables used in the multiple regression analysis

\section{Set}

History

Hetero-anamnesis

Physical examination, ancillary tests

\section{Variables}

age, sex, living situation (e.g. living alone or with others), occupation (e.g. fulltime, part-time, unemployed), education level (e.g. low or high), medication, history of febrile seizures, epileptic seizures, head injury, and eating disorders, complaints of headache or memory loss, concomitant diseases (e.g. diabetes mellitus, cardiovascular diseases, depression), treatment by a psychiatrist or psychologist, family history of epilepsy, number of seizures before the index seizure, onset of first seizure, frequency of seizures, duration of the index seizure, the way the index seizure starts and ends (i.e. acute or gradually), provoking factors (e.g. alcohol abuse, sleep deprivation, stress) and presentiment (e.g. dizziness, rising epigastric sensation) of the index seizure, loss of consciousness, tongue bite, incontinence for urine or feces, injury during the seizure, postictal confusion and muscle pain, time and location of the index seizure, witnesses, emotions before the index seizure, memory of the index seizure, and epileptic seizure ever witnessed

relation of witness with patient, falling on the ground during the index seizure, jerks, movement of arms or legs, pelvic thrust, back arching, state of the body, head and eyes during the index seizure, color of the skin, making sounds with the lips, responsiveness and reaction on painful stimuli during the index seizure findings from physical and neurological examination, laboratory tests, ECG, EEG, CT, and MRI

TABLE 2. Baseline characteristics of the patients with epileptic and non-epileptic seizures

\begin{tabular}{|c|c|c|c|c|c|c|c|c|}
\hline \multirow[t]{3}{*}{ Age groups (yr) } & \multicolumn{2}{|c|}{ US } & \multicolumn{2}{|c|}{ NES of organic origin } & \multicolumn{4}{|c|}{ NES of psychogenic origin } \\
\hline & Male & Female & Male & Female & \multicolumn{2}{|c|}{ Male } & \multicolumn{2}{|c|}{ Female } \\
\hline & n $\quad(\%)$ & n $\quad(\%)$ & n $\quad(\%)$ & n $\quad(\%)$ & n & $(\%)$ & $\mathbf{n}$ & $(\%)$ \\
\hline $14-24$ & $18(20.0)$ & $8 \quad(9.6)$ & $5(16.1)$ & $7(14.9)$ & 7 & (33.3) & 15 & $(35.7)$ \\
\hline $25-44$ & $13(14.4)$ & $16(19.0)$ & $7(22.6)$ & $10(21.3)$ & 7 & (33.3) & 10 & $(23.8)$ \\
\hline $45-64$ & $26(28.9)$ & $29(34.5)$ & $12(38.7)$ & $16(34.0)$ & 6 & (28.6) & 13 & (30.9) \\
\hline$\geq 65$ & $33(36.7)$ & $31(36.9)$ & $7(22.6)$ & $14(29.8)$ & 1 & $(4.8)$ & 4 & $(9.6)$ \\
\hline Total & 90 & 84 & 31 & 47 & 21 & & 42 & \\
\hline
\end{tabular}

US, unprovoked seizures; NES, non-epileptic seizures

\section{Comparison of two groups of patients}

The group of patients who were not investigated in a standardized manner appeared to be significantly older than the other group of patients. The mean age of the first group was 57.4 whilst the mean age of the latter group was 47 . These groups of patients also differed significantly with respect to the findings on CT and MRI. The PNS group had more abnormalities on the CT-scan (40\%) and the MRI (19\%) than the PS group $18.6 \%$ and $15.9 \%$, 
TABLE 3. Prevalence and odds ratios (OR) with $95 \%$ Confidence Intervals $(95 \% \mathrm{CI})$ of the diagnostic factors for the epileptic and non-epileptic seizures.

Results of the multiple regression analysis.

\begin{tabular}{|c|c|c|c|c|c|}
\hline \multirow[t]{3}{*}{ Diagnostic factors } & \multirow[t]{3}{*}{$\begin{array}{l}\text { OR ( } 95 \% \mathrm{Cl}) \\
\text { Predicting for NES of } \\
\text { non-organic origin }\end{array}$} & \multirow{2}{*}{\multicolumn{2}{|c|}{$\begin{array}{c}\begin{array}{c}\text { US and NES of } \\
\text { organic origin } \\
n=252\end{array} \\
\text { Prevalence } \\
\end{array}$}} & \multirow{2}{*}{\multicolumn{2}{|c|}{$\begin{array}{c}\begin{array}{c}\text { NES of } \\
\text { non-organic origin } \\
n=63\end{array} \\
\text { Prevalence } \\
\end{array}$}} \\
\hline & & & & & \\
\hline & & $\mathrm{n}$ & $(\%)$ & $\mathbf{n}$ & $(\%)$ \\
\hline \multicolumn{6}{|l|}{ Age groups (yr) } \\
\hline $25-44$ & $0.27(0.09-0.76)$ & 46 & 18 & 17 & 27 \\
\hline $45-64$ & $0.23(0.08-0.65)$ & 83 & 32.9 & 19 & 30 \\
\hline 265 & $0.66(0.18-0.24)^{a}$ & 85 & 33.7 & 5 & 8 \\
\hline Febrile seizures & $5.8(1.19-28.04)$ & 11 & 4 & 7 & 11 \\
\hline $\begin{array}{l}\text { Treatment by psychologist } \\
\text { psychiatrist }\end{array}$ & $9.1(3.41-24.26)$ & 14 & 7 & 24 & 43 \\
\hline $\begin{array}{l}\text { Onset of first seizure } \\
\text { more than } 1 \text { month ago }\end{array}$ & $3.3(1.49-7.45)$ & 113 & 45 & 46 & 73 \\
\hline Postictal confusion & $0.09(0.03-0.27)$ & 120 & 55.8 & 8 & 14 \\
\hline $\begin{array}{l}\text { MRI } \\
\text { abnormal }\end{array}$ & $0.09(0.02-0.38)$ & 54 & 21.9 & $\cdot$ & $\cdot$ \\
\hline Presentiment of index seizure ${ }^{b}$ & $3.7(1.38-10.09)$ & 99 & 39.3 & 45 & 71 \\
\hline Postictal muscle pain & $4.2(1.002-17.52)$ & 35 & 14 & 11 & 17 \\
\hline $\begin{array}{l}\text { EEG }^{b} \\
\text { epileptiform discharges }\end{array}$ & $0.09(0.01-0.53)$ & 47 & 19 & 3 & 5 \\
\hline History of COPD ${ }^{6}$ & $34.8(1.79-677.08)$ & 10 & 4 & 4 & 6 \\
\hline $\begin{array}{l}\text { End of index seizure' } \\
\text { gradually }\end{array}$ & $22.1(2.39-205.09)$ & 6 & 2 & 6 & 9 \\
\hline Loss of consciousness ${ }^{e}$ & $1141.9(40.64-32081.86)$ & 205 & 82.3 & 51 & 80.9 \\
\hline Memory of index seizure $^{e}$ & $279.8(12.45-6287.98)$ & 39 & 15 & 18 & 29 \\
\hline Jerks $^{c}$ & $0.004(0.001-0.12)$ & 131 & 54.1 & 20 & 34 \\
\hline Movement of arms/legs ${ }^{e}$ & $57.9(2.15-1556.82)$ & 105 & 51.9 & 18 & 37 \\
\hline $\begin{array}{l}\text { State of the body during index } \\
\text { seizure } \\
\text { other than normal }\end{array}$ & $0.03(0.002-0.32)$ & 59 & 23.4 & 12 & 19 \\
\hline $\begin{array}{l}\text { Color of skin } \\
\text { other than normal }\end{array}$ & $0.02(0.002-0.27)$ & 67 & 27.9 & 14 & 24 \\
\hline
\end{tabular}

US, unprovoked seizures; NES, non-epileptic seizures; COPD, chronic obstructive pulmonary diseases ${ }^{a} \mathrm{p}<0.001$

badded after changing the significance level into $p=0.15$

' added after changing the significance level into $p=0.20$

respectively. In the first group of patients, no vascular malformations or mesial temporal sclerosis was identified. However, in this group of patients proportionally more brain metastases and brain tumors were identified on the MRI than in the PS group. Concerning the diagnosis of the index seizure, the PS group was significantly associated with non-epileptic seizures of non-organic origin ( $22 \%$ versus $10 \%$ in the PNS group) whereas the PNS group was significantly associated with acute symptomatic seizures $(12 \%$ versus $6 \%$ in the PS group). Other characteristics of the index seizure were also significantly different between these two groups. As such, in the PNS group, more patients were seen immediately after one seizure (52\% versus $36 \%$ in the PS group) and more patients were seen in less than a month after the first seizure ( $65 \%$ versus $49 \%$ in the PS group). Moreover, the PNS had more patients with a seizure that lasted less than five minutes $(87 \%)$ than the PS group $(56 \%)$. As well the chi-square test as the Mann-Whitney rank sum test were significant for the frequency 
of seizures. It appeared that the PS group included more patients with a variable frequency of seizures (20\% versus $14 \%$ in the PNS group) while the PNS group had more patients who had experienced just one seizure ( $68 \%$ versus $44 \%$ in the PS group). Finally, both groups did not differ significantly with respect to sex and findings from blood screening tests and EEG.

\section{TABLE 4. Prevalence and odds ratios (OR) with 95\% Confidence Intervals (95\% CI) of the diagnostic factors for the epileptic and non-epileptic seizures. \\ Results of the multiple regression analysis.}

\begin{tabular}{|c|c|c|c|c|c|}
\hline \multirow[t]{3}{*}{ Diagnostic factors } & \multirow{3}{*}{$\begin{array}{c}\text { OR }(95 \% \mathrm{Cl}) \\
\text { Predicting for NES of } \\
\text { organic origin }\end{array}$} & \multirow{2}{*}{\multicolumn{2}{|c|}{$\begin{array}{c}\text { US } \\
n=174 \\
\text { Prevalence }\end{array}$}} & \multirow{2}{*}{\multicolumn{2}{|c|}{ 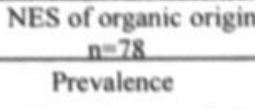 }} \\
\hline & & & & & \\
\hline & & n & (\%) & $n$ & (\%) \\
\hline Medication & $5.0(1.51-16.56)$ & 89 & 55.6 & 47 & 66 \\
\hline History of hypertension & $7.5(1.57-36.36)$ & 18 & 14 & 11 & 33 \\
\hline Provoking factors of index seizure & $13.4(3.34-54.02)$ & 24 & 18 & 27 & 42 \\
\hline Postictal confusion & $0.09(0.03-0.29)$ & 104 & 70.3 & 16 & 24 \\
\hline $\begin{array}{l}\text { Location of index seizure } \\
\text { out of doors }\end{array}$ & $11.4(3.47-37.14)$ & 66 & 43.4 & 53 & 72.6 \\
\hline Movement of arms/legs & $0.07(0.02-0.27)$ & 94 & 65.7 & 11 & 19 \\
\hline $\begin{array}{l}\text { EEG } \\
\text { epileptiform discharges }\end{array}$ & $0.02(0.002-0.12)$ & 43 & 31 & 3 & 5 \\
\hline $\begin{array}{l}\text { CT } \\
\text { abnormal }\end{array}$ & $0.04(0.01-0.16)$ & 62 & 36 & 7 & 9 \\
\hline $\begin{array}{l}\text { MRI } \\
\text { abnormal }\end{array}$ & $0.07(0.02-0.27)$ & 51 & 29.6 & 3 & 4 \\
\hline
\end{tabular}

US, unprovoked seizures; NES, non-epileptic seizures

\section{Diagnostic items}

Tables 3 and 4 show the diagnostic factors for epileptic and non-epileptic seizures that appeared to be statistically significant from the logistic regression analysis. Several items from the history, the hetero-anamnesis, and findings from diagnostic tests discriminated significantly the one group of patients from the other. However, the findings from the laboratory or ECG tests and from the physical and neurological examination did not prove to discriminate significantly the different groups of patients.

For instance, older age, postictal confusion, a change of the state of the body (e.g. stiffness) and of the skin (e.g. turning blue or red) during the index seizure, having jerks during the index seizure, an abnormal MRI, and an epileptiform EEG pattern were more likely to appear in patients with unprovoked seizures and non-epileptic seizures of organic origin than in the group of patients with non-epileptic seizures of non-organic origin. Alternatively, the latter group of patients was characterized with ten items from the history and hetero-anamnesis (history of febrile seizures, treatment by a psychologist or psychiatrist, the first seizure experienced at least more than a month ago, history of chronic obstructive pulmonary diseases, presentiment of the index seizure, loss of consciousness, postictal muscle pain, movement of arms or legs during the index seizure, gradual end of the index seizure, and memory of the index seizure). The difference between movements of arms or legs and jerks during a seizure is that the term movements of arms or legs is more general than the last one, and that it can also include uncoordinated and asymmetric movements of the extremities. As such, jerks seem to be more specific for seizures of somatic origin than for seizures of nonorganic origin. Concerning the presentiment of the index seizure, it appeared that the most common forebodes for the group of patients with non-epileptic seizures of non-organic origin were: difficulties with vision (33.9\%), a feeling of choking ( $22.3 \%)$, tingling $(20.3 \%)$, and 
TABLE 5. Prevalence and odds ratios (OR) with $95 \%$ Confidence Intervals (95\% CI) of the diagnostic factors for the subgroup of patients with epileptic and non-epileptic seizures that have been investigated in a standardized manner.

Results of the multiple regression analysis.

\begin{tabular}{|c|c|c|c|c|c|}
\hline \multirow[t]{3}{*}{ Diagnostic factors } & \multirow{3}{*}{$\begin{array}{l}\text { OR }(95 \% \mathrm{CI}) \\
\text { Predicting for NES of } \\
\text { non-organic origin }\end{array}$} & \multicolumn{2}{|c|}{$\begin{array}{l}\text { US and NES of organic origin } \\
\qquad n=177\end{array}$} & \multicolumn{2}{|c|}{$\begin{array}{l}\text { NES of non-organic origin } \\
n=53\end{array}$} \\
\hline & & \multicolumn{2}{|c|}{ Prevalence } & \multicolumn{2}{|c|}{ Prevalence } \\
\hline & & $\mathrm{n}$ & (\%) & $\mathrm{n}$ & $(\%)$ \\
\hline Febrile seizures & $11.6(1.71-78.42)$ & 10 & 6 & 7 & 13 \\
\hline $\begin{array}{l}\text { Treatment by } \\
\text { psychologist/ psychiatrist }\end{array}$ & $26.4(7.02-98.95)$ & 13 & 7 & 24 & 46 \\
\hline $\begin{array}{l}\text { Number of seizures before } \\
\text { index seizure } \\
1 \text { or more }\end{array}$ & $8.2(1.94-34.92)$ & 106 & 60.2 & 48 & 91 \\
\hline $\begin{array}{l}\text { Presentiment of index } \\
\text { seizure }\end{array}$ & $5.2(1.72-15.52)$ & 79 & 44.9 & 40 & 75 \\
\hline Postictal confusion & $0.04(0.01-0.18)$ & 95 & 54.6 & 7 & 13 \\
\hline Back arching & $102.2(2.42-4310.37)$ & 1 & 0.6 & 4 & 8 \\
\hline \multirow[t]{3}{*}{ Diagnostic factors } & $\begin{array}{c}\text { OR }(95 \% \mathrm{CI}) \\
\text { Predicting for NES of }\end{array}$ & \multicolumn{2}{|c|}{$\underset{n=119}{\text { US }}$} & \multicolumn{2}{|c|}{$\begin{array}{c}\text { NES of organic origin } \\
n=58\end{array}$} \\
\hline & & \multicolumn{2}{|c|}{ Prevalence } & \multicolumn{2}{|c|}{ Prevalence } \\
\hline & & $\mathbf{n}$ & $(\%)$ & n & $(\%)$ \\
\hline $\begin{array}{l}\text { Sex } \\
\text { Female }\end{array}$ & $3.4(1.16-10.23)$ & 55 & 46.2 & 39 & 67 \\
\hline Loss of consciousness & $0.16(0.04-0.70)$ & 110 & 92.4 & 40 & 69 \\
\hline Postictal confusion & $0.19(0.06-0.57)$ & 81 & 69.2 & 14 & 25 \\
\hline $\begin{array}{l}\text { Location of index seizure } \\
\text { out of doors }\end{array}$ & $5.6(1.77-17.69)$ & 49 & 41 & 41 & 71 \\
\hline Movement of arms/legs & $0.17(0.04-0.64)$ & 60 & 63.8 & 9 & 22 \\
\hline $\begin{array}{l}\text { EEG } \\
\text { epileptiform discharges }\end{array}$ & $0.05(0.01-0.36)$ & 32 & 33 & 2 & 5 \\
\hline $\begin{array}{l}\text { CT } \\
\text { abnormal }\end{array}$ & $0.08(0.02-0.28)$ & 35 & 30 & 5 & 9 \\
\hline $\begin{array}{l}\text { MRI } \\
\text { abnormal }\end{array}$ & $0.05(0.01-0.22)$ & 34 & 29 & 1 & 2 \\
\hline
\end{tabular}

US, unprovoked seizures; NES, non-epileptic seizures

palpitations (15.2\%). Only patients from the other group reported forebodes that are more specific for seizures such as a rising epigastric sensation, and the feeling of a strange smell or taste in the mouth. Conversely, this last group did not include any patient who reported hyperventilation just before the index seizure started.

Furthermore, the items postictal confusion, movement of the arms or legs during the index seizure (e.g. jerks), an epileptiform EEG pattern, and abnormal findings on CT or MRI discriminated significantly the group of patients with unprovoked seizures whereas four items from the history (medication, history of hypertension, provoking factors of the index seizure, and location of the index seizure out of doors) characterized the group of patients with nonepileptic seizures of organic origin. The most common provoking factors reported by this group of patients were exercise and warmth ( $25 \%)$, followed by stress $(10.9 \%)$, and tiredness $(6.2 \%)$. The sensitivity analysis showed that the analysis for these two groups of patients provided a quite robust model since no other items were added after a change of the significance level. 
Finally, the multiple regression analysis was repeated for two groups of patients separately (i.e. the PS and PNS group) in order to evaluate the value of the standardized investigation of patients with seizures (Table 5). This analysis showed that for the PS group, several items from the history, the hetero-anamnesis and findings from diagnostic tests can discriminate significantly the subgroups of patients with epileptic and non-epileptic seizures. In particular, postictal confusion was more likely to occur in the group of patients with epileptic seizures whilst the group of patients with non-epileptic seizures of non-organic origin was characterized with five items from the history (history of febrile seizures, treatment by a psychologist or psychiatrist, one or more seizures experienced before the index seizure, presentiment of the index seizure, and back arching). Moreover, the items loss of consciousness, postictal confusion, movement of arms or legs, an epileptiform EEG pattern, and abnormal findings on CT or MRI discriminated significantly the group of patients with unprovoked seizures. Conversely, two items from the history (female sex and location of the index seizure out of doors) were more likely to appear in the group of patients with nonepileptic seizures of organic origin. The majority of the women with non-epileptic seizures of organic origin appeared to have had a vasovagal syncope. However, in the case of the PNS group, no diagnostic item was found to discriminate significantly the subgroups of patients with epileptic and non-epileptic seizures.

\section{DISCUSSION}

This study shows that certain items from history, hetero-anamnesis and findings from ancillary tests can be helpful in differentiating epileptic seizures from non-epileptic seizures. As expected, postictal confusion, movement of the arms or legs during the index seizure (e.g. jerks), an epileptiform EEG pattern, and abnormal findings on CT or MRI were diagnostic indicators for the group of patients with unprovoked seizures whereas medication, history of hypertension, provoking factors of the index seizure, and location of the index seizure out of doors proved to be diagnostic indicators for the group of patients with non-epileptic seizures of organic origin. Exercise and warmth were the most common provoking factors reported by this group of patients which may explain the high likelihood of this type of seizures in occurring out of doors. With respect to patients with non-epileptic seizures of non-organic origin, the diagnostic items that differentiated this group of patients from the group of patients with seizures from somatic origin were a history of febrile seizures, treatment by a psychologist or psychiatrist, the first seizure experienced at least more than a month ago, history of chronic obstructive pulmonary diseases, presentiment of the index seizure (e.g. a feeling of choking, tingling, and palpitations), loss of consciousness, postictal muscle pain, movement of arms or legs during the index seizure (e.g. uncoordinated and asymmetric movements of the extremities), gradual end of the index seizure, and memory of the index seizure. The fact that patients with non-epileptic seizures of non-organic origin were more likely to have a history of febrile seizures and of psychiatric disorders is in keeping with the literature. Several authors indicate that patients with non-epileptic seizures of non-organic origin have often a personal and family history of psychiatric disorders, a history of neurological disease, including true seizure disorders, and a family history of epilepsy (7-10). A history of chronic obstructive pulmonary disease also appeared to be a distinctive feature for this group of patients. Apparently, because of this disease these patients have breathing difficulties and in some cases they might hyperventilate, which can lead to a loss of the consciousness. Another possible explanation is that pulmonary obstructive diseases give rise to stress and anxiety, which under certain circumstances can cause hyperventilation or anxiety attacks. Furthermore, the characteristic postictal muscle pain seems to be related to a prolonged seizure with prominent movements of the extremities. In contrast, the 
characteristics loss of consciousness and memory of the seizure seem to be opposed to each other. However, it is likely that these patients encounter a disturbance of consciousness rather than a true loss of consciousness. This disturbance of consciousness explains the reverse of an apparent amnesia in patients with seizures of non-organic origin by hypnosis, as has been indicated by Kuyk et al. (11).

In this study we attempted to investigate the patients with seizures in a standardized manner. However, we were not able to systematically evaluate a subgroup of patients with seizures (i.e. the PNS group). This group of patients was consisted mostly of patients who had a bad clinical condition at the time of their admittance and were usually discharged to the nursing homes directly. In a few cases, this group of patients included patients with a known neurological disease such as brain tumor or cerebrovascular disease. These patients were often referred to the neurologists who had seen them regularly at the outpatient department of neurology.

To some extent, the PNS group differed from the group of patients who were seen by one of the authors (i.e. the PS group). The PNS group consisted mainly of older patients, who had proportionally more abnormalities on neuroimaging studies, including brain metastases and brain tumors, than the PS group. The PNS group had also experienced more acute symptomatic seizures and, therefore, compared to the other group of patients, the patients were more likely to be seen immediately after the index seizure which in most of the cases was also the first seizure. Consequently, we separately analyzed these groups of patients. This analysis provided for the PS group some additional diagnostic items whereas for the PNS group no diagnostic item could discriminate significantly the subgroups of patients with epileptic and non-epileptic seizures. Among other diagnostic items, the items back arching during the seizure and one or more seizures experienced before the index seizure differentiated the subgroup of patients with non-epileptic seizures of non-organic origin from the patients with seizures of somatic origin. The item one or more seizures experienced before the index seizure is related to the item onset of first seizure more than a month ago and may, therefore, be interchangeable. Seizures of non-organic origin can manifest themselves with an extreme variety of individual symptoms $(11,12)$. Thus, at an early stage these seizures may not be recognized immediately as an entity by the patient as well as by the referring physician. Unsurprisingly, the item loss of consciousness was added as a diagnostic indicator for the subgroup of patients with unprovoked seizures, whereas for the subgroup of patients with non-epileptic seizures of organic origin the characteristic female sex was added. There is evidence that females consult more often their general practitioner for episodes of disturbed consciousness than males (13) and in this study more than half of the patients with seizures was female (53.4\%). In particular, proportionally more women than men had non-epileptic seizures whilst the population of patients with unprovoked seizures consisted of more men than women.

It is obvious that the symptomatology of epileptic and non-epileptic seizures varies widely. Hence, the differentiation between epileptic and non-epileptic seizures is complex. So et al.(14) presented a comprehensive list of non-epileptic events that are often confused with epilepsy. The potential of misdiagnosis is higher when clinicians have to deal with a single event that may be imperfectly described to them. A structured investigation of patients with seizures allows a better characterization of patients with epileptic and non-epileptic seizures and a more precise diagnosis early in the course of the seizure disorder. This study found after a standardized investigation of patients with seizures a number of certain diagnostic items that can assist in distinguishing patients with epileptic from patients with non-epileptic seizures. The diagnosis of the different types of seizures may be much more complicated when they coexist in the same individual. However, such cases were not included in this study. Moreover, the studied number of patients did not allow the analysis of infrequent subgroup patterns. 
Therefore, the findings of this study need to be verified by other population-based studies with larger samples of patients. Also, in such studies a further differentiation of subgroups would be possible. 


\section{REFERENCES}

1. Knottnerus JA, Leffers $P$. The influence of referral patterns on the characteristics of diagnostic tests. $J$ Clin Epidemiol. 1992;45:1143-54.

2. Knottnerus JA. The effects of disease verification and referral on the relationship between symptoms and diseases. Med Decis Making. 1987;7:139-48.

3. Commission on Classification and Terminology of the International League Against Epilepsy. Proposal for revised classification of epilepsies and epileptic syndromes. Epilepsia. 1989;30:389-99.

4. Commission on Epidemiology and Prognosis, International League Against Epilepsy. Guidelines for epidemiologic studies on epilepsy. Epilepsia. 1993;34:592-6.

5. ILAE Commission Report. The epidemiology of the epilepsies: future directions. Epilepsia. 1997; 38:614-8.

6. Hosmer DW, Lemeshow S. Applied Logistic Regression New York: Academic Press; 1989.

7. Trimble MR. Pseudoseizures. Neurol Clin. 1986;4(3):531-548.

8. Lowman RL, Richardson LM. Pseudoepileptic seizures of psychogenic origin: A review of the literature. Clinical Psychology Review. 1987;7:363-389.

9. Kristensen O, Alving J. Pseudoseizures-risk factors and prognosis. Acta Neurol Scand. 1992;85:177. 180.

10. Alper K. Nonepileptic seizures. Neurologic Clinics. 1994;12(1):153-173.

11. Kuyk J, Leijten F, Meinardi H, Spinhoven P, Dyck Rv. The diagnosis of psychogenic non-epileptic seizures: a review. Seizure. 1997;6:243-253.

12. Francis P, Baker GA. Non-epileptic attack disorder (NEAD): a comprehensive review. Seizure. 1999;8:53-61.

13. Morell DC, Gage HG, Robinson NA. Symptoms in general practice. J R Coll Gen Pract. 1971;21:3243.

14. So NK, Andermann F. Differential diagnosis. In: J. Engel J, Pedley TA, eds. Epilepsy: A comprehensive textbook. Vol. 70. Philadelphia: Lippincott-Raven Publishers; 1997:791-7. 
Methodological issues in studies of the costs of epilepsy: a review

Authors: Kotsopoulos IAW, Evers SMAA, Ament AJHA, de Krom MCTFM

Published as: Kotsopoulos IAW, Evers SMAA, Ament AJHA, de Krom MCTFM.

Methodological issues in studies of the costs of epilepsy: a review. In: Pfaffflin M, Specht U, Thorbecke R, eds. Comprehensive care in epilepsy. London: John-Libbey, 2001: 247-55. 


\section{Summary}

Purpose: To review systematically studies of the costs of epilepsy and to describe key methodological issues of these studies.

Methods: A Medline literature search was conducted from 1966 to March 2000. Several methodological aspects (perspective, study design, estimation basis, estimation procedure, cost components, estimation of indirect costs, sensitivity analysis, costs associated with comorbid conditions, and different prognostic groups) were examined to the extent to which these aspects have been employed in the studies reviewed.

Results: Fifteen studies were identified and analyzed. $67 \%$ of the selected studies had a retrospective study design and used data commonly derived from existing databases. Almost all studies estimated the costs by using the bottom-up approach and prevalence based data but did not use a sensitivity analysis to control for the assumptions made in the calculations. Only three studies mentioned the method they used to estimate the indirect costs.

Conclusions: Studies of the costs of epilepsy care show a wide variation in the methods and definitions used. Recommendations (e.g. a transparant methodology and analysis of data, a clear description of the definitions used, and consideration of the temporal aspects of epilepsy by stratifying the costs and by obtaining data prospectively) are given to increase the comparability among studies and to make the information provided by these studies suitable for economic evaluation studies. 


\section{INTRODUCTION}

As the costs of health care in general are rising, there is a growing interest in the economic aspects of epilepsy. Epilepsy has a financial burden with regard to individual patients and society. Persons with intractable epilepsy have greater demands on health and social services than those of the general epilepsy population and they often have associated learning or other mental and physical disabilities.

Furthermore, new antiepileptic drugs (AED) are several times more expensive than the older, existing AED. Similarly, epilepsy surgery, when considered in isolation, is a rather expensive intervention based on high technological developments. Next to medical expenses, when epilepsy is not well controlled, the patient has a reduced productivity and a reduced quality of life $(1,2)$. In these cases the introduction of a new AED or epilepsy surgery may appear to be the most cost effective among other therapeutic modalities.

Economic appraisal studies consider several aspects of care of people with epilepsy and assist decisions on the allocation of health care services. In the last few years the costs of epilepsy have been studied in various countries.

In this chapter, first, key methodological issues in Cost of illness studies (COI) are described. Second, epilepsy cost studies are systematically reviewed with the aim of describing several methodological aspects of these studies. Moreover, methodological issues which have to be considered in order to make $\mathrm{COI}$ studies more relevant for health policy decisions are discussed.

\section{METHODOLOGICAL ASPECTS OF COST OF ILLNESS STUDIES}

Cost of illness studies (COI) estimate the burden of specific diseases for the community. Some authors $(3,4)$ have disputed the value of COI studies while others, such as Luce and Elixhauser (5), indicate that the information provided by this type of studies can be useful because (1) it provides an estimate of the social impact of the disease which can help decision maker in priority setting, and (2) it can be incorporated in other economic evaluation studies like cost-effectiveness analysis by providing a baseline estimate against which new interventions can be assessed

Before undertaking a COI study several methodological issues should be considered:

\section{Perspective}

The perspective of the study defines the viewpoint from which the cost analysis is conducted. The choice of the study perspective determines which costs will be counted and how they will be valued (6). The costs incurred by a disease can be considered from the viewpoint of the affected individual, third party payer, health provider or society. The preferred approach is the societal perspective, which is the broadest and is always relevant $(6,7)$.

2. Study design

Costs of illness can be assessed by using: (1) self reported data, (2) medical chart data, or (3) a model which defines patterns of treatment.

The data may be primary (a primary or prospective research design), secondary (a secondary or retrospective research design) or hypothetical (a modeling design). The validity of the results of a secondary or modeling design depends primarily on the degree of error introduced by using data derived from a variety of sources and on the accuracy of the estimations based on expert opinions $(6,8)$.

3. Estimation basis

COI studies can estimate costs using prevalence or incidence based data. Prevalence based data provide an estimate of the economic burden resulting from the prevalence of disease 
during a year. The incidence approach is a longitudinal analysis which takes into account the temporal aspects of a disease and the impact of a particular treatment on the course of a disease $(9,10)$. Costs estimated by the prevalence approach, which is a cross-sectional analysis, generally have to be disaggregated into costs by disease stage or phase before they can be incorporated in economic evaluation or disease models. For this reason, cost estimations based on the incidence of a disease are preferred (9-11).

4. Estimation procedure

There are two methods of analyzing the costs of a disease: the bottom up (BU) and the top down (TD) approach. According to the TD approach, $\mathrm{COI}$ is a percentage of the total health expenditure. The BU approach uses the summation of cost data of individual patients or specific patient groups to arrive at total disease costs (11). The first method is a service-based analysis, whereas the latter one is an individual-based analysis.

5. Cost components

Because of time and resources detailed and actual data of all cost components associated with a disease can not be obtained. Drummond (7) suggested that only the costs from the most important settings should be used. There are two main types of economic cost: direct and indirect.

a. Direct costs. Direct costs are the costs of goods and services used to treat a disease. These include medical costs such as drugs, investigations, hospital care and non-medical costs, such as transportation to and from medical services $(10,12)$. The estimation of the direct costs can be based on billing data, on nationally representative payment rates data or on existing data from previous economic evaluation studies. There is no consensus as to which components of the direct costs should be included in the cost analysis.

b. Indirect costs. Indirect costs are the monetary value of lost output due to reduced productivity of a patient as a result of morbidity or mortality. Included in this category are the losses due to reduced paid and unpaid production of a patient and the indirect costs generated by the family and/or friends for taking care of the patient $(10,12,13)$.

Beside the direct and indirect costs the total burden of a disease for the patient consists also of the intangible costs which reflect the patient's perspective of the disease and its complications. Although the intangible costs are a significant component of the total burden of illness, they are difficult to quantify in a standardized manner and it is difficult to integrate their non-monetary information with the direct and indirect cost estimations (10).

6. Estimation of indirect costs

While there is much variation as to how direct costs are measured, there are standard approaches for the estimation of indirect costs (14). Several approaches can be used to calculate the indirect costs (13). The most common approach is the Human Capital method. According to the Human Capital (HC)-cost approach indirect costs are estimated as foregone earnings due to reduced mortality and morbidity (13). Psychosocial costs are not included in this method as it is difficult to put a monetary value on them. Thus, the HC method is an incomplete measure of the value of life (12). A method which attempts to estimate the psychosocial costs is the willingness to pay method (WTP). The WTP method is a method of valuing indirect costs based on the values people place on health and illness. These values can be deduced from the amount people would be willing to pay in order to reduce the risk of illness or death (5).

7. Sensitivity analysis

Lack of knowledge regarding mortality, morbidity, and medical care utilization associated with disease leads to uncertainty regarding the study results. Under such circumstances a sensitivity analysis can test the importance of particular assumptions. Sensitivity analysis can demonstrate the dependence or, alternatively, the independence of the study's conclusion on a particular assumption (5-7). 


\section{Costs associated with comorbid conditions}

Economic consequences associated with clinical conditions unrelated to the disease under study should be identified when apportioning appropriate costs. It is difficult to separate the costs of a disease from the costs of coexisting conditions. Johnson et al. (8) describe three methods of analyzing group differences in costs, i.e. the control-experimental group method, attribution of costs by procedure or diagnosis codes, and decomposition of cost differentials. Begley et al. (15) also address the problem of cost attribution and suggest different approaches for the direct and indirect costs. They note that the choice of a method for the attribution of direct costs is associated with the type of data which are used to measure the direct costs (survey data, chart or billing data).

9. Different prognostic groups

The costs of a disease may vary enormously with the nature, severity and complications of the disease. Different prognostic groups will incur different costs. Thus, a stratification of costs is desirable.

\section{COST OF ILLNESS STUDIES IN EPILEPSY-A META-ANALYSIS}

\section{Approach}

A Medline literature search from 1966 to October 1999 was conducted under the search term "Costs of epil*" and thesaurus terms "Costs of illness" and "epilepsy". In addition, in order to maximize the number of studies reviewed, the references cited in the selected studies were screened for additional relevant publications. Only articles written in English were included. In the selected studies the methodological aspects mentioned earlier were examined to the extent to which several issues regarding the techniques used and cost components included have been employed.

\section{Results of the meta-analysis}

14 studies were identified and analyzed. Most of these studies have been performed in the US and UK. The methodological aspects of these COI studies are summarized in table 1. Of the $14 \mathrm{COI}$ studies one appears to be a "general" study, i.e. estimating the costs of a range of diseases (16). The remainder is "specific" i.e. estimating the costs of 1 specific disease. The majority of the COI studies have been performed from the broad societal perspective. Griffiths et al. (17) estimated the annual medical costs of care for patients with epilepsy from the perspective of a third-party payer. This perspective ignores costs paid by other payers (for example patient, health provider) or incurred by the patient due to disability, such as lost wages, and by other caregivers.

$65 \%$ of the selected $\mathrm{COI}$ studies have a retrospective research design and use data commonly derived from existing databases. Only few COI studies used a model to assess the costs of care of people with epilepsy. Blom (18) developed a model which expresses the impact of a disease on the Gross National Product (GNP) by comparing two samples of a population equal in all aspects except the prevalence of the studied disease. This model provides no accurate estimation of the costs, but expresses the costs of a disease in relation to the costs of other diseases and the total GNP. Murray (19) estimated the annual costs of refractory epilepsy in adults by using expert opinions and evidence from published studies. The study of Begley et al. (20) describes the lifetime costs of a cohort of hypothetical patients with epilepsy using expert opinions to define different patterns of health care utilization. Only one study assessed the costs of care of people with epilepsy by obtaining prospective cost data (21). In this study the cost analysis was based on a prevalent and an incident population of patients with epilepsy. Longitudinal costs were calculated for each year after a patient with newly diagnosed epilepsy entered the study up to 8 years of follow up. 
Table 1. Methodological aspects of $\mathrm{COI}$ studies

\begin{tabular}{|c|c|c|c|c|c|c|c|}
\hline Country & Study & Perspective & $\begin{array}{l}\text { Study } \\
\text { design }\end{array}$ & $\begin{array}{l}\text { Estim } \\
\text { basis }\end{array}$ & $\begin{array}{l}\text { Estim. } \\
\text { procedure }\end{array}$ & $\begin{array}{l}\text { Diff prog } \\
\text { groups }\end{array}$ & Comments \\
\hline Netheriands & (18) & societal & M & $\mathbf{P}$ & TD & $\mathrm{Y}$ & $\begin{array}{l}\text { included transfer costs } \\
\text { in calculations }\end{array}$ \\
\hline Netherlands & (16) & societal & $\mathbf{R}$ & $\mathbf{P}$ & $\mathrm{TD}$ & $\mathrm{N}$ & general COI study \\
\hline Australia & $(25,27)$ & socictal & $\mathbf{R}$ & $\mathbf{P}$ & $\mathrm{TD}$ & $\mathbf{N}$ & $\begin{array}{l}\text { included transfer } \\
\text { payments in } \\
\text { calculations }\end{array}$ \\
\hline Switzerland & (22) & societal & R & P & $\mathrm{TD}$ & $\mathbf{Y}$ & \\
\hline UK & (21) & societal & $\begin{array}{l}\text { (1) } \mathrm{R} \\
\text { (2) } \mathrm{Pr}\end{array}$ & $\begin{array}{l}\text { (1) } \mathrm{P} \\
\text { (2) } \mathrm{I}\end{array}$ & BU & $\mathbf{Y}$ & $\begin{array}{l}\text { estimated costs of } \\
\text { incident population up } \\
\text { to } 8 \text { years of follow } \\
\text { up }\end{array}$ \\
\hline UK & (24) & societal & $\mathbf{R}$ & $\mathbf{P}$ & BU & $\mathbf{Y}$ & \\
\hline UK & (28) & societal & $\mathbf{R}$ & $\mathbf{P}$ & BU & $\mathrm{N}$ & small group study \\
\hline Sweden & (29) & societal & $\mathbf{R}$ & $\mathbf{P}$ & TD & $\mathrm{N}$ & \\
\hline USA & (20) & societal & M & I & BU & $\mathbf{Y}$ & $\begin{array}{l}\text { estimated lifetime } \\
\text { costs }\end{array}$ \\
\hline USA & (17) & $\begin{array}{l}\text { third party } \\
\text { payer }\end{array}$ & $\mathbf{R}$ & $\mathbf{P}$ & BU & $\mathrm{N}$ & \\
\hline USA & (19) & societal & M & $I$ and $P$ & BU & $\mathrm{N}$ & $\begin{array}{l}\text { small group study, } \\
\text { expert opinions }\end{array}$ \\
\hline Europe & $(1,23)$ & societal & $\mathbf{R}$ & $\mathbf{P}$ & BU & $\mathbf{Y}$ & $\begin{array}{l}\text { estimated costs over } 3 \\
\text { months }\end{array}$ \\
\hline
\end{tabular}

Pr, prospective, R, retrospective, M, mode, P, prevalent population, 1 , incident population, TD, top down, BU, bottom up, N, no, Y, yes

Almost all COI studies estimated the costs by using the BU approach and prevalence based data. However, few studies define which costs are due to comorbid conditions. In their cost analysis Blom (18) and Begley et al. (20) excluded from the estimates the indirect costs for the patients who were institutionalized. They assumed that the productivity losses of this group of patients are not attributed to epilepsy but to coexisting conditions. In addition, Begley et al. (20) counted only the medical care costs of the institutionalized patients in the direct cost estimates.

Some COI studies have considered the distribution of costs in different prognostic groups. However, these studies stratified patients with epilepsy differently according to the perspective and estimating methods of the study. For instance, the prevalence studies by Blom (18)and Gessner et al. (22) assessed the costs of epilepsy by using the top down approach and divided the population of subjects with epilepsy in 3 main categories: (a) outpatients, (b) inpatients requiring temporary care, and (c) inpatients requiring chronic care. Griffiths et al. (17) stratified patients with epilepsy according to the type of health services they received during the observation period. The incidence study by Begley et al. (20) identified six prognostic groups based on the clinical course or epilepsy. Furthermore, other studies $(21,23$, 24) stratified patients with epilepsy by seizure frequency. Table 2 shows the cost components of the COI studies. Although almost all studies calculated direct and indirect costs it is difficult to compare them as in each study different components of the direct and indirect 
costs were investigated. The list of cost items included in the cost estimations can vary from lists limited to the medical direct cost items to comprehensive lists of direct and indirect costs which include medical and non-medical direct costs as well as components of the indirect costs such as productivity losses, household activity losses and employment related items. Only 2 studies mention the method they used to estimate the indirect costs. Both studies (20, 22) used the HC method to calculate the indirect costs.

Furthermore, only a minority of studies used sensitivity analysis to control for the assumptions made for calculating the costs. Not mentioning the methods used to estimate and analyze the indirect costs introduces potential uncertainties into the results, thereby, limiting their value.

Table 2. Cost components of COI studies

\begin{tabular}{|c|c|c|c|c|c|}
\hline Country & Study & Difect costs & Tndirect costs & HC & Sensitivity analysis \\
\hline Netherlands & (18) & $\mathrm{Y}$ & $\mathrm{Y}$ & 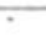 & $\mathrm{N}$ \\
\hline Netherlands & (16) & $\mathbf{Y}$ & $\mathrm{N}$ & - & $\mathrm{N}$ \\
\hline Australia & $(25,27)$ & $\mathbf{Y}$ & $\mathbf{Y}$ & $\cdot$ & $\mathbf{N}$ \\
\hline Switzerland & (22) & $\mathbf{Y}$ & $\mathbf{Y}$ & $\mathbf{Y}$ & $\mathbf{Y}$ \\
\hline UK & (21) & $\mathbf{Y}$ & $\mathbf{Y}$ & $\cdot$ & $\mathrm{N}$ \\
\hline UKa & (24) & $\mathbf{Y}$ & $\mathrm{N}$ & $\cdot$ & $\mathrm{N}$ \\
\hline UK & (28) & $\mathbf{Y}$ & $\mathrm{N}$ & - & $\mathrm{N}$ \\
\hline Sweden & (29) & $\mathbf{Y}$ & $\mathbf{Y}$ & $\cdot$ & $\mathrm{N}$ \\
\hline USA & (20) & $\mathbf{Y}$ & $\mathbf{Y}$ & $\mathrm{Y}$ & $\mathbf{Y}$ \\
\hline USA & (17) & $\mathbf{Y}$ & $\mathrm{N}$ & $\cdot$ & $\mathrm{N}$ \\
\hline USA & (19) & $\mathrm{Y}$ & $\mathbf{Y}$ & $\cdot$ & $\mathrm{N}$ \\
\hline Europe & $(1,23)$ & $\mathrm{Y}$ & $\mathbf{Y}$ & $\cdot$ & $\mathrm{N}$ \\
\hline
\end{tabular}

$\mathrm{N}$, no; Y, yes; - not clear or applicable; HC, Human Capital method

$\alpha$ Report production losses

\section{DISCUSSION}

Up till now a few studies of the costs of epilepsy have been performed. Only 2 studies describe the impact of epilepsy on the Gross National Product (GNP) which is the total value of goods and services produced in a nation over a certain period, normally a year. Gessner et al. (22)estimated that the total direct costs of epilepsy equal approximately $0.08 \%$ of the GNP while Polder et al. (16) estimated that these costs of epilepsy equal approximately $0.06 \%$ of the GNP. The analysis of the impact of a disease on the GNP or on the total health expenditures makes a comparison of different diseases with respect to their influence on a nation's economy possible. However, the potential utility of this analysis for studies of the costs of epilepsy has not been adequately explored. The failure to use this type of analysis can be considered as an important shortcoming of the research to date.

The studies by Beran et al. (25), Gessner et al. (22), Cockerell et al. (21), Jacoby et al. (24), Begley et al. (20)and van Hout et al. (23) provide the most comprehensive estimates of direct and indirect costs and clearly describe their methods and the limitations of the results. These studies differ in terms of selection of a sample of cases, the cost elements that are included or the methods of estimation. Begley et al. (15) proposed which important items of the direct costs (medical and non-medical) should be considered for the cost estimations. With respect to the indirect costs, the HC method appears to be the most frequently used method for estimating the indirect costs. In spite of its limitations the ILAE (26) recommends 
the Human Capital (HC) model because it has a more reliable access to valid statistics and productivity.

There is no consensus regarding the various methodological issues of the COI studies. Thus, until COI studies adopt more comparable methods, the true costs of epilepsy will remain unknown. The value of the information provided by most of the COI studies is very limited because prevalence based cost estimations are not directly suitable for economic appraisal studies. These cost estimations provide information on current costs without links to expected cost development. Moreover, the results of most of the COI studies are difficult to use in economic evaluations since the methods used in estimating the costs are often not clear. Furthermore, the results of COI studies differ due to the differences in health care provision across the countries. Countries with approximately similar demographic and economic features may differ in the balance between primary and secondary care, the provision of inpatient and outpatient services, the availability of specialized investigations and epilepsy surgery, the quality of training, audit and research, and the total expenditure on health. In addition, countries may differ with regard to the intensity and type of treatment of patients with epilepsy, modes of reimbursement and insurance.

An important item of the assessment of the costs of epilepsy care is also the type of the health care setting. Different types of health care setting may have different standards of epilepsy care. Therefore, the management of a certain prognostic epilepsy group may vary significantly when university hospitals are compared to general hospitals. Optimal management of people with epilepsy meets medical, social and economic considerations. A better knowledge of the economic factors will support the further development of epilepsy services. A COI study can assist health policy decisions if the COI information can be incorporated in economic evaluations. Therefore, a COI study needs to: a. have a transparant methodology and analysis of the data, b. clearly describe the definitions used, c. state the limitations of the data, $\mathrm{d}$. mention which costs are associated with comorbid conditions, and $\mathrm{d}$. take into account the temporal aspects of epilepsy by stratifying the costs and by obtaining prospectively data from an incident population of patients with epilepsy. 


\section{REFERENCES}

1. Baker GA, Gagnon D, McNulty P. The relationship between seizure frequency, seizure type and quality of life: Findings from three European countries. Epilepsy Res. 1998;30:231-40.

2. Jacoby A, Baker GA, Steen N, Potts P, Chadwick DW. The clinical course of epilepsy and its psychosocial correlates: findings from a U.K. Community study. Epilepsia. 1996;37(2):148-61.

3. Drummond M. Cost-of-illness studies. A major headache? Pharmacoeconomics. 1992;2(1):1-4.

4. Shiel A, Gerard K, Donaldson C. Cost of illness studies: an aid to decision making? Health Pol. 1987;8:317-23.

5. Luce BR, Elixhauser A. Standards for economic evaluation of health care products and services Berlin: Springer-Verlag; 1990. (Culyer AJ, ed.

6. Torrance GW, Siegel JE, Luce BR. Framing and designing the cost-effectiveness analysis. In: Gold MR. Siegel JE, Russel LB, Weinstein MC, eds. Cost-effectiveness in health and medicine. New York: Oxford University Press; 1996:54-81.

7. Drummond MF, Stoddart GL, Torrance GW. Methods for the economic evaluation of health care programmes. 2nd ed Oxford: Oxford University Press; 1997.

8. Johnson W, Nuwer MR. Cost of treating patients. In: J. Engel J, Pedley TA, eds. Epilepsy: A comprehensive textbook. Philadelphia: Lippincott-Raven Publishers; 1997:2893-2900.

9. Ament AJHA, Evers SMAA. Cost of illness studies in health care: A comparison of two cases. Health Policy. 1993;26:29-42.

10. Hodgson TA, Meinders MR. Cost-of-illness methodology: a guide to current practices and procedures. Vol. 60 Milbank Q; 1982.

11. Koopmanschap MA. Cost-of-illness studies. Useful for health policy? Pharmacoeconomics. $1998 ; 14(2): 143-8$.

12. Luce BR, Elixhauser A. Estimating costs in the economic evaluation of medical technologies. Int J Technology Assess Health Care. 1990;6:57-75.

13. Liljas B. How to calculate indirect costs in economic evaluations. Pharmacoeconomics. 1998;13(1):1-7.

14. Luce BR, Simpson K. Methods of cost-effectiveness analysis: areas of consensus and debate. Clinical Therapeutics. 1995:17(1):109-125.

15. Begley CE, Annegers JF, Lairson DR, Reynolds TF. Methodological issues in estimating the costs of epilepsy. Epilepsy Res. 1999;33:39-55.

16. Polder JJ, Meerding WJ, Koopmanschap MA, Bonneux L, Maas PJvd. Kosten van ziekten in Nederland 1994 Rotterdam: Instituut Maatschappelijke Gezondheidszorg 1997; 1994.

17. Griffiths RI, Schrammel PN, Morris GL, Wills SH, Labiner DM, Strauss MJ. Payer costs of patients diagnosed with epilepsy. Epilepsia. 1999;40(3):351-58.

18. Blom J. The value for society of epidemiology and economics of epilepsy. In: Beran RG, Pachlatko C, eds. Cost of epilepsy. Proceedings of the 20th International Epilepsy Congress. Wehr/Baden: Ciba-Geigy Verlag; 1995:55-65.

19. Murray MI, Halpern M, Leppik IE. Cost of refractory epilepsy in adults in the USA. Epilepsy Res. 1996;23:139-48.

20. Begley CE, Annegers JF, Lairson DR, Reynolds TF, Hauser WA. Costs of epilepsy in the United States: a model based on incidence and prognosis. Epilepsia. 1994;35 (6):1230-43.

21. Cockerell OC, Hart YM, Sander JWAS, Shorvon SD. The cost of epilepsy in the United Kingdom: an estimation based on the results of the two population-based studies. Epilepsy Res. 1994;18:249-60.

22. Gessner U, Sagmeister M, Horisberger B. The economic impact of epilepsy in Switzerland. In: Beran RG, Pachlatko C, eds. Cost of epilepsy. Proceedings of the 20th International Epilepsy Congress.

Wehr/Baden: Ciba-Geigy Verlag; 1995:67-74.

23. Hout Bv, Gagnon D, Souetre E, et al. Relationship between seizure frequency and costs and quality of life of outpatients with partial epilepsy in France, Germany, and United Kingdom. Epilepsia. 1997;38(1):1221-26.

24. Jacoby A, Buck D, Baker G, McNamee P, Graham-Jones S, Chadwick D. Uptake and costs of care for epilepsy: findings from a U.K. regional study. Epilepsia. 1998;39(7):776-86.

25. Beran RG, Banks GK. Indirect costs of epilepsy in Australia. In: Beran RG, Pachlatko C, eds. Cost of epilepsy. Proceedings of the 20th International Epilepsy Congress. Wehr/Baden: Ciba-Geigy Verlag; 1995:49-54.

26. Beran RG, Pachlatko C. Final report of the ILAE Commission on Economic Aspects of Epilepsy, 19941997. Epilepsia. 1997;38(12):1359-1362.

27. Banks GK, Regan KJ, Beran RG. The prevalence and direct costs of epilepsy in Australia. In: Beran RG, Pachlatko C, eds. Cost of epilepsy. Proceedings of the 20th International Epilepsy Congress.

Wehr/Baden: Ciba-Geigy Verlag; 1995:39-48. 
74 | The costs of epilepsy

28. Swingler RJ, Davidson DL, Roberts RC, Moulding F. The cost of epilepsy in patients attending a specialist epilepsy service. Seizure. 1994;3(2):115-20.

29. Silfvenius H. Economic costs of epilepsy--treatment benefits. Acta Neurol Scand. 1988;117:136-54. 


\section{Estimating the costs of epilepsy: an international comparison of epilepsy cost studies}

Authors: Kotsopoulos IAW, Evers SMAA, Ament AJHA, de Krom MCTFM

Published as: Kotsopoulos IAW, Evers SMAA, Ament AJHA, de Krom MCTFM. Estimating the costs of epilepsy: an international comparison of epilepsy cost studies. Epilepsia 2001;42: $634-40$. 


\section{Summary}

Purpose: To systematically compare the national and per capita estimates of the cost of epilepsy in different countries.

Methods: Studies for this literature review were selected by conducting a Medline literature search from January 1966 to March 2000. Key methodological, country-related and monetary issues of the selected epilepsy cost studies were evaluated in order to compare their direct cost estimates and explore their distribution. The results of the selected studies were made comparable by converting them with different types of conversion factors and expressing them as a proportion of the national expenditure on health care.

Results: 10 epilepsy cost studies were reviewed. The proportion of national health care expenditure on epilepsy shows a range of $0.12 \%$ to $1.12 \%$ or $0.12 \%$ to $1.05 \%$ depending on the type of conversion factor. The list of cost components included in the estimation of the direct costs of epilepsy differs from study to study. A comprehensive list is associated with a decrease in the contribution of drug and hospital costs to the total direct costs of epilepsy.

Conclusions: This study highlights the importance of studying the economic consequences of epilepsy and of interpreting the results on the international level. The results of epilepsy cost studies can provide insight into the distribution of the costs of epilepsy and the impact of epilepsy on the national expenditure on health care. 


\section{INTRODUCTION}

Epilepsy is a common chronic neurological disorder which affects about one of 200 people (1), creating significant economic and social burdens. The economic consequences of epilepsy are vast in terms of the use of health-care resources and loss of productivity. The prevailing emphasis on cost containment and managed care has led to increased interest in the economic evaluation of epilepsy. Economic appraisal studies consider several aspects of care for people with epilepsy and assist in making decisions on the allocation of health care services. Cost-of-illness (COI) studies are widely used in epilepsy research. COI studies estimate the burden of specific diseases for the community in a descriptive manner: they quantify all costs related to a particular disease without comparing alternative uses or resources. Some authors $(2,3)$ have disputed the value of COI studies while others, such as Luce and Elixhauser (4), indicate that the information provided by this type of study can be useful because (1) it provides an estimate of the socioeconomic impact of the disease, which can help decision makers in setting priorities, and (2) it can be incorporated in other economic evaluations by providing a baseline estimate against which new interventions can be assessed. Over the last 5-year period there has been a marked increase in the number of publications on the economic aspects of epilepsy (5). With the rapid international spread of new diagnostic and treatment measures for epilepsy, there is a need to understand the economic implications of these changes and interpret economic evaluations on the international level. The ways in which cross-national differences affect the costs of epilepsy or their evaluation have never been studied systematically.

This article is the first to explore these issues by systematically reviewing epilepsy cost studies and comparing their results. It presents an international comparison of health care expenditure on epilepsy in order to assess if extra information can be gained from this crossnational comparison. Therefore, key methodological, country-related and monetary issues in epilepsy cost studies have been evaluated in order to compare the direct cost estimates of studies which have a similar study design and methodology and to analyze the distribution of the direct costs of epilepsy.

\section{METHODS}

\section{Selection of studies}

The studies for this literature review were selected by conducting a Medline literature search from January 1966 to March 2000 with the search term "Costs of epil*"and thesaurus terms "Costs of illness"and "Epilepsy". Additional relevant publications were found by tracking references.

The selected studies had to meet the following criteria: (a) the study had to have been published as an article, (b) costs were estimated by using prevalence-based data and (c) costs were estimated from the societal perspective.

Most of the recently published prevalence studies of epilepsy define it and use measurement indexes as recommended by the International League Against Epilepsy in 1993 (6).

However, incidence studies of epilepsy lack common definitions. The inclusion of single seizures, febrile seizures and acute symptomatic seizures may vary from study to study, and this may increase incidence rates several-fold (7). Thus, COI studies which assessed the costs of epilepsy by obtaining incidence-based data were not included, as it is difficult to find comparable incidence figures across countries. 


\section{A cross-national comparison of $\mathrm{COI}$ studies}

Begley et al. (8), Johnson et al. (9) and Begley et al. (10) have critically evaluated the methodologies of $\mathrm{COI}$ studies and pointed out the following methodological issues as being relevant: (a) perspective of the study, (b) study design (model, prospective or retrospective research design), (c) estimation basis (data sources, study population), (d) estimation procedure (bottom up or top down approach), (e) types of economic costs and list of cost components included in the study (direct and indirect costs), (g) costs associated with comorbid conditions, and (h) stratification of costs in different prognostic groups.

A cross-national comparison of the results of COI studies must take into account not only the differences in the studies' methodology, but also issues associated with the countries in which the COI studies have been conducted, such as: (a) demographic factors (incidence, prevalence of epilepsy), (b) stage of economic development, and (c) organization of the health care sector.

Countries with approximately similar demographic and economic features may differ in the balance between secondary and primary care, the provision of inpatient and outpatient services, the availability of specialized investigations and epilepsy surgery, the quality of training, audit and research, and the total expenditure on health. Moreover, countries may differ with regard to the intensity and type of treatment of patients with epilepsy, cultural attitudes about health and health care, modes of reimbursement and insurance, absolute and relative price structures and administrative costs.

To enable a comparison among the COI studies we developed a checklist which took into account the aforementioned issues (Appendix 1). The selected COI studies which met the criteria of the checklist formed a subset of COI studies with a similar methodology and study design. The results of these studies could then be compared and analyzed.

\section{Conversion of the results of COI studies}

In addition, in a cross-national comparison of COI studies several monetary issues have to be considered, such as fluctuating exchange rates, different purchasing powers of currencies and the rate of inflation.

For comparison, estimates from different countries were translated into US dollars using the foreign exchange rate at the time of the study; this was obtained from the OECD

(Organization for Economic Cooperation and Development) health data published in 1998. In addition, all the COI results were converted with GDP (Gross Domestic Product) PPPs

(Purchasing Power Parities), i.e. global PPP, and Health PPPs at the time of the study. All the figures were updated to 1996 dollars according to the rate of inflation. Inflation was measured by the Consumer Price Index, published by the U.S. Bureau of Labor Statistics. PPPs were obtained from the OECD health data, published in 1998.

GDP PPPs and Health PPPs were defined as followed:

-GDP PPPs are the rates of currency conversion that equalise the purchasing power of different currencies. This means that a given sum of money, when converted into different currencies at the PPPs rates, will buy the same basket of goods and services in all countries. Thus PPPs are the rates of currency conversion which eliminate differences in price levels between countries (11).

-Health PPPs are the rates of currency conversion that equalise the purchasing power of different currencies across the full range of goods and services contained in health care (11).

\section{Comparison of the direct costs of epilepsy}

The selected COI studies were compared with respect to the direct costs of epilepsy. Direct costs are the costs of goods and services used to treat a disease. These include medical costs such as drugs, investigations, hospital, and non-medical costs, like transportation to and from 
medical services $(12,13)$. Indirect costs are the monetary value of lost output due to a patient's reduced productivity as a result of morbidity or mortality $(12,13)$.

In each COI study, the total direct costs of epilepsy have been estimated by using the prevalence figures reported in the study. If the study did not provide any prevalence rates, the rates reported in prevalence studies conducted in the same country and at approximately the same period of time as the COI study were used. We excluded transfer costs from our estimations since these are not real costs to society, but simply represent the redistribution of money between individuals (4). The estimated total direct costs are expressed as a proportion of the national expenditure on health. Figures for the national expenditure on health in different countries and demographic figures at the time of the study were obtained from the OECD health data, published in 1998.

\section{Direct cost distribution}

Although the list of cost items included in the direct cost estimations may vary from study to study, almost all studies assessed the costs of hospital services (inpatient- and outpatient-care, emergency) and the costs of drug(s) treatment. Thus, in order to explore the distribution of the costs of epilepsy, direct costs were split into three items: hospital, drugs and others. The results were aggregated by applying the same criteria to all studies: costs of hospital services and drug costs were distinguished from other costs. The costs of general practice consultations were excluded.

TABLE 1. COI studies on epilepsy reviewed

\begin{tabular}{llrrccc}
\hline Study & Country & $\begin{array}{c}\text { Study } \\
\text { Population }\end{array}$ & $\begin{array}{c}\text { Year of } \\
\text { estimate }\end{array}$ & Study design & $\begin{array}{c}\text { Estimation } \\
\text { procedure }\end{array}$ & $\begin{array}{c}\text { Specific patient } \\
\text { group }\end{array}$ \\
\hline Silfvenius (33) & Sweden & 83,000 & 1975 & $\mathrm{R}$ & $\mathrm{TD}$ & $\mathrm{N}$ \\
Blom(21) & Netherlands & 110,000 & 1987 & $\mathrm{M}$ & $\mathrm{TD}$ & $\mathrm{N}$ \\
Banks et al. (34) & Australia & 102,000 & 1990 & $\mathrm{R}$ & $\mathrm{TD}$ & $\mathrm{N}$ \\
Cockerell et al. (26) & UK & 1,628 & 1990 & $\mathrm{R}$ & $\mathrm{BU}$ & $\mathrm{N}$ \\
Gessner et al. (29) & Switzerland & 37,000 & 1990 & $\mathrm{R}$ & $\mathrm{TD}$ & $\mathrm{N}$ \\
Swingler et al. (24) & UK & 303 & 1991 & $\mathrm{R}$ & $\mathrm{BU}$ & $\mathrm{Y}$ \\
Jacoby et al. (28) & UK & 785 & 1993 & $\mathrm{R}$ & $\mathrm{BU}$ & $\mathrm{N}$ \\
Murray et al. (22) & USA & 335,167 & 1994 & $\mathrm{M}$ & $\mathrm{BU}$ & $\mathrm{Y}$ \\
Polder et al. (27) & Netherlands & 110,000 & 1994 & $\mathrm{R}$ & $\mathrm{TD}$ & $\mathrm{N}$ \\
Begley et al. (25) & USA & $2,326,513$ & 1995 & $\mathrm{R}$ & $\mathrm{BU}$ & $\mathrm{N}$ \\
\hline
\end{tabular}

$\mathrm{M}$ and $\mathrm{R}$, model and retrospective; $\mathrm{BU}$ and $\mathrm{TD}$, bottom up and top down; $\mathrm{N}$ and $\mathrm{Y}$, no and yes

\section{RESULTS}

\section{Selected studies}

The literature search identified 17 studies of the costs of epilepsy care. A further evaluation of the selected studies resulted in the inclusion of $10 \mathrm{COI}$ studies and the exclusion of the following studies: Begley et al. (14) (incidence-based COI study), Baker et al. (15) and Hout et al. (16) (described the costs for three months of a small sample of patients with epilepsy from different countries), Burke et al. (17) (estimated the costs attributable to epilepsy by using two approaches), Beran et al. (18) (estimated only the indirect costs of epilepsy), Mak et al. (19) (no OECD health data are available for China) and Griffiths et al. (20) (estimated costs from the perspective of a third-party payer).

Table 1 presents general information for the $10 \mathrm{COI}$ studies reviewed. Eight of the selected $\mathrm{COI}$ studies have a retrospective research design and used data commonly derived from existing databases. Only two studies $(21,22)$ used a model to assess the costs of care of 
people with epilepsy. Blom (21) developed a model which expresses the impact of a disease on the Gross National Product (GNP) by comparing two samples of a population equal in all aspects except for the prevalence of the studied disease. This model provides no accurate estimation of costs, but expresses the costs of a disease in relation to the costs of other diseases and the total GNP. Murray et al. (22) estimated the annual costs of refractory epilepsy in adults by using expert opinions and evidence from published studies. An equal number of studies used the Top Down (TD) and the Bottom Up (BU) approach to estimate the costs of epilepsy care. According to the TD approach, $\mathrm{COI}$ is a percentage of the total health expenditure. The $\mathrm{BU}$ approach uses the summation of cost data of individual patients or specific patient groups to arrive at total disease costs (23). The first method is a service-based analysis, whereas the latter one is an individual-based analysis. It appears that the studies of Swingler et al. (24) and Murray et al. (22) have restricted their cost estimations to patients attending a specialist epilepsy service and to adults with refractory epilepsy respectively. Therefore, the results of these studies were analyzed separately from the other $\mathrm{COI}$ studies.

\section{TABLE 2. Estimations of national health care expenditure on epilepsy per country ${ }^{a}$}

\begin{tabular}{|c|c|c|c|c|c|c|c|}
\hline \multicolumn{4}{|c|}{ Study design and estimation procedure: } & \multicolumn{2}{|c|}{$\mathrm{R}$ and TD } & \multirow[b]{2}{*}{ Rank } & \multirow[b]{2}{*}{$\begin{array}{l}\text { \% NEH on epilepsy } \\
\text { (Health PPPs) }\end{array}$} \\
\hline Study & $\begin{array}{l}\text { Direct costs } \\
\text { per person }\end{array}$ & $\mathrm{NEH}^{5}$ & $\begin{array}{l}\text { \% NEH on } \\
\text { epilepsy }\end{array}$ & Rank & $\begin{array}{l}\text { \% NEH on epilepsy } \\
\text { (GDP PPPs) }^{c}\end{array}$ & & \\
\hline Banks et al. (34) & 2,167 & 33,984 & 0.82 & 1 & 0.75 & 1 & 0.82 \\
\hline Gessner et al. (29) & 5,278 & 29,790 & 0.76 & 2 & 0.48 & 2 & 0.50 \\
\hline Polder et al. (27) & 1,608 & 34,067 & 0.55 & 3 & 0.47 & 3 & \\
\hline Silfvenius(33) & 680 & 21,696 & 0.28 & 4 & 0.18 & 4 & \\
\hline \multicolumn{4}{|c|}{ Study design and estimation procedure: } & $\mathbf{R}$ & and $\mathrm{BU}$ & & \\
\hline Cockerell et al. (26) & 2,879 & 79,833 & 1.12 & 1 & 1.05 & 1 & 1.50 \\
\hline Jacoby et al. (28) & 2,546 & 79,833 & 0.99 & 2 & 1.04 & 2 & 2.02 \\
\hline Begley et al. (25) & 750 & $1,035,080$ & 0.12 & 3 & 0.12 & 3 & \\
\hline \multicolumn{4}{|c|}{ Study design and estimation procedure: } & M & and TD & & \\
\hline Blom(21) & 1,532 & 34,067 & 0.52 & & 0.45 & & \\
\hline
\end{tabular}

Abbreviations as in Table 1.

${ }^{a}$ in 1996 US S

${ }^{b}$ NEH: National expenditure on health (in thousand US \$)

${ }^{\circ}$ GDP PPPs: Gross Domestic Product Purchasing Power Parities

TABLE 3. Estimations of national health care expenditure on epilepsy per country ${ }^{\alpha}$ based on specific patient groups

\begin{tabular}{|c|c|c|c|c|}
\hline \multicolumn{2}{|c|}{ Study design and estimation procedure: } & \multicolumn{3}{|c|}{$\mathrm{R}$ and $\mathrm{BU}$} \\
\hline Study & $\begin{array}{l}\text { Direct costs per } \\
\text { person }\end{array}$ & $\mathrm{NEH}^{\mathrm{b}}$ & $\begin{array}{l}\text { \% NEH on } \\
\text { epilepsy }\end{array}$ & $\begin{array}{l}\% \text { NEH on epilepsy } \\
\text { (GDP PPPs) }\end{array}$ \\
\hline Swingler et al. (24) & 1,060 & 79,833 & 0.41 & 0.37 \\
\hline \multicolumn{3}{|c|}{ Study design and estimation procedure: } & $\mathrm{M}$ and & \\
\hline Murray et al. (22) & 2,885 & $1,035,080$ & 0.44 & 0.44 \\
\hline
\end{tabular}

Abbreviations as in Table 1.

${ }^{a}$ in 1996 US \$

'NEH: National expenditure on health (in thousand US \$)

'GDP PPPs: Gross Domestic Product Purchasing Power Parities

\section{Estimates of the cost of epilepsy}

Tables 2 and 3 show the results of all the papers reviewed, in US dollars at the exchange rate in 1996, the year on which the costs estimations of the most recently published studies (19, 20 ) have been based. The estimated proportions of national health care expenditure on epilepsy, estimated with a different study design and a different estimation procedure, overlap 
each other and range from $0.12 \%(25)$ to $1.12 \%(26)$ and $0.12 \%(25)$ to $1.05 \%(27)$ depending on the type of conversion factor.

However, the per capita estimates of the costs of epilepsy vary greatly from country to country. For instance, in studies with a retrospective study design and a TD estimation procedure the direct costs per patient with epilepsy range from $\$ 680$ (33) to $\$ 5,278$ (29). These different estimates reflect partly differences in the list of cost components included in the direct cost estimations. Silfvenius (33) assessed the direct costs of epilepsy in Sweden by calculating the health care costs, whereas Gessner et al. (29) included in their estimations also costs outside the health care sector such as the costs of special education and vocational training of patients with epilepsy.

The three COI studies which were performed in the UK at approximately similar periods of time and with a similar study design and estimation procedure, show great differences with regard to the size of the estimated expenditure on epilepsy care. These differences may be attributed to the type of study population. The study of Swingler et al. (24) is restricted to a specific patient group, whereas the studies of Cockerell et al. (26) and Jacoby et al. (28) are both community-based studies.

For many of the countries studied, a conversion of the expenditures on epilepsy with Health PPPs was not possible because of lack of data. In addition, no Health PPPs earlier than the year 1980 could be obtained from the OECD health data.

In general, the size of the national health care expenditure on epilepsy depends on the type of conversion factor. It appears that all studies with a retrospective design, which have not restricted their cost estimates to a specific patient group, show the same rank with exchange rates and GDP PPPs conversion.

TABLE 4. Distribution of direct costs

\begin{tabular}{lccc}
\hline Study & $\begin{array}{c}\text { \% Hospital } \\
\text { costs }\end{array}$ & $\begin{array}{c}\text { \% Drug } \\
\text { costs }\end{array}$ & Others \\
\hline Polder et al. (27) & 82.19 & 11.55 & 6.25 \\
Swingler et al. (24) & 29.73 & 48.48 & 21.79 \\
Murray et al. (22) & 55,44 & 17.21 & 27.35 \\
Begley et al. (25) & 39.07 & 30.98 & 29.94 \\
Silfvenius (33) & 19.51 & 36.59 & 43.90 \\
Banks et al. (34) & 33.59 & 10.83 & 55.58 \\
Jacoby et al. (28) & 31.99 & 10.26 & 57.76 \\
Cockerell et al. (26) & 29.80 & 8.30 & 61.90 \\
\hline
\end{tabular}

\section{Distribution of direct costs}

The majority of the COI studies assessed the costs of hospital services (inpatient- and outpatient-care, emergency) and the costs of drug(s) treatment. The distribution of these components of direct costs shows great variability (Table 4). Two COI studies did not allow this analysis because data were not provided $(21,29)$. The list of cost components included in the estimation of the direct costs of epilepsy differs from study to study. A comprehensive list of cost components is associated with a decrease in the contribution of drug and hospital costs to the total direct costs of epilepsy.

\section{DISCUSSION}

Studies of the costs of epilepsy have been conducted in a few industrialized countries. The existing COI studies provide a range of estimates of the total cost of epilepsy, the average cost per person and the distribution between direct and indirect costs. 
In the present analysis, we evaluated different studies of the costs of epilepsy by means of a checklist in which several methodological, country-related and monetary issues were taken into consideration. However, many of these COI studies do not fully explain their methods, introducing potential uncertainties into the results and consequently limiting their value. This might be due to the researchers' lack of economic awareness, as the majority of the studies were performed by medical specialists.

Inevitably, there are some limitations related to several methodological issues of the epilepsy cost studies, and these limitations should be considered in interpreting the results. These limitations, which have also been indicated by Begley et al. (8), are the lack of consideration of non-medical and family-related costs, and the problem of attribution and variation of costs by severity.

Economic consequences associated with clinical conditions unrelated to the disease under study should be identified when apportioning appropiate costs. It is difficult to separate the costs of a disease from the costs of coexisting conditions. In their cost analysis Begley et al. (25) counted only the epilepsy-related medical costs in the direct cost estimates.

Few studies explored the variation in costs by severity. The costs of a disease may vary enormously with the nature, severity and complications of the disease. Different prognostic groups will incur different costs. Thus, a stratification of costs is desirable. Although some COI studies have considered the distribution of costs in different prognostic groups, these studies stratified patients with epilepsy differently according to the estimating methods of the study. For instance, Blom (21) and Gessner et al. (29) divided the population of subjects with epilepsy into three main categories: (a) outpatients, (b) inpatients requiring temporary care, and (c) patients requiring chronic care. Begley et al. (25) divided cases into three broad prognostic groups based on the clinical course of epilepsy. Furthermore, other studies $(26,28)$ stratified patients with epilepsy by seizure frequency.

Although the selected COI studies used different methodologies, databases and study periods, the size of the estimated expenditure on epilepsy care is roughly similar. The proportion of national health care expenditure on epilepsy, estimated from studies performed from the societal perspective, shows a range of $0.12 \%$ to $1.12 \%$ or $0.12 \%$ to $1.05 \%$ depending on the type of conversion factor.

Gerdtham et al. (30) indicate that the results of COI studies are preferably made comparable with purchasing power parities rather than with exchange rates. They (30) argue that exchange rates conversion tends to overstate the spread of health care expenditure as the production of non-tradables (such as health care) differs from the production of tradables, and exchange rates reflect only the equalization of prices of internationally traded goods. Thus costs converted with purchasing power parities reflect differences in the size of medical consumption or of health care quantity but do not reflect price differences. However, there is great uncertainty regarding the calculation of PPPs, in particular of Health PPPs. The measurement of Health PPPs is a recent development, and for this reason the OECD cannot provide Health PPPs before 1980.

If we convert the results of the Griffiths'study (20) and express them as a proportion of the national expenditure on health, then the estimated proportion of national health care expenditure on epilepsy will be $0.00016 \%$. In comparison with other COI studies, the Griffiths'study (20) estimated the costs of epilepsy from the narrow perspective of a thirdparty payer, ignoring costs paid by other payers (for example patients, health provider) or costs incurred by the patient due to disability, such as lost wages, as well as costs incurred by other caregivers. As a consequence of this narrow perspective, there is an underestimation of the total direct costs of epilepsy which is reflected in a low estimate of the health care expenditure on epilepsy. 
Therefore, when interpreting the results of a COI study, one has to consider factors such as the perspective of the study and the type of the study population. The studies of Griffiths et al. (20) and Swingler et al. (24) indicate that a narrow perspective and a specific patient group can affect the cost estimations.

The total indirect costs of epilepsy were not calculated, as in the majority of the studies the method used to estimate these type of costs is not clear. Not mentioning the methods used to estimate and analyse the indirect costs introduces potential uncertainties into the results, thereby prohibiting further analysis. Nevertheless, these studies show that the indirect costs are several times higher than the direct costs of epilepsy (31). In addition, no epilepsy cost study has estimated the intangible costs of epilepsy which are difficult to quantify (32) and which, combined with the other costs of epilepsy, contribute to the burden for the patient with epilepsy. This means that the direct costs of epilepsy are only a small proportion of the total costs of epilepsy for society.

Therefore, the results of this study have to be treated with great caution, as neither the indirect costs nor the intangible costs were included in the calculations. However, the results of the study do provide insight into the distribution of the direct costs of epilepsy and the impact of epilepsy on the national expenditure on health care.

Analysis of the impact of a disease on the national health care expenditure makes it possible to compare different diseases with respect to their influence on a nation's economy as well as making it possible to assess the impact of a specific disease on the national health care expenditure across countries. Based on this analysis, decisions on budgets and the allocation of health care services can be tailored much more specifically to the needs of patients with different diseases.

In conclusion, this study highlights the importance of studying the economic consequences of epilepsy and of interpreting the results on the international level. As Pachlatko (5) noted, a better understanding of the economic aspects of epilepsy leads to the further development of epilepsy care. COI studies can assist the improvement of care for people with epilepsy if they can be incorparated in economic evaluations. Therefore, COI studies should have a clear methodology and analysis of the data. In this way, COI studies could provide more comprehensive results and would facilitate the extrapolation of results from country to country. 


\section{REFERENCES}

1. Shorvon SD. Epidemiology, classification, natural history, and genetics of epilepsy. Lancet 1990;336:93-6.

2. Drummond M. Cost-of-illness studies. A major headache? Pharmacoeconomics 1992;2:1-4.

3. Shiel A, Gerard K, Donaldson C. Cost of illness studies: an aid to decision making? Health Pol 1987:8:317-23.

4. Luce BR, Elixhauser A. Standards for economic evaluation of health care products and services. Berlin: Springer-Verlag, 1990.

5. Pachlatko C. The relevance of health economics to epilepsy care. Epilepsia 1999;40(suppl 8):S3-7.

6. Commission on Epidemiology and Prognosis, International League Against Epilepsy. Guidelines for epidemiological studies on epilepsy. Epilepsia 1993;34:592-6.

7. Sander JWAS, Shorvon SD. Incidence and prevalence studies in epilepsy and their methodological problems: a review. J Neurol Neurosurg Psychiatry 1987;50:829-39.

8. Begley CE, Annegers JF, Lairson DR, Reynolds TF. Methodological issues in estimating the costs of epilepsy. Epilepsy Res 1999;33:39-55.

9. Johnson WG, Nuwer MR. Cost of treating patients. In: Engel J, Pedley TA, eds. Epilepsy: A comprehensive textbook. Philadelphia: Lippincott-Raven Publishers, 1997:2893-2900.

10. Begley CE, Annegers JF, Lairson DR, Lairson TF. Estimating the cost of epilepsy. Epilepsia. 1999;40(suppl 8):S8-13.

11. OECD. OECD Health data 98. Paris: OECD, 1998.

12. Hodgson TA, Meinders MR. Cost-of-illness methodology: a guide to current practices and procedures. Milbank $Q 1982 ; 60: 429-62$.

13. Luce BR, Elixhauser A. Estimating costs in the economic evaluation of medical technologies. Int $J$ Technol Assess Health Care 1990;6:57-75.

14. Begley CE, Annegers JF, Lairson DR, Reynolds TF, Hauser WA. Costs of epilepsy in the United States: a model based on incidence and prognosis. Epilepsia 1994;35:1230-43.

15. Baker GA, Nashef L, Hout BAv. Current issues in the management of epilepsy: the impact of frequent seizures on cost of illness, quality of life, and mortality. Epilepsia 1997;38(suppl 1):S1-8.

16. Hout Bv, Gagnon D, Souetre E, et al. Relationship between seizure frequency and costs and quality of life of outpatients with partial epilepsy in France, Germany, and United Kingdom. Epilepsia 1997;38:1221-6.

17. Burke TA, McKee JR, Pathak DS, Donahue RMJ, Parasuraman TV, Battenhorst AS. Costs of epilepsy in an intermediate care facility for persons with mental retardation. Am J Ment Retard 1999;104:148-57.

18. Beran RG, Banks GK. Indirect costs of epilepsy in Australia. In: Beran RG, Pachlatko C, eds. Costs of epilepsy. Proceedings of the 20th International Epilepsy Congress. Wehr/Baden: Ciba-Geigy Verlag, 1995:49-54.

19. Mak W, Fong JKY, Cheung RYF, Ho JL. Costs of epilepsy in Hong Kong: experience from a regional hospital. Seizure 1999;8:456-64.

20. Griffiths RI, Schrammel PN, Morris GL, Wills SH, Labiner DM, Strauss MJ. Payer costs of patients diagnosed with epilepsy. Epilepsia 1999;40:351-8.

21. Blom J. The value for society of epidemiology and economics of epilepsy. In: Beran RG, Pachlatko C, eds.Costs of epilepsy. Proceedings of the 20th International Epilepsy Congress. Wehr/Baden: CibaGeigy Verlag, 1995:55-65.

22. Murray MI, Halpern M, Leppik IE. Cost of refractry epilepsy in adults in the USA. Epilepsy Res 1996;23:139-48.

23. Koopmanschap MA. Cost-of-illness studies. Useful for health policy? Pharmacoeconomics 1998; 14:143-8.

24. Swingler RJ, Davidson DL, Roberts RC, Moulding F. The cost of epilepsy in patients attending a specialist epilepsy service. Seizure 1994;3:115-20.

25. Begley CE, Famulari M, Annegers JF, et al. The costs of epilepsy in the United States: an estimate from population-based clinical and survey data. Epilepsia 2000;41:342-51.

26. Cockerell OC, Hart YM, Sander JWAS, Shorvon SD. The cost of epilepsy in the United Kingdom: an estimation based on the results of the two population-based studies. Epilepsy Res 1994;18:249-60.

27. Polder JJ, Meerding WJ, Koopmanschap MA, Bonneux L, Maas PJvd. In: Kosten van Ziekten in Nederland 1994. Rotterdam: Instituut Maatschappelijke Gezondheidszorg, 1997.

28. Jacoby A, Buck D, Baker G, McNamee P, Graham-Jones S, Chadwick D. Uptake and costs of care for epilepsy: findings from a U.K. regional study. Epilepsia 1998;39:776-86. 
29. Gessner U, Sagmeister M, Horisberger B. The economic impact of epilepsy in Switzerland. In: Beran RG, Pachlatko C, eds. Casts of epilepsy. Proceedings of the 20th International Epilepsy Congress. Wehr/Baden: Ciba-Geigy Verlag, 1995:67-74.

30. Gerdtham UG, Jonson B. Conversion factor instability in international comparisons of health care expenditure. $J$ Health Econ 1991;10:227-34.

31. Johnson WG. The costs of epilepsy and cost-based evaluations of anticonvulsants. Pharmacoeconomics 1997; 12:446-59.

32. Beran RG. The burden of epilepsy for the patient: the intangible costs. Epilepsia 1999:40(suppl 8):S403.

33. Silfvenius H. Economic costs of epilepsy-treatment benefits. Acta Neurol Scand 1988;117:136-54.

34. Banks GK, Regan KJ, Beran RG. The prevalence and direct costs of epilepsy in Australia. In: Beran RG, Pachlatko C, eds. Costs of epilepsy. Proceedings of the 20th International Epilepsy Congress. Wehr/Baden: Ciba-Geigy Verlag, 1995:39-48. 


\section{APPENDIX 1. Checklist of epilepsy cost studies}

\section{A. Methodological issues}

1. Perspective

-societal

-individual

-third party payer

-health provider

2. Study design

-a model

-a prospective research design

-a retrospective research design

3. Estimation basis

-type of study population: community based or specific patient groups

4. Estimation procedure

-bottom up approach

-top down approach

5. Types of costs

-direct costs

-indirect costs

-intangible costs

6. Costs associated with comorbid conditions

7. Stratification of costs in different prognostic groups

8. Cost components of direct costs

-medical costs: drug, hospital and other costs

-non-medical costs

B. Country-related issues

1. Stage of economic development

-developed country

-developing country

2. Demographic factors

-incidence of epilepsy

-prevalence of epilepsy

\section{Monetary issues}

-exchange rate

-different purchasing powers of currencies

-rate of inflation 
8

The costs of epilepsy in three different populations of patients with epilepsy

Authors: Kotsopoulos IAW, Evers SMAA, Ament AJHA, Kessels FGH, de Krom MCTFM, Twellaar M, Metsemakers JFM, Knottnerus JA 


\section{Summary}

Purpose: To estimate the costs of care in three different populations of patients with epilepsy (general practices, university hospital, and epilepsy center), and to evaluate for each group of patients the association of the costs of epilepsy with the quality of life and seizure severity. Methods: A cost diary was developed to obtain prospective information on epilepsyattributable service use over a period of three months. Similar information over the previous three months was obtained from a cost questionnaire. In addition, a quality of life inventory (QOLIE-31) was used. Standard cost lists were applied for the valuation of the direct cost items. A sensitivity analysis was performed for certain cost items for which no reliable data were available.

Results: 116 patients with established epilepsy were included and the mean costs per patient per month (in Euros $€$ ) ranged from 52.08 to 357.63 . Patients from general practices appeared to have lower direct costs, spent less time in seeking or undergoing a treatment, and reported lower seizure frequencies and less severe seizure types than the patients from the other patient groups. Patients from the epilepsy center reported the highest productivity changes and unemployment rates and also had the lowest scores on the QOLIE-31. The cost items antiepileptic drugs, hospital services, unpaid care, and transportation accounted for the majority of the total direct costs.

Conclusions: The costs are influenced by the prognosis of epilepsy and patients groups from different health care settings are characterized by different patterns of medical consumption. 


\section{INTRODUCTION}

There has been an exponential growth in the treatment and diagnosis of epilepsy during the last decade. New antiepileptic drugs (AEDs) and other therapies, such as vagal nerve stimulation, have recently been introduced alongside several developments in the investigation of epilepsy including functional magnetic resonance imaging (fMRI), magnetoencephalography (MEG), and improvements in video-EEG monitoring technology. These innovations in epilepsy care have a significant impact on health care expenditures. Along with these medical costs epilepsy has, as a chronic health condition, a wide range of added health care costs such as the costs of unemployment, and the costs of caregivers. Estimates of the costs of epilepsy are often based on retrospective data or models of epilepsy management because of the time and resources involved in obtaining direct actual data (1). There are various sources to obtain direct data such as patient records, data bases from insurance companies, interviews with patients or providers, questionnaires and diaries. Cost diaries can provide detailed resource use information prospectively. Thus, they generally provide detailed and reliable data reporting over a period of time. Although cost diaries have been used for the estimation of the direct and indirect costs of chronic diseases such as fibromyalgia and chronic back pain (2), so far, no cost diary has been developed to estimate total resource use for patients with epilepsy. Therefore, we developed a cost-diary to estimate the costs of care for three different populations of patients with epilepsy prospectively and we also estimated the costs of epilepsy retrospectively with cost questionnaires, which have been applied earlier as a method to measure the direct and indirect costs of epilepsy retrospectively (3).

A number of epilepsy cost studies have investigated the relationship between the costs of epilepsy, seizure frequency, and the quality of life $(4,5)$. According to these studies higher seizure frequencies are associated with poorer outcomes with respect to the costs of epilepsy and the quality of life. Other studies have stratified the costs of epilepsy by prognosis and found that the costs of epilepsy vary significantly depending on the severity of the disease (3, 6-8). Moreover, previous studies have identified that particular aspects of care contribute the most to the overall cost of epilepsy $(1,3,7,9-11)$. These aspects were antiepileptic drug treatment and medical services. Concerning the aspect of employment in patients with epilepsy, the studies by Begley et al. (7) and Jacoby et al. (3) reported high rates of unemployment and large productivity changes among patients with epilepsy. Similarly, underemployment seems to occur often in patients with epilepsy (12). However, so far, only one study has compared the costs of epilepsy from three different health care settings (6). Based on these considerations, we conducted a study of the costs of epilepsy care in three different populations of patients with epilepsy in the Netherlands. The objectives of this study were: (a) to gain insight into the direct and indirect costs of epilepsy care, (b) to compare the costs estimated prospectively with a cost diary and retrospectively with a cost questionnaire, and (c) to investigate for each group of patients the association of the costs of epilepsy with the patients' perception of their quality of life, and with their seizure severity.

\section{METHODS}

\section{Selection of patients}

Patients with established epilepsy were recruited from three different patient populations. The first subgroup of patients was selected from 14 general practices throughout the province of Limburg, which is located in the south of the Netherlands. These patients were expected to have a good prognosis of epilepsy with seizures that were easily controlled with antiepileptic drugs (AEDs). They were included in the study if (a) only general practitioners were 
responsible for their actual care and if (b) at least three months before their enrolment in the study they had been discharged from further follow-up visits at the outpatient department of neurology. The patients of the second and third subgroup were treated by specialists from the outpatient department of neurology of the university hospital in Maastricht and from the outpatient department of the epilepsy center in Heeze respectively. The university hospital is the only hospital in the area of Maastricht to which patients with epilepsy can be referred to. Consequently, selection bias for patients with severe epilepsy is unlikely.

We hypothesized that patients from the outpatient department of neurology of the university hospital would have a good or uncertain prognosis of epilepsy (13), whereas patients from the outpatient department of the epilepsy center would have an uncertain or bad prognosis of epilepsy. Thus, we assumed that the different subgroups of patients with epilepsy would, as a result of their different prognosis of epilepsy, have different patterns of medical consumption and would therefore incur different costs. Accordingly, patients with frequent seizures would be more likely to incur significant direct costs and be unemployed than patients with well controlled epilepsy.

\section{Data collection}

We developed a cost questionnaire and a cost diary to obtain detailed information on several elements of epilepsy care responsible for the direct (medical, non-medical) and indirect costs of epilepsy care. In order to obtain as complete information as possible, the layout of the questionnaire and the cost diary was designed to be suitable for self-completion by the patient or his caregiver. The cost diaries collected information about service use and the state of employment prospectively over a period of three months, each diary covering a period of four weeks. The cost questionnaire obtained similar information over the last three months. The cost questionnaire as well as the cost diaries were accompanied by instructions and an example of a completed questionnaire or diary. In addition, we used the quality of life in epilepsy inventory (QOLIE-31) (14), which provides insight into the burden imposed on the patients as a consequence of their epilepsy.

Patients who could not reasonably complete the questionnaire satisfactorily (young children, patients with severe developmental disabilities), were considered ineligible for this quality of life questionnaire. We were able, though, to elicit information about these patients' resource use from their caregivers who were asked to complete the cost questionnaire and cost diaries. Patients and caregivers were instructed to record only epilepsy-related issues.

To encourage a high response, prepaid envelopes were provided to return the questionnaires and diaries. Each patient was asked to return a cost diary after one month and received two diaries thereafter to complete for the subsequent two months. If the diaries or the questionnaire were incomplete or not returned, the patients were called and received a reminder letter with the kind request to complete and return them.

With respect to the patients from the outpatient department of neurology and the epilepsy center, the cost questionnaire was completed through an interview of the patient by one of the investigators (IK). For practical reasons, for patients from general practices we had to adopt the postal method for data collection.

\section{Cost estimation}

For the estimation of the direct costs of epilepsy we used the following steps:

First, we used as much as possible standard cost lists for the valuation of the direct cost items. However, for several cost items no standard cost list was available. For these items we had to use other sources to obtain nationally representative unit costs. The cost measures and sources used to estimate the cost items captured in the study are shown in Table 1. 
Second, a number of assumptions was taken in order to estimate the direct costs of epilepsy. Patients with epilepsy were treated with specified (e.g. physiotherapy, speech therapy) and unspecified forms of therapy. In the case of the unspecified forms of therapy, we assumed that the most common form would be Cesar/Mensendieck therapy and used its unit cost unless it was otherwise reported by the patient. After physiotherapy, Cesar/Mensendieck therapy is the most common paramedical treatment of Dutch patients $(15,16)$. The drug costs were calculated from the Drug Formulary by multiplying the price of a certain drug at its defined daily dosis (DDD) by the duration of its prescription (17). For topiramate we had to use its unit price for the year 2000 since it was not reimbursed earlier by the public and/or private insurance companies. Based on the standard distances from a patient's house to the general practice or hospital (18), we could calculate the transportation costs by taxi for the groups of patients from the general practices and university hospital. However, for the patients from the epilepsy center no such information existed. Hence, the transportation costs by taxi were calculated on the basis of the mean of distances from the patients' private addresses to the epilepsy center. For the cost items child minder and unpaid care no market prices were available and we used the "shadow price" suggested by Oostenbrink et al. (18) to value them. "Shadow pricing" is a method to impute values on cost items for which no market prices are available. In this case, for the estimation of the cost of care provided by relatives or friends of a patient with epilepsy the relevant wage of professional caregivers was used. For each cost item, the overall mean costs per patient per month were derived by dividing the sum of costs across services by the number of study observations. All figures were updated to 1999 Dutch guilders according to the rate of inflation and then the costs were converted into Euros ( 1 $f=0.45 €$ ). Inflation was measured by the Consumer Price Index published by the Dutch Central Bureau of Statistics (internet: www.cbs.nl).

Third, as a form of sensitivity analysis, we used the mean of the reported patient's out-ofpocket expenses for a child minder to calculate this cost item. We also performed a sensitivity analysis for other cost items (unspecified forms of therapy, transportation costs by taxi). Therefore, a range of $5 \%$ was chosen to test the likelihood of the assumptions made when measuring these costs. This range has also been applied in other cost studies (19).

We reported time costs as the mean number of hours per month spent by the patient in seeking a treatment or undergoing an intervention, and we reported lost or reduced productivity as the mean number of days per month or hours per month of work lost respectively. Furthermore, we reported the current employment status of the enrolled patients (e.g. employment full- or part-time, unemployed, retired, registered permanently sick). In order to determine the frequency of several types of seizures, we assumed that a patient would have had at least ten seizures per day if he reported that he had had a countless number of seizures per day over a certain period of time. In this study, only three patients reported that they had experienced a countless number of absences per day.

\section{Statistical analysis}

Since cost variables and seizure frequencies are not normally distributed, we used nonparametric tests such as the Kruskall-Wallis test for global cost differences across the three patient groups and, in case of significance, we used Mann-Whitney tests for group-by-group comparisons.

The Wilcoxon Signed Ranks test was used to evaluate for each patient group the significance of differences between the estimated retrospective data (reflect mean data in the last three months) and mean prospective data.

To compare the results of our study with those of other Dutch cost studies, we had to extrapolate our findings. Therefore, we estimated for each patient group the total number of patients with established epilepsy living in the circumscribed area of Maastricht, which has 
194,540 inhabitants: 467 from the general practices, 266 from the outpatient department of neurology of the university hospital, and 74 from the outpatient department of the epilepsy center. We then multiplied the number of patients from each patient group with the cost estimates for each patient group. Next, we summed up these products and divided this sum by the total number of patients with epilepsy to arrive at the total direct costs of epilepsy per patient per month.

We also calculated the Spearman's rank correlation coefficients to test in each patient group the level of association between the direct costs of epilepsy and each seizure type and the total score on the QOLIE-31. Therefore, based on the Chalfont Seizure Severity Scale (20) we rated the severity of seizures as follows: 0.5 for seizures of unknown type, 1 for simple partial seizures, 2 for absences, 18 for mild complex partial seizures or 86 for severe complex partial seizures, and 104 for generalized seizures. Subsequently, we multiplied the frequency of each seizure type with its rate of severity and estimated the level of association of this product with the direct costs of epilepsy. We performed this twice and each time we used a different score for the complex partial seizures. All statistical tests were two sided, with a P-value $<0.01$ considered statistically significant.

TABLE 1. Cost measures and sources used to estimate the costs of epilepsy

\begin{tabular}{llll}
\hline Cost item & Cost measures & Unit costs (in Euros $€$ ) & Sources of costs \\
\hline $\begin{array}{l}\text { Medical costs } \\
\text { GP services }\end{array}$ & & \\
Phone calls & Cost per call & 8.71 & CTG \\
Visits & Cost per visit & 16.59 & $(18)$ \\
Visits at home & Cost per visit & 26.14 & CTG \\
Physician services & Cost per visit & $72.60 \mathrm{UH}$ & CTG, (18) \\
& & $54.45 \mathrm{EC}$ & \\
Hospital services & Cost per admission day & 331.71 UH & CTG, (18) \\
& & $291.33 \mathrm{EC}$ & \\
Diagnostic procedures & & & \\
Laboratory tests & Cost per procedure & 9.46 & $(18)$ \\
EEG & Cost per procedure & 77.43 & $(27)$ \\
CT & Cost per procedure & 186.01 & $(27)$ \\
MRI & Cost per procedure & 411.21 & $(27)$ \\
Physiotherapist & Cost per visit & 18.15 & $(18)$ \\
Speech therapist & Cost per visit & 19.06 & $(18)$ \\
Occupational therapist & Cost per visit & 9.98 & CTG \\
Social worker & Cost per visit & 34.29 & CTG \\
Psychologist & Cost per visit & 56.72 & CTG \\
Other therapy & Cost per visit & 17.69 & $(18)$ \\
Non-medical costs & & & \\
Transportation & & & \\
Taxi & Cost per km & 1.35 & $(18)$ \\
Ambulance & Cost per trip & 334.89 & $(18)$ \\
Paid care & & & \\
Home care & Cost per hour & 22.82 & $(18)$ \\
Family care & Cost per hour & 25.09 & $(18)$ \\
ADL help & Cost per hour & 32.67 & $(18)$ \\
Child minder & Cost per hour & 7.94 & $(18)$ \\
Unpaid care & Cost per hour & 7.94 & \\
\hline Ur & & &
\end{tabular}

UH; university hospital, EC; epilepsy center

${ }^{a}$ National Institute for tariffs in health care: www.ctgzorg.nl 


\section{RESULTS}

\section{Study population}

In total 116 patients with established epilepsy [24 patients from general practices (GP), 49 from the outpatient department of neurology of the university hospital (UH), and 43 patients from the outpatient department of the epilepsy center $(\mathrm{EC})]$ returned at least one cost diary or cost questionnaire. In total $67 \%$ of the returned diaries and cost questionnaires were completed for all variables whereas the rest was partly completed for some of the variables. In particular, $71 \%$ of the patients from the GP, $81 \%$ of the patients from the UH, and $51 \%$ of the patients from the EC returned the cost diaries and questionnaires. Furthermore, $43 \%$ of the patients completed the diaries and cost questionnaire for the entire study period (i.e. $38 \%$ of the patients from the GP, $59 \%$ of the patients from the UH, and $27.9 \%$ of the patients from the EC). The patient characteristics are shown in Table 2.

TABLE 2. Patient characteristics

\begin{tabular}{lllll}
\hline & $\mathrm{GP}^{a}$ & $\mathrm{UH}^{b}$ & $\mathrm{EC}^{c}$ & Total \\
\hline Sex & & & & \\
$\mathrm{N}$ (mean age) & $10(52.4)$ & $25(47.8)$ & $24(42.0)$ & $59(46.3)$ \\
Male & $14(49.1)$ & $24(44.0)$ & $19(33.0)$ & $57(41.4)$ \\
Female & $24(50.5)$ & $49(45.9)$ & $43(38.2)$ & $116(44.0)$ \\
Total & 70.98 & 64.31 & 62.87 & 65.60 \\
Mean score on QOLIE-31 & & & \\
\hline a GP: patients from general practices & & & \\
${ }^{b}$ UH: patients from the university hospital & & & \\
'EC: patients from the epilepsy center & &
\end{tabular}

TABLE 3. Average costs per patient per month for each patient group and type of cost (in Euros 6 )

\begin{tabular}{llll}
\hline Cost items & GP & UH & EC \\
\hline Medical costs & & & \\
GP services & 3.97 & 2.70 & 5.91 \\
Physician services & 10.08 & 28.95 & 17.33 \\
Hospital services & 0 & 49.76 & 137.57 \\
Diagnostic procedures & 7.32 & 27.59 & 13.49 \\
Paramedical therapy & 6.92 & 15.83 & 15.90 \\
Drugs & 23.31 & 53.31 & 84.33 \\
Total & 51.60 & 178.14 & 274.53 \\
Non-medical costs & & & \\
Transportation & 0 & 16.97 & 28.48 \\
Paid care & 0 & 3.18 & 3.48 \\
Unpaid care & 0.48 & 84.43 & 51.14 \\
Total & 0.48 & 104.58 & 83.10 \\
\hline Total direct costs & 52.08 & 282.72 & 357.63 \\
\hline Total patient's out-of- & 7.03 & 147.25 & 97.00 \\
pocket expenses & & & \\
\hline Abbrian
\end{tabular}

Abbreviations as in Table 2

\section{Direct costs}

The average costs per patient with epilepsy per month for each patient group and type of cost are presented in Table 2. Overall, patients from general practices appeared to incur the least direct costs ( $52.08 €$ vs. $282.72 €$ of the patients from the $\mathrm{UH}$, and $357.63 €$ of the patients from the EC). Patients from the EC produced the most direct medical costs $(274.53 €)$ 
whereas patients from the UH produced the most direct non-medical costs (104.58 $€$ ). In particular, the items hospital services and drugs contributed the most to the medical costs, and these were the highest in the group of patients from the EC. Concerning the non-medical costs, the cost items transportation and unpaid care contributed the most to these costs. The costs for the unpaid care were the highest in the group of patients from the UH.

Table 2 also displays the mean patient's out-of-pocket expenses per month for each patient group. It appeared that patients from the UH had the highest patient's out-of-pocket expenses $(147.25 \epsilon)$.

\section{Distribution of the costs of epilepsy across the patient groups}

In general, the direct costs differed significantly across the three patient groups $(\mathrm{P}<0.01)$, but only for the patients from the UH were these costs significantly higher compared with the patients from the general practices. Figure 1 shows the distribution of the several cost items in each patient group. For the patients from the GP as well as for the patients from the EC, the drug costs obtained the largest proportion of the total direct costs of care $(57.7 \%$ and $45.3 \%$ respectively). In contrast, for the patients from the UH, the costs of unpaid care constituted the largest proportion of the total direct costs $(41.6 \%)$. For this group of patients the drug costs formed the second largest proportion of the total direct costs $(16.9 \%)$.

\section{Comparison of prospective with retrospective cost data}

Compared to the estimated retrospective direct cost data, the prospective data differed significantly only in the patients from the $\mathrm{UH}$ for the cost items physician services, diagnostic procedures, and unpaid care. In particular, the prospective cost data of the first two cost items appeared to be significantly smaller than the retrospective data, while the prospective data of the latter cost item (unpaid care) were significantly larger than the data collected retrospectively.

\section{Time costs and the indirect costs of epilepsy}

In comparison with the other patient groups, patients from the GP had the least time costs (i.e. the costs of the time a patient spends per month in seeking or undergoing a treatment). The mean number of hours per month that this patient group spent in seeking or undergoing a treatment was 0.13 , while patients from the $\mathrm{UH}$ and EC spent 0.93 and 0.73 hours per month respectively.

During the inclusion period of the study one patient with epilepsy, a patient from the epilepsy center, 55 years of age, died. The productivity changes varied with each patient group, and the highest changes were found in patients from the EC. For this patient group the mean reduced productivity was 0.92 hours per month, and the mean lost productivity was 0.26 days per month. In comparison, the mean reduced productivity for the patients from the UH was 0.30 hours per month. Moreover, it was found that the mean lost productivity for this patient group and the mean lost and reduced productivity for the patients from the GP obtained such small values that they could be considered as negligible.

Among the patients who agreed to participate, $34.5 \%$ supplied information regarding their employment state. The mean age of these patients was 60 whereas the mean age of the patients who did not provide any information about their employment state was 37 . As expected, the highest unemployment rates were reported from the patients from the epilepsy center. Of the 14 patients from the EC who provided information about their employment state, four were registered as temporarily sick, three were registered as permanently sick, two worked on therapeutic base, two were unemployed, two patients were retired and one patient got an early retirement. The majority of the patients from the UH were retired. In particular, 11 of the 21 patients who provided information on this subject were retired, while seven were 
registered as temporarily sick, two patients were early retired, and one patient had a part-time job. Similarly, most of the patients from the GP were retired. More specifically, three of the five patients who reported on this subject were retired, whereas one patient was registered as temporarily sick, and one patient was employed part-time.

\section{Patients from GP}

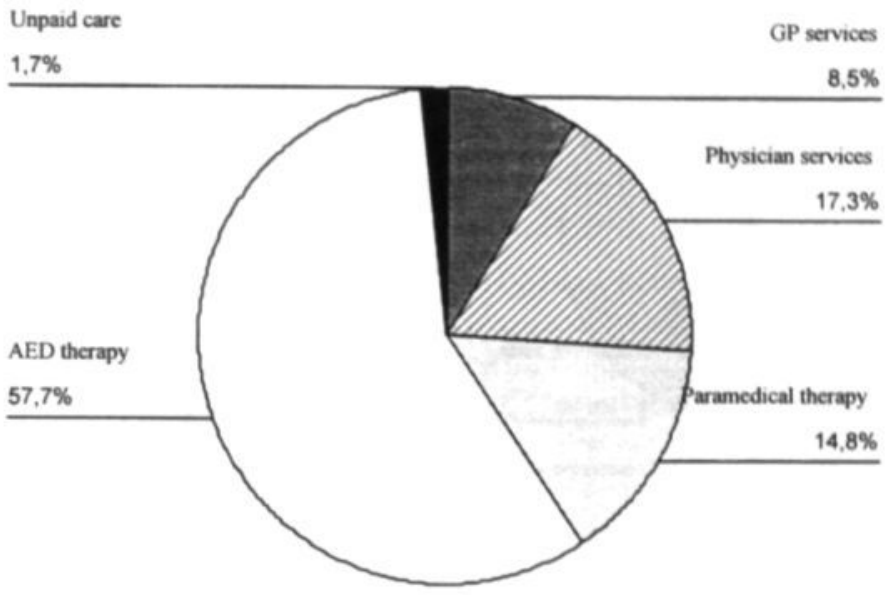

Patients from UH

GP services

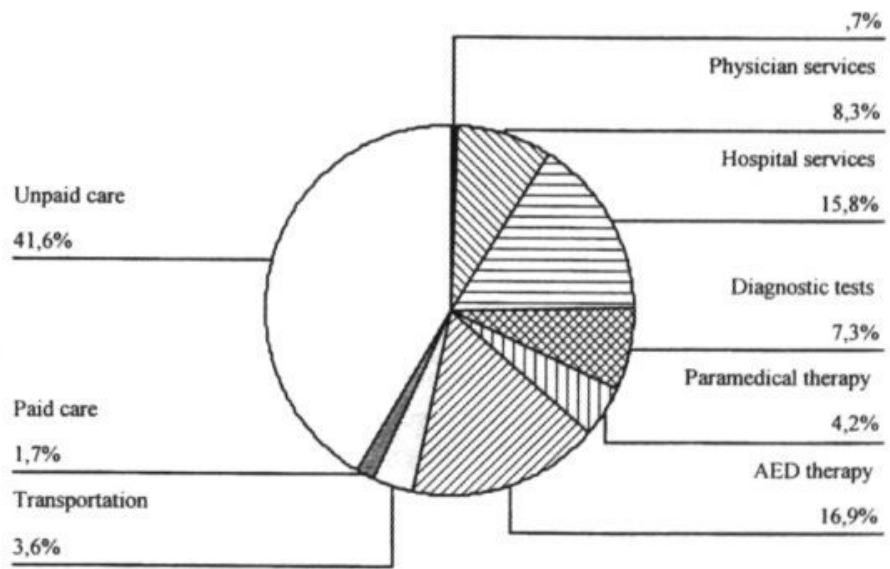




\section{Patients from EC}

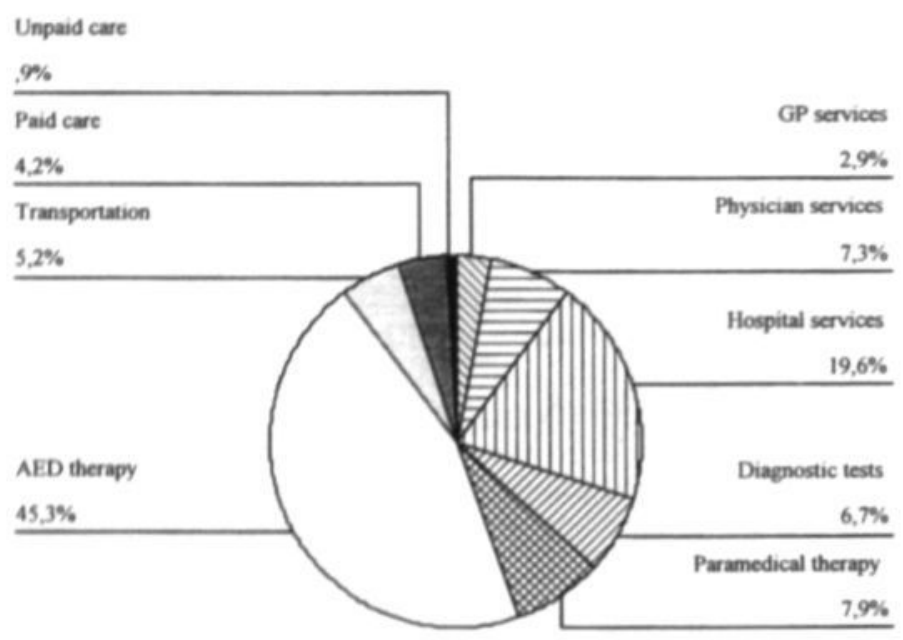

FIG. 1. Distribution of the direct costs items of epilepsy in each patient group (GP; general practice, UH; university hospital, EC; epilepsy center)

\section{Comparison with other cost studies}

Two prevalence-based studies in the Netherlands have reported earlier the costs of epilepsy $(21,22)$. Although these studies are difficult to compare with this present study due to differences in study design, in the valuation of the cost items, in the types of costs and the list of cost components included in the study, we attempted to compare their cost estimations with our estimates of the costs of epilepsy by extrapolating our results. Thus, we estimated that the total direct cost of epilepsy per patient per month (in Euros $€$ ) are 156.12 compared to 115.83 (22) and $112.08(21)$.

\section{The costs of epilepsy in relation to the quality of life and the seizure severity}

As it is shown in table 2, patients from the EC had the lowest mean total scores (62.87) on the QOLIE-31, indicating that these patients, compared with the patients from the other patients groups, experienced a diminished quality of life. However, the total score on the QOLIE-31 was not significantly associated with the total direct costs across the different patient groups. Only for the patients from the general practices there was a moderate, but non significant, association between the total score on the quality of life inventory and the total direct costs $(\mathrm{P}=0.056)$. In contrast, the total score on the QOLIE-31 was significantly associated with the total sum of direct costs from all patient groups (Spearman's rho=-0.263, $\mathrm{P}=0.017$ ).

The distribution of seizure frequencies across the three patient groups according to seizure type is shown in figure 2. It appeared that patients from GP reported lower seizure frequencies than patients from the UH or EC. Moreover, these patients recorded less severe seizure types (e.g. absences and seizures of unknown type) than the patients from the other two groups. In accordance with these findings, the seizure severity appeared to be significantly associated 
estimations we attempted to be complete by including as many epilepsy-related cost items as possible. However, these cost estimates are conservative since we did not put a monetary value on the time costs. We also did not assess the monetary value of the indirect and intangible costs of epilepsy. Nevertheless, the results of these difficult to quantify items indicate that epilepsy has significant implications for the costs of health care and emphasize the importance of good seizure control.

The methods used to collect information about medical consumption and service use of the patients with epilepsy had some limitations. First, we based our cost estimations on the data reported by the patients, which we assumed that they have been correctly recorded. Goossens et al. (2) examined in their study the validity of their cost diary by comparing the self-reported information with data obtained from insurance companies. They (2) noted that precautions should be taken when relying on patients to record cost data. However, many of the epilepsyrelated items cannot be easily identified (23). These items are often indirect effects of epilepsy or its treatment but are not registered as such (e.g. admission to the hospital due to a seizure related accident, or due to serious side effects of the AEDs). Moreover, the cost diary and cost questionnaire enabled us to obtain actual data on direct non-medical costs such as transportation costs and the costs of unpaid care which cannot be easily captured through other sources such as hospital databases and patient records.

Patients from the general practices are probably a selection of the more severe cases, since these patients may be more inclined to participate at this study. Consequently, the cost estimates from this patient group show less contrast with the cost estimates from the other patient groups. Nevertheless, the findings from this patient group corroborate with our assumption, namely that patients with a good prognosis of epilepsy will require less service use and will incur less costs.

A further limitation of our study is that we did not enroll patients admitted at the epilepsy center, which means that our cost calculations are likely to underestimate the true costs of epilepsy care.

The relatively short time perspective of the study (three months retrospectively and three months prospectively) may have also affected our cost estimations. In general, the time perspective of a study should be long enough to include all the major consequences of epilepsy (24). It is likely that the information obtained during six months through the cost diaries and cost questionnaire is representative for the information drawn from prevalent cases of epilepsy during a longer period of observation (e.g. one year). However, this issue needs to be verified by further research. Goossens et al. (2) examined in their study whether keeping a cost diary for a part of a year would be representative compared to keeping a diary for the whole year. They (2) concluded that collecting data for an abbreviated period can be a good alternative but they also noted that, in general, in this way the variance of the estimates will increase. Thus, requiring less effort per patient must be weighted against including more patients.

A number of important findings were observed in this study. We found that the patient groups, reflecting patients with a different prognosis of epilepsy, were significantly associated with the total direct cost estimates and that patients with a good prognosis of epilepsy are likely to incur less costs than patients from other prognostic groups. Similar results have been reported in other studies $(3,5,7,25)$. Antiepileptic drugs and hospitalization were responsible for the majority of the direct medical costs, which corresponds with the findings in other studies $(3,7,9-11)$. Moreover, it appeared that transportation and unpaid care accounted for the majority of the non-medical direct costs, and that a great proportion of patients with severe epilepsy (i.e. patients from the epilepsy center) is unemployed and reports large productivity losses. These findings are reflected by the low score of these patients on the quality of life inventory, which provides insight into the social consequences of epilepsy. 
Similar patterns of unemployment and productivity changes have been reported by Begley et al. (7) and Jacoby et al.(3). Elwes et al. (26) indicated that high unemployment rates among patients with epilepsy consist only one aspect of a wider spectrum of social and economic disadvantages. In addition, patients from the epilepsy center and university hospital spent more time in seeking or undergoing a treatment than patients from the general practices. With respect to the distribution of the total direct costs, the direct costs differed significantly across the three patient groups, but only for the patients from the university hospital were these costs significantly higher compared with the patients from the general practices.

Furthermore, in contrast with the other patient groups in which drug costs obtained the largest proportion of the total direct costs, in the group of patients from the university hospital the costs of unpaid care contributed the most to the total direct costs. It was also found that only in this patient group the prospective data differed significantly from the retrospective data for the cost items physician services, diagnostic procedures, and unpaid care. These findings may indicate that these patients may have a totally different pattern of health care resource use across time than the patients from the other two patient groups.

In this study, no reliable data were available for certain cost items. To investigate the extent to which the assumptions we made for the estimation of these cost items may have induced some bias, we performed a sensitivity analysis. The cumulative effect of the modifications in the total mean direct costs gives rise to a 1.9 to $2.2 \%$ change. Consequently, we may conclude that our findings regarding the total direct costs of epilepsy are quite robust. Despite the fact that we did not include in our calculations the costs of patients admitted at the epilepsy center as the studies by Polder et al. (22) and Blom (21) had done, we estimated higher total direct costs than these studies. This might indicate that cost diaries can provide more meticulous information on service use of the patients with epilepsy than retrospective databases or models.

In summary, this study demonstrates that cost estimations can be influenced by the prognosis of epilepsy and that certain cost items (drugs, hospitalization, transportation, and unpaid care) account for the majority of the total direct costs. Moreover, it can be deduced from the comparison of the retrospective with the prospective cost data that different patient groups may be characterized by a certain pattern of health care resource use across time. However, more studies with a larger number of patients from each health care setting are needed to investigate the pattern of health care resource use across the different patient groups. 


\section{REFERENCES}

1. Begley CE, Annegers JF, Lairson DR, Reynolds TF. Methodological issues in estimating the costs of epilepsy. Epilepsy Res. 1999;33:39-55.

2. Goossens ME, Rutten van Molken MP, Vlaeyen JW, van der Linden SM. The cost diary: a method to measure direct and indirect costs in cost-effectiveness research. J Clin Epidemiol. 2000;53(7):688-95.

3. Jacoby A, Buck D, Baker G, MeNamee P, Graham-Jones S, Chadwick D. Uptake and costs of care for epilepsy: findings from a U.K. regional study. Epilepsia. 1998;39(7):776-86.

4. Baker GA, Nashef L, Hout BAv. Current issues in the management of epilepsy: the impact of frequent seizures on cost of illness, quality of life, and mortality. Epilepsia. 1997;38(Suppl 1):S1-8.

5. Hout $B v$, Gagnon D, Souetre E, et al. Relationship between seizure frequency and costs and quality of life of outpatients with partial epilepsy in France, Germany, and United Kingdom. Epilepsia. 1997;38(1): 1221-26.

6. Guerrini R, Battini R, Ferrari AR, et al. The costs of epilepsy in childhood epilepsy in Italy: comparative findings from three health care settings. Epilepsia. 2001;42:641-6.

7. Begley CE, Famulari M, Annegers JF, et al. The costs of epilepsy in the United States: an estimate from population-based clinical and survey data. Epilepsia. 2000;41(3):342-51.

8. Begley CE, Annegers JF, Lairson DR, Reynolds TF, Hauser WA. Costs of epilepsy in the United States: a model based on incidence and prognosis. Epilepsia. 1994;35 (6):1230-43.

9. Berto P, Tinuper P, Viaggi S, Group TE. Cost-of-illness of epilepsy in Italy. Pharmacoeconomics. 2000;17:197-208.

10. Cockerell OC, Hart YM, Sander JWAS, Shorvon SD. The cost of epilepsy in the United Kingdom: an estimation based on the results of the two population-based studies. Epilepsy Res. 1994;18:249-60.

11. Zelicourt Md, Buteau L, Fagnani F, Jallon P. The contributing factors to medical costs of epilepsy: an estimation based on a French prospective cohort study of patients with newly diagnosed epileptic seizures (the CAROLE study). Seizure. 2000;9:88-95.

12. Heaney D. Epilepsy at work: Evaluating the cost of epilepsy in the workplace. Epilepsia. 1999;40 (Suppl. 8):S44-7.

13. Sander JW. Some aspects of prognosis in the epilepsies: a review. Epilepsia. 1993;34(6):1007-16.

14. Cramer JA, Perrine K, Devinsky O, Bryant-Comstock L, Meador K, Hermann B. Development and Cross-Cultural Translations of a 31-Item Quality of Life in Epilepsy Inventory. Epilepsia.

15. Welling BJM, Delnoij DMJ, Hutten JBF, Kwartel AJJvd, Smit RLC. (Netherlands Institute for research of health care (NIVEL)). Brancherapport curatieve somatische zorg. 1999.

16. Rijken PM, Heugten CMv, Dekker J. (Netherlands Institute for research of health care (NIVEL)). Brancherapport paramedische zorg. 1996.

17. College van zorgverzekeringen. Farmacotherapeutisch Kompas Amstelveen; 1999/2000.

18. Oostenbrink JB, Koopmanschap MA, Rutten FFH. Handleiding voor kostenonderzoek, methoden en richtlijnprijzen voor economische evaluaties in de gezondheidszorg Amstelveen:; 2000.

(zorgverzekeringen $\mathrm{Cv}$, ed.

19. Evers SMAA, Engel GL, A.J.H.A.Ament. Cost of stroke in the Netherlands from a societal perspective. Stroke. 1997;28(no 7):1375-81.

20. Duncan JS, Sander JWAS. The Chalfont Seizure Severity Scale. J Neurol Neurosurg Psychiatry. 1991;54:873-6.

21. Blom J. The value for society of epidemiology and economics of epilepsy. In: Beran RG, Pachlatko C, eds. Cost of epilepsy. Proceedings of the 20th International Epilepsy Congress. Wehr/Baden: CibaGeigy Verlag; 1995:55-65.

22. Polder JJ, Meerding WJ, Koopmanschap MA, Bonneux L, Maas PJvd. Kosten van ziekten in Nederland 1994 Rotterdam: Instituut Maatschappelijke Gezondheidszorg 1997; 1994.

23. Frost FJ, Hurley JS, Petersen HV, Gunter MJ, Gause D. A comparison of two methods for estimating the health care cost of epilepsy. Epilepsia. 2000;41:1020-6.

24. Torrance GW, Siegel JE, Luce BR. Framing and designing the cost-effectiveness analysis. In: Gold MR, Siegel JE, Russel LB, Weinstein MC, eds. Cost-effectiveness in health and medicine. New York: Oxford University Press; 1996:54-81.

25. Baker GA, Gagnon D, McNulty $P$. The relationship between seizure frequency, seizure type and quality of life: Findings from three European countries. Epilepsy Res. 1998;30:231-40.

26. Elwes RD, Marshall J, Beattie A, Newman PK. Epilepsy and employment. A community based survey in an area of high unemployment. J Neurol Neurosurg Psychiatry. 1991;54(3):200-3.

27. Ziekenfondsraad. Diagnostisch Kompas Amstelveen; 1997. 
9

General discussion 
Epilepsy is a common chronic neurological disorder that affects people worldwide irrespective of age, sex or race, creating significant economic and social burdens. In this thesis the epidemiological as well as the economic aspects of epilepsy have been studied. Thus, this thesis consists of two sections, a section about the incidence and diagnostic aspects of epileptic seizures and a section about the costs of epilepsy. In this chapter, the main findings and conclusions of both sections will be discussed followed by some recommendations for future research.

\section{Incidence of epilepsy and diagnostic aspects of epileptic and non-epileptic seizures}

During the last three decades several studies of the incidence of epilepsy and unprovoked seizures (i.e. seizures that are not resulting from an acute disturbance of brain structure or metabolism or an acute systemic metabolic disturbance) have been performed in industrialized and in developing countries. In a systematic review of the methodology of incidence studies of epilepsy and unprovoked seizures and a meta-analysis of their results, we showed that the age-specific incidence of epilepsy had a bimodal distribution with the highest peak in childhood. Possible causes of epilepsy in childhood are congenital, developmental, and genetic conditions $(1,2)$. The most common cause of epilepsy in the elderly population is cerebrovascular disease (1-3). However, our findings regarding the incidence of unprovoked seizures and other specific incidence rates of epilepsy (i.e. sex-specific incidence and incidence by seizure type) did not reach significance due to the low power of the studies. For the same reason, no definite conclusions could be reached for the trends of both the incidence of epilepsy and unprovoked seizures over time and the pattern of the age-specific incidence of epilepsy in developing countries. In addition, these studies appeared to have a considerable heterogeneity in study design and definitions. Therefore, a sensitivity analysis was carried out by removing successively incidence studies with a low methodological quality score. This resulted in lower median incidence rates of epilepsy and unprovoked seizures, which may reflect a better case ascertainment method, classification, and definition of epileptic seizures. Our evaluation of the methodology of the incidence studies was based on a checklist which we developed according to proposals for reporting meta-analyses of observational studies (4). So far, though, no standardized checklist for the methodological assessment of observational studies has been developed yet.

Similarly, our conclusions from the systematic review of the recent literature on the etiology of the non-epileptic seizures (NES) are not based on a earlier available standardized checklist. We developed a checklist in order to evaluate the methodological quality of the studies reviewed and assess the information provided by these studies regarding the etiology of NES. Concerning the methodological quality of the reviewed studies, this systematic review showed that the studies of NES are characterized by a wide methodological heterogeneity and generally have a low methodological quality. Thus, the quality of evidence regarding the possible risk factors is low. Several psychological factors may underlie the development and maintenance of NES, but a number of issues, such as unclear definition and selection criteria, lack of standardized methods to assess and describe patients with NES, small sample size, short follow up and lack of control groups, inhibit definite conclusions.

Based on the findings of both systematic reviews we concluded that for unbiased evaluations of several variables of interest population-based studies with a prospective design are needed. Therefore, we conducted such a study from October 1, 1998 to September 30, 2000 in Maastricht and its surroundings, which is a well circumscribed area located at the southern part of the Netherlands. In this study a strong effort was made to identify all possible cases with epileptic seizures and to avoid selection bias. For this purpose, the surveillance procedure used several sources to identify cases and all cases were discussed collectively and decisions were consensus-based. A total of 350 cases was entered in this study. Unprovoked 
seizures were diagnosed in the majority of the cases ( $49.7 \%)$, followed by the non-epileptic seizures of organic origin ( $22.3 \%)$, the non-epileptic seizure of non-organic origin $(18 \%)$, and the acute symptomatic seizures $(7.7 \%)$. Ninety-four $(54 \%)$ of the 174 cases with unprovoked seizures fulfilled the diagnostic criteria for epilepsy as they appeared to have had two or more recurrent unprovoked seizures. The comprehensiveness of our case-ascertainment could be confirmed by the fact that for more than half of the patients $(62.4 \%)$ the first seizure had appeared in a period of less than a month. In addition, we also attempted to examine as much as possible cases in a standardized manner. Thus, the information collected would be more likely to provide the clinical details necessary for a reliable diagnosis of the seizures and for an accurate classification of the epileptic seizures according to the ILAE criteria. In all, $71.1 \%$ of the patients were examined in a standardized manner by one of the authors (IK) whereas $28.9 \%$ of the patients were not seen by this author. This last group of patients was consisted mostly of patients who had a bad clinical condition at the time of their admittance and were usually discharged to the nursing homes directly. In a few cases, this last group of patients included patients with a known neurological disease such as brain tumor or cerebrovascular disease. These patients were often referred to the neurologists who had seen them regularly at the outpatient department of neurology. The overall incidence of epilepsy and unprovoked seizures found in this study was similar to results from other population-based studies in industrialized countries. Moreover, the age-specific incidence increased with age in concordance with other studies in developed countries. Similarly, the incidence and distribution of certain seizure types and epilepsy syndromes was in accordance with other studies. However, in this study a relatively high proportion of cases remained unclassified, as compared to other studies (5-7), partly due to differences in the interpretation of the ILAE classification. These difficulties in interpretation of the ILAE classification have also been highlighted by other authors $(8,9)$ and recently, a proposal for a new classification of the epilepsies and epilepsy syndromes has been published (10).

Furthermore, in this study we also focused on the characteristics of the cohort with epileptic and non-epileptic seizures in order to identify predictive factors with which patients with epileptic seizures can be distinguished from patients with non-epileptic seizures. As expected, the strongest predictor for patients with unprovoked seizures was an epileptiform EEG pattern whereas for the patients with non-epileptic seizures of organic origin there was a high probability of a history of hypertension or cardiovascular disease. The predictive model of patients with non-epileptic seizures of non-organic origin included female sex and, quite unexpectedly, a history of head injury. However, there is evidence that a history of trauma and physical abuse may be common in patients with this type of seizures (11). In addition, head injury as an event can give rise to stress in susceptible individuals. However, as this study included no cases who had both epileptic and non-epileptic seizures, these conclusions probably can not be applied to these patients.

Since two thirds of the cases included in this study were evaluated in a standardized manner, we investigated whether there is a cluster of diagnostic items which can assist in the early identification of patients with epileptic seizures. It appeared that certain items from the history, hetero-anamnesis and findings from ancillary tests can be helpful in differentiating epileptic from non-epileptic seizures. In particular, the logistic regression analysis for the group of patients who were evaluated in a systematic way showed that for the subgroup of patients with unprovoked seizures the items loss of consciousness, postictal confusion, epileptiform EEG pattern and abnormal finding on the CT and MRI were a distinctive feature. Similarly, the items female sex and location of the seizure out of doors were diagnostic indicators for the subgroup of patients with non-epileptic seizures of organic origin. The fact that females more often than males consult their physician for episodes of disturbed consciousness (12) and that exercise and warmth were the most common provoking factors 
reported by this group of patients, may explain these items as a distinctive feature for the group of patients with non-epileptic seizures of organic origin. The group of patients with non-epileptic seizures of non-organic origin was characterized with the items a history of febrile seizures, treatment by a psychiatrist or psychologist, more than one seizure experienced, presentiment of the seizure (e.g. a feeling of choking, tingling, palpitations) and back arching during the seizure. These findings are in agreement with other studies which report probable characteristics of this group of patients $(11,13-16)$.

In sum, this study showed that certain ancillary tests (EEG, CT, and MRI) are in particular a diagnostic indicator for the group of patients with unprovoked seizures whereas for the two subgroups of patients with non-epileptic seizures (seizures of organic and non-organic origin) certain items from the history and hetero-anamnesis rather than from ancillary tests seem to be an important distinctive feature. Thus, by obtaining information on certain items from the history and hetero-anamnesis a physician would be able to reach a reliable diagnosis of the non-epileptic seizures at an early stage. In contrast, for the diagnosis of epileptic seizures a physician would first need to apply some ancillary tests in order to obtain more certainty about the diagnosis of these seizures. However, the conclusions of this study are to some extent limited because they are based on a relatively small sample of patients. Only $63(18 \%)$ of the 350 cases included in this study were diagnosed with non-epileptic non-organic seizures. In addition, these findings probably can not be applied to patients in whom both epileptic and non-epileptic seizures co-exist. Therefore, the findings of this study need to be verified by other population-based studies with larger samples of patients. Also, in such studies a further differentiation of subgroups would be possible.

\section{Costs of epilepsy}

Cost of illness (COI) studies estimate the burden of specific diseases in the community. Epilepsy has a financial burden with regard to individual patients and society and in the last few years the costs of epilepsy have been studied in various countries. In a systematic review we first assessed several methodological aspects of these studies and second we compared systematically their results. We found that epilepsy cost studies are not directly comparable due to differences in the methods and definitions used and due to the differences in the health care provision and economic conditions between different countries. We concluded that $\mathrm{COI}$ studies can provide comprehensive estimates of the cost of epilepsy and can assist health policy decisions if they have a transparant methodology and analysis of the data, clearly describe the definitions used, state the limitations of the data, mention which costs are associated with comorbid conditions, and take into account the temporal aspects of epilepsy by stratifying the costs and by obtaining data from a population of patients with epilepsy prospectively.

Furthermore, based on key methodological, country-related, and monetary issues in epilepsy cost studies, we compared the direct cost estimates of studies that have a similar study design and method, and we analyzed the distribution of the direct costs of epilepsy. Thus, we estimated that the proportion of the national health care expenditure on epilepsy varies between 0.12 and $1.12 \%$ or between 0.12 and $1.05 \%$ depending on the type of the conversion factor (i.e. exchange rate, purchasing powers of currencies). In addition, the majority of the epilepsy cost studies assessed the costs of hospital services and the costs of drug treatment. However, the contribution of these costs components to the total direct costs of epilepsy decreases in more comprehensive lists of cost components. In our estimations of the direct costs of epilepsy we encountered a number of limitations related to several methodological issues of the epilepsy cost studies. These limitations are the lack of consideration of the nonmedical and family-related costs, the problem of comorbid conditions, which can lead to an overestimation of the costs of epilepsy, and the variation of the costs by severity of epilepsy. 
Moreover, we did not calculate the indirect and intangible costs of epilepsy. Consequently, our estimations of the costs of epilepsy are conservative. Nevertheless, we concluded that an analysis of the impact of a disease on the national health care expenditure provides the possibility to make comparison across different countries and across different diseases. Since prospective studies can provide reliable data over the costs of epilepsy over time, we prospectively calculated the direct and indirect costs of epilepsy in three different populations of patients with epilepsy: general practices (GP), university hospital (UH), and epilepsy center (EC). These groups of patients reflected patients with a different prognosis of epilepsy. We also used a quality of life inventory to obtain information on the intangible costs of epilepsy (i.e. the economic cost of the burden imposed on the patients as a consequence of their epilepsy). This study showed that the mean costs per patient per month ranged from 52.1 to 357.6 (in Euros €). Unsurprisingly, patients from the GP, who were assumed to have a good prognosis of epilepsy, generated the lowest direct costs and reported lower seizure frequencies and less severe seizure types than the other groups of patients. In contrast, patients from the EC, who were assumed to have an uncertain or bad prognosis of epilepsy, incurred the highest direct costs and had the lowest scores on the quality of life inventory.

Although we attempted to be comprehensive by including as many epilepsy-related cost items as possible, our cost estimations are conservative since we did not put a monetary value on the time costs (i.e. the time a patient spends in seeking or undergoing a treatment) and on the indirect and intangible costs of epilepsy. Our cost estimations encountered also some other limitations. First, the estimations are based on a cost diary which was developed according to cost diaries of other chronic diseases. Second, we assumed that the data have been correctly reported by the patients, since it was difficult to evaluate the value of this information by using other data sources. Third, no patients admitted at the epilepsy center were included in this study. This exclusion means that the true costs of epilepsy care in the epilepsy center are likely to be underestimated. Fourth, the short time perspective of the study (i.e. three months prospectively) may have also afflicted the cost estimations. Despite these limitations, our cost estimations are more comprehensive compared to those of other studies in the Netherlands $(17,18)$, which did not have a prospective design. Our cost estimations proved also to be higher than those estimated in the other Dutch studies $(17,18)$.

\section{Future perspectives}

The prospective population-based study described in this thesis resulted in a cohort of patients with newly diagnosed epilepsy and a cohort of patients with non-epileptic non-organic seizures (NES). Since population-based studies provide the opportunity to make unbiased observations resulting in an elucidation of risk factor-outcome associations, it would be very interesting to enlarge this cohort of patients and study their long-term outcome.

A long-term follow up of patients with newly diagnosed epilepsy can provide more insight into the prognosis of epilepsy, the risk factors for medical resistance, and the associated morbidity and mortality of these patients. Most patients with newly diagnosed epilepsy become seizure free, and the majority of them can also discontinue the antiepileptic drugs without experiencing further seizures. The challenge is to clarify factors associated with a good or bad prognosis. Kwan et al.(19) found in their prospective study of 525 patients with epilepsy that the subgroup of patients who had many seizures before therapy or who had an inadequate response to initial treatment with antiepileptic drugs were more likely to have refractory epilepsy. In addition, there is evidence that patients with epilepsy, particularly patients with epilepsy of unknown cause, are at increased risk for death (20). The reasons for this are unclear. Similar epidemiological projects are now being conducted in other European countries (e.g. Germany, Sweden) and in the future it is likely that through scientific cooperation the long-term outcome of patients with epilepsy will be much more clarified. 
Much less is known about the long-term outcome of patients with NES. Patients with NES are a heterogeneous group and it is important to identify them early in the course of the seizure disorder in order to offer them appropriate treatments. It is still unclear which risk factors contribute to the development and maintenance of these seizures. An enlargement of the cohort of these patients would shed more light on these factors and would help in determining the baseline characteristics of this group of patients. In this way, a cluster of diagnostic and prognostic items with which these patients can be distinguished from patients with epileptic seizures could be defined, and the long-term prognosis could be predicted.

Concerning the costs of epilepsy, in this thesis a new instrument for estimating the costs of epilepsy care prospectively has been investigated. Cost diaries have already been used in cost studies of other chronic diseases and proved to provide detailed and reliable information prospectively (21). In this thesis, the cost diary has been studied in a relatively small sample of patients with epilepsy. Its utility needs to be confirmed in a larger sample of patients with epilepsy. Thereafter, the cost diary can be implemented in other economic evaluations studies (e.g. cost-effectiveness, cost-utility studies), which estimate the value of several interventions for patients with epilepsy. 


\section{REFERENCES}

1. Sander JW, Shorvon SD. Epidemiology of the epilepsies. J Neurol Neurosurg Psychiatry. 1996;61(5):433-43.

2. Hauser WA. Incidence and prevalence. In: jr JE, Pedley TA, eds. Epilepsy: A comprehensive Textbook. Philadelphia: Lippincott-Raven Publishers; 1997:47-57.

3. Stephen LJ, Brodie MJ. Epilepsy in elderly people. Lancet. 2000;355:1441-6.

4. Stroup DF, Berlin JA, Morton SC, et al. Meta-analysis of observational studies in epidemiology. JAMA. 2000;283:2008-12.

5. Zarelli MM, Beghi E, Rocca WA, Hauser WA. Incidence of epileptic syndromes in Rochester, Minnesota: 1980-1984. Epilepsia. 1999;40:1708-14.

6. Manford M, Hart YM, Sander JW, Shorvon SD. National General Practice Study of Epilepsy (NGPSE) partial seizure patterns in a general population. Neurology. 1992;42(10):1911-7.

7. Loiseau J, Loiseau P, Guyot M, Duche B, Dartigues JF, Aublet B. Survey of seizure disorders in French southwest. I. Incidence of epileptic syndromes. Epilepsia. 1990;31:391-6.

8. Blume WT, Berkovic SF, Dulac O. Search for a better classification of the epilepsies. In: Engel J, Jr, Pedley TA, eds. Epilepsy: a comprehensive textbook. Vol. 69. Philadelphia: Lippincott-Raven Publishers; 1997:779-89.

9. Wolf P. International classification of the epilepsies. In: Engel J, Jr, Pedley TA, eds. Epilepsy: $a$ comprehensive textbook. Vol. 68. Philadelphia: Lippioncott-Raven Publishers; 1997:773-7.

10. Engel J, Jr. A proposed diagnostic scheme for people with epileptic seizures and epilepsy: report of the ILAE task force on classification and terminology. Epilepsia. 2001;42:1-8.

11. Krumholz A. Nonepileptic seizures:diagnosis and management. Neuroly. 1999;53(Suppl. 2):S76-S83.

12. Morell DC, Gage HG, Robinson NA. Symptoms in general practice. J R Coll Gen Pract. 1971;21:3243.

13. Alper K. Nonepileptic seizures. Neurologic Clinics. 1994;12(1):153-173.

14. Kristensen O, Alving J. Pseudoseizures-risk factors and prognosis. Acta Neurol Scand. 1992;85:177. 180.

15. Lowman RL, Richardson LM. Pseudoepileptic seizures of psychogenic origin: A review of the literature. Clinical Psychology Review. 1987;7:363-389.

16. Trimble MR. Pseudoseizures. Neurol Clin. 1986;4(3):531-548.

17. Blom J. The value for society of epidemiology and economics of epilepsy. In: Beran RG, Pachlatko C, eds. Cost of epilepsy. Proceedings of the 20th International Epilepsy Congress. Wehr/Baden: CibaGeigy Verlag; 1995:55-65.

18. Polder JJ, Meerding WJ, Koopmanschap MA, Bonneux L, Maas PJvd. Kosten van ziekten in Nederland 1994 Rotterdam: Instituut Maatschappelijke Gezondheidszorg 1997; 1994.

19. Kwan P, Brodie MJ. Early identification of refractory epilepsy. N Engl J Med. 2000;342:314-9.

20. Hauser WA. Overview: epidemiology, pathology and genetics. In: Engel J, Jr, Pedley TA, eds. Epilepsy: a comprehensive textbook. Vol. 2. Philadelphia: Lippincott-Raven Publishers; 1997:11-3.

21. Goossens ME, Rutten van Molken MP, Vlaeyen JW, van der Linden SM. The cost diary: a method to measure direct and indirect costs in cost-effectiveness research. J Clin Epidemiol. 2000;53(7):688-95. 
108 | General discussion 


\section{Summary}

Epilepsy is a complex symptom caused by a variety of pathological processes in the brain. It is characterized by recurrent (two or more) epileptic seizures, unprovoked by any immediate cause. An epileptic seizure has been defined as a clinical manifestation resulting from an abnormal and excessive discharge of a set of neurons in the brain.

After headache, epilepsy is the second most common chronic neurological condition. Epilepsy affects about one of 200 people in the developed countries, creating significant economic and social burdens. The social and personal costs of epilepsy are significant, as evidenced by the high rate of unemployment and underemployment among epileptic patients. The first part of this thesis (chapters 2 to 5) focuses on the incidence (annual rate of appearance of new cases) and diagnosis of epileptic seizures whereas the second part (chapters 6 to 8 ) focuses on the economic aspects of epilepsy.

In chapter 2, a systematic review of incidence studies of epilepsy and unprovoked seizures is described with the aim to evaluate the methodology of these studies and assess the value of their findings by synthesizing their results. The literature for the period January 1966 to December 1999 was searched and independently evaluated by two authors who used a newly developed checklist. In total, 40 studies met the inclusion criteria. There was a considerable heterogeneity in study methodology and the methodological quality was generally low. The median incidence rate of epilepsy and unprovoked seizures was 47.4 and 56/100,000 respectively. The age-specific incidence was high in those aged 60 years or older but the highest in childhood. However, no definite conclusions could be reached for the incidence of unprovoked seizures and other specific incidence rates of epilepsy (sex- and seizure-specific incidence) due to the small number of the incidence studies.

The recent literature (from January 1995 to December 1999) is systematically reviewed in chapter 3 in order to provide more insight into the recent evidence on the risk factors and mechanisms that are associated with the non-epileptic seizures (NES). NES are defined as a sudden change in a person's behavior, which is usually time limited, and is often mistaken for epilepsy, but is unaccompanied with the characteristic changes on the EEG which indicate true epilepsy, and is not caused by an organic disease. The methodological quality was independently evaluated by two authors who used a newly developed checklist. In addition, several items which can provide evidence about the possible risk factors for NES were assessed. Overall, 33 studies met the inclusion criteria. There was a wide heterogeneity in study methodology which was associated with a low methodological quality. While several psychological factors may underlie the development and maintenance of NES, no definite conclusion could be reached regarding their etiology.

Chapter 4 describes a prospective population-based study in the area of Maastricht with the aim to estimate the incidence of unprovoked seizures and epilepsy in this area in relation to age, sex, etiology and seizure type and to identify predictive factors of the epileptic and nonepileptic seizures. All patients aged $\geq 14$ years who have experienced their first seizure or who had undiagnosed seizures before the study period (October 1998 to September 2000) were included in this study. These patients were identified through different sources and were independently evaluated and classified by a team of three neurologists. Moreover, predictive factors for the diagnosis of epileptic and non-epileptic seizures were examined.

The total incidence was $55 / 100,000$ and $30 / 100,000$ for the unprovoked seizures and epilepsy respectively. The age-specific incidence increased with age and was highest for the patients aged $\geq 65$ years. In males the incidence of epilepsy and unprovoked seizures was higher than 
in females and partial seizures prevailed over the generalized seizures. In about $35 \%$ of the patients with epilepsy and epileptic seizures an underlying cause could be identified. The most common causes were cerebrovascular disease and brain tumors. The results of this study are similar to those reported by other developed countries. Furthermore, certain predictive factors were identified for patients with epileptic and non-epileptic seizures of organic origin. These were an epileptiform EEG pattern for the first group and a history of hypertension or cardiovascular disease for the second group of patients. Strong predictors for the patients with non-epileptic seizures of non-organic origin were female sex a history of head injury.

A prospective-population based study of a cohort of patients aged $\geq 14$ years, suspected with a first seizure, is reported in chapter 5 . The aim of this study was to define systematically a cluster of diagnostic items which can assist in the early identification of epileptic and nonepileptic seizures. Two thirds of the patients included in this study were examined in a standardized manner. In these patients, several diagnostic items (history, hetero-anamnesis, and findings from the physical examination and diagnostic tests) for epileptic and nonepileptic seizures were investigated. In total 350 cases were entered in this study. Certain distinctive features for patients with epileptic and non-epileptic seizures of organic origin were identified. For instance, patients with epileptic seizures were characterized with items such as postictal confusion, an epileptiform EEG pattern, and abnormal neuroimaging findings. Similarly, patients with non-epileptic seizures of organic origin were characterized with items such as a history of hypertension, and provoking factors (e.g. exercise and warmth). Distinctive features for the patients with non-epileptic seizures of non-organic origin were items such as a history of febrile seizures, treatment by a psychologist or psychiatrist, presentiment of the seizure (e.g. feeling of choking, palpitations), a history of chronic obstructive pulmonary disease, gradual end of the seizure, and a memory of the seizure. A separate analysis for the patients who were investigated systematically provided some additional diagnostic items for the subgroups of patients with epileptic and non-epileptic seizures. For example, back arching during the seizure for the patients with seizures of nonorganic origin, and female sex for the patients with non-epileptic seizures of organic origin. Concerning the patients who were not examined in a systematic way, no diagnostic item was found that could discriminate significantly the different subgroups of patients.

In chapters 6 and 7 a systematic review of epilepsy cost studies is provided. The purpose of this review is twofold. First, to review systematically key methodological issues of these studies and second, compare in a systematic way the national and per capita estimates of the costs of epilepsy in different countries. The literature was searched from 1966 to March 2000. Several methodological aspects, concerning the study design and estimation procedure used for the calculation of the costs of epilepsy, were examined to the extend to which these aspects have been employed in the studies reviewed. In total, 15 studies were identified and analyzed. $67 \%$ of the selected studies had a retrospective design and used data commonly derived from existing databases. Only a minority of studies used a sensitivity analysis to control for the assumptions made in the calculations. In general, studies of the costs of epilepsy show a wide variation in the methods and definitions used. Therefore, several recommendations were proposed. In particular, a transparant methodology and analysis of the data, a clear description of the definitions used, and consideration of the natural course of epilepsy by analyzing the costs for each prognostic group separately and by obtaining data prospectively, was suggested.

Furthermore, in this review key methodologic, country-related, and monetary issues of the selected epilepsy costs studies were evaluated to compare their direct cost estimates (costs of goods and services used to treat a disease) and to explore their distribution. Ten epilepsy cost 
studies were reviewed. The proportion of national health care expenditure on epilepsy showed a range of $0.12-1.12 \%$ or $0.12-1.05 \%$ depending on the type of the conversion factor. The conversion factors were exchange rate and purchasing power of currencies. Purchasing power parities (PPPs) mean that a given sum of money, when converted into different currencies at the PPPs rates, will buy the same amount of goods and services in all countries. Moreover, it was found that the list of cost components included in the estimation of the direct costs of epilepsy (e.g. drug costs, hospital costs, transportation costs from and to the hospital) differed from study to study. A comprehensive list was associated with a decrease in the contribution of the drug and hospital costs to the total direct costs of epilepsy.

Chapter 8 describes a study of the costs of epilepsy care in three different populations of patients with epilepsy (general practices, university hospital, and epilepsy center). The costs were calculated for three months prospectively by means of a cost diary and for three months retrospectively with a cost questionnaire. In addition, a quality of life inventory was used to obtain insight into the burden imposed on the patients as a consequence of their epilepsy. 116 patients with established epilepsy participated in this study and the mean costs per month ranged from 52.1 to 357.6 (in Euros $€$ ). Patients from the general practices, who were assumed to have a good prognosis of epilepsy, appeared to have lower direct costs, spent less time in seeking or undergoing a treatment, and reported lower seizure frequencies and less sever seizure types than the patients from the other patient groups. In contrast, patients from the epilepsy center, who were assumed to have an uncertain or bad prognosis of epilepsy, reported the highest productivity changes and unemployment rates and also had the lowest scores on the quality of life inventory. Furthermore, higher cost estimations were found in this study compared to other studies in the Netherlands which had a retrospective study design.

In chapter 9 the results of the studies are discussed and some future perspectives are given. The prospective population-based study described in this thesis resulted in a cohort of patients with newly diagnosed seizures and a cohort of patients with non-epileptic non-organic seizures (NES). A long-term follow up and an enlargement of both cohorts has been suggested in order to obtain more insight into the prognosis of epilepsy, the associated mortality and morbidity of patients with epilepsy, and the long-term outcome of patients with NES. In addition, an enlargement of the cohort of patients with NES would help in clarifying which risk factors contribute to the development and maintenance of these seizures, and would help in determining the baseline characteristics of this group of patients. Thus, a cluster of diagnostic items with which these patients can be distinguished from patients with epileptic seizures could be defined. Concerning the study of the costs of epilepsy, the estimation of the costs prospectively were based on a cost diary. More research is warranted to evaluate the utility of this cost diary, which can be also implemented in other economic evaluation studies (e.g. cost-effectiveness, cost-utility studies). Economic evaluation studies could then estimate the value of several interventions for patients with epilepsy. 


\section{Samenvatting}

Epilepsie is een chronische ziekte die kan ontstaan door een groot aantal aandoeningen van de hersenen, zoals een hersentumor, een herseninfarct, een erfelijke aanleg of zo maar, zonder dat een oorzaak kan worden vastgesteld. Wordt de diagnose epilepsie gesteld, dan is er sprake (geweest) van twee of meer epileptische aanvallen die niet werden opgewekt door een directe oorzaak. Deze aanvallen heten dan ook ongeprovoceerde aanvallen. Als onmiddellijk wel een directe oorzaak kan worden aangewezen zoals een klap op het hoofd, een koortsende ziekte, nekkramp met een bijkomende ontsteking van de hersenen, ernstig slaapgebrek of alcoholmisbruik dan spreekt men van acuut symptomatische epileptische aanvallen maar niet van epilepsie.

Een epileptische aanval bestaat uit uiteenlopende klinische verschijnselen die opgewekt worden door spontane, plotselinge en kortdurende ontladingen van een groep hersencellen. $\mathrm{Na}$ hoofdpijn is epilepsie de meest voorkomende chronische neurologische aandoening. Ongeveer een op de 200 mensen in ontwikkelde landen heeft epilepsie, hetgeen betekent dat epilepsie belangrijke economische en maatschappelijke gevolgen heeft. De maatschappelijke en individuele kosten die gepaard gaan met epilepsie zijn niet onaanzienlijk aangezien vele patiënten met epilepsie werkloos zijn of beduidend onder hun opleidingsniveau werken. In Nederland is geen recent epidemiologisch onderzoek gedaan naar het aantal nieuwe gevallen van epilepsie per 100,000 inwoners, naar risicofactoren voor het ontstaan van epileptische en niet epileptische aanvallen en naar de manier waarop je de diagnose epilepsie stelt. Ook de economische aspecten van epilepsie verdienden een nieuw onderzoek in Nederland.

De hoofdstukken twee tot en met vijf van dit proefschrift richten zich op de incidentie (aantal nieuwe gevallen per 100,000 inwoners per jaar) en de diagnose van epileptische aanvallen, terwijl in de hoofdstukken 6 tot en met 8 de economische aspecten van epilepsie worden besproken.

Hoofdstuk 2 biedt een systematisch overzicht van de literatuur betreffende de incidentie van epilepsie en van ongeprovoceerde aanvallen. Van de geselecteerde onderzoeken werd de methodologie beoordeeld en de resultaten samengevat. Hiervoor werd een nieuwe checklist ontwikkeld waarmee twee onderzoekers onafhankelijk van elkaar de literatuur uit de periode januari 1966 tot december 1999 hebben beoordeeld. In totaal voldeden 40 onderzoeken aan de inclusie criteria. Deze onderzoeken verschilden aanzienlijk met betrekking tot de methodologie die veelal ondermaats was. De mediane incidentie ratio van epilepsie en van ongeprovoceerde aanvallen was respectievelijk 47.4 en 56/100,000. De leeftijdspecifieke incidentie van epilepsie was hoog onder mensen van 60 jaar en ouder maar was het hoogst op kinderleeftijd. Desondanks konden met betrekking tot de incidentie van ongeprovoceerde aanvallen en van andere specifieke incidentie ratio's van epilepsie (aanvalstype- en geslachtspecifieke incidentie) geen duidelijke conclusies getrokken worden vanwege het kleine aantal onderzoeken.

In hoofdstuk 3 wordt een systematische samenvatting gegeven van de literatuur van januari 1995 tot december 1999 inzake niet epileptische aanvallen. Er is gekozen voor de periode vanaf januari 1995 omdat in 1994 een nieuwe editie van de DSM criteria gepubliceerd werd (DSM IV) waarmee in de samen te vatten literatuur rekening zou zijn gehouden. Bij het bewerken van de recente literatuur hebben we sterk rekening gehouden met recente inzichten inzake de risicofactoren en de mechanismen die geassocieerd zijn met het ontstaan van niet epileptische aanvallen (NEA). NEA worden gedefinieerd als aanvallen met een plotselinge gedragsverandering, die meestal kortdurend is en vaak lijkt op een epileptische aanval, maar 
die niet gepaard gaat met de voor epilepsie kenmerkende veranderingen op het EEG en waarvoor geen organische oorzaak gevonden kan worden.

Onafhankelijk van elkaar hebben twee onderzoekers de geselecteerde onderzoeken beoordeeld op de methodologische kwaliteit. Hiervoor werd een nieuwe checklist ontwikkeld. 33 onderzoeken voldeden aan de inclusie criteria. Bij deze onderzoeken werden ook de resultaten beoordeeld die inzicht leverden in de mogelijke risico factoren voor het krijgen van NEA. De diverse onderzoeken waren methodologisch vaak verschillend en op zijn best matig van kwaliteit. Hoewel er aanwijzingen zijn dat verschillende psychologische factoren een rol kunnen spelen bij het ontstaan en in stand houden van NEA, was het niet mogelijk om op basis van de recente literatuur duidelijke conclusies te trekken ten aanzien van de etiologie van NEA.

Hoofdstuk 4 beschrijft een prospectief onderzoek onder de algemene bevolking in de regio Maastricht, een aaneengesloten gebied met ongeveer 150.000 inwoners. Doel van dit onderzoek was enerzijds het berekenen van de incidentie van ongeprovoceerde aanvallen en epilepsie in deze regio en anderzijds het bestuderen van deze incidentie in relatie met leeftijd, geslacht, etiologie en aanvalstype teneinde factoren te identificeren die epileptische dan wel niet epileptische aanvallen voorspellen (de voorspellende factoren). Geïncludeerd werden alle patiënten vanaf 14 jaar die gedurende de onderzoeksperiode (1 oktober 1998 tot en met 30 september 2000) een eerste aanval hebben gehad dan wel vóór die onderzoeksperiode aanvallen hebben gehad waarvan de diagnose nog niet bekend was. Deze patiënten werden geìdentificeerd via verschillende bronnen (huisarts, poli neurologie, EHBO en andere afdelingen in het academisch ziekenhuis Maastricht, het enige ziekenhuis in die regio) en werden beoordeeld en geclassificeerd door twee neurologen, die onafhankelijk van elkaar tot een gelijkluidende diagnose probeerden te komen en die bij verschil van mening met de hulp van een derde neuroloog tot een besluit kwamen. Daarnaast werden voorspellende factoren voor de diagnose van epileptische en niet epileptische aanvallen onderzocht.

De totale incidentie was $55 / 100,000$ en 30/100,000 respectievelijk voor de ongeprovoceerde aanvallen en voor epilepsie. De leeftijdspecifieke incidentie nam toe met de leeftijd en was het hoogst bij de patiënten van 65 jaar en ouder. Bij mannen was de incidentie van epilepsie en ongeprovoceerde aanvallen hoger dan bij vrouwen. Daarnaast kwamen de partiële aanvallen vaker voor dan de gegeneraliseerde aanvallen. Bij ongeveer $35 \%$ van de patiënten met epilepsie en epileptische aanvallen kon een onderliggende oorzaak vastgesteld worden. De meest voorkomende oorzaken waren cerebrovasculaire aandoeningen en hersentumoren. De resultaten van dit onderzoek zijn vergelijkbaar met de bevindingen van onderzoeken in andere ontwikkelde landen.

In dit onderzoek werden ook specifieke voorspellende factoren voor epileptische en niet epileptische aanvallen gevonden. Epileptiforme afwijkingen op het EEG bleken voorspellend te zijn voor de groep patiënten met epileptische aanvallen, terwijl hart- en vaatziekten of hypertensie in de voorgeschiedenis voorspellend waren voor de groep patiënten met niet epileptische aanvallen van organische origine. Voor de groep patiënten met niet epileptische aanvallen van niet organische origine bleken het vrouwelijk geslacht en een hersenletsel in de voorgeschiedenis een hoge voorspellende waarde te hebben.

In hoofdstuk 5 wordt een prospectief onderzoek onder de algemene bevolking besproken van een cohort patiënten van 14 jaar of ouder die een eerste aanval hebben gehad. Dit onderzoek had als doel de systematische identificatie van een cluster van factoren waarmee epileptische en niet epileptische aanvallen vroegtijdig gediagnostiseerd kunnen worden. In totaal zijn 350 patiènten geïncludeerd in dit onderzoek. Twee derde van de patiënten zijn op een gestandaardiseerde wijze onderzocht. $\mathrm{Bij}$ deze patiënten zijn verschillende diagnostische 
factoren (voorgeschiedenis, hetero-anamnese, en bevindingen van het lichamelijk en aanvullend onderzoek) voor de epileptische en niet epileptische aanvallen bestudeerd. Via logistische regressie analyse werden de volgende specifieke diagnostische factoren voor epileptische en niet epileptische aanvallen gevonden:

1. patiënten met epileptische aanvallen werden gekenmerkt door factoren als postictale verwardheid, epileptiforme afwijkingen op het EEG en afwijkende bevindingen bij het radiodiagnostisch onderzoek (CT scan, MRI scan);

2. patiënten met niet epileptische aanvallen van organische origine werden gekarakteriseerd door factoren als hypertensie in de voorgeschiedenis en uitlokkende factoren

(bijvoorbeeld warmte en inspanning);

3. patiënten met niet epileptische aanvallen van niet organische origine werden gekenmerkt door koortsstuipen of een chronische obstructieve longziekte in de voorgeschiedenis, behandeling door een psycholoog of psychiater, het voelen aankomen van de aanval (bijvoorbeeld een gevoel van benauwdheid of hartkloppingen), het geleidelijk stoppen van de aanval, en het zich herinneren (althans van een gedeelte) van de aanval.

Een analyse van de groep patiënten die op een gestandaardiseerde wijze werden onderzocht leverde enkele aanvullende diagnostische factoren op voor de subgroepen van patiënten met epileptische en niet epileptische aanvallen:

1. het achterwaarts krommen van de rug tijdens de aanval (waardoor de patiënt als het ware op hielen en achterhoofd staat, de zogenaamde arc de cercle) bleek geassocieerd te zijn met niet-epileptische aanvallen van niet organische origine;

2. het vrouwelijk geslacht bleek geassocieerd te zijn met niet-epileptische aanvallen van organische origine.

Bij de groep patiënten die niet op een gestandaardiseerde wijze onderzocht zijn daarentegen, is geen diagnostische factor gevonden die de verschillende subgroepen van patiënten statisch significant van elkaar kon onderscheiden.

De hoofdstukken 6 en 7 bieden een systematisch overzicht van de onderzoeken naar de kosten van epilepsie. Literatuur uit de periode 1966 tot maart 2000 werd gelezen. Hierbij werd gestreefd enerzijds naar een systematische beoordeling van de methodologie van deze onderzoeken en anderzijds naar een systematische vergelijking van de resultaten van deze onderzoeken in de vorm van de nationale en per individu geschatte kosten van epilepsie in verschillende landen. Verschillende aspecten van de methodologie, zoals de opzet van het onderzoek en de procedure waarmee de kosten van epilepsie geschat zijn, zijn onderzocht naar de mate waarmee deze aspecten zijn toegepast in de geselecteerde onderzoeken. In totaal werden 15 onderzoeken geselecteerd en geanalyseerd. Van de geselecteerde onderzoeken had $67 \%$ een retrospectieve opzet en gebruikte gegevens van bestaande databestanden. Opvallend was dat slechts een klein percentage van de onderzoeken een gevoeligheidsanalyse heeft gebruikt als controle voor de veronderstellingen die gemaakt zijn tijdens de berekeningen. Over het algemeen vertoonden de onderzoeken naar de kosten van epilepsie een grote variatie in de toegepaste methoden en definities. Naar aanleiding hiervan zijn verschillende aanbevelingen geformuleerd zoals:

(a) het gebruik van een transparante methodologie en analyse van de data;

(b) een duidelijke beschrijving van de toegepaste definities;

(c) een kostenanalyse naar prognose zodat rekening wordt gehouden met het natuurlijke beloop van epilepsie;

(d) het verzamelen van prospectieve data.

In het literatuur overzicht werden ook methodologische, land gerelateerde, en monetaire aspecten van de geselecteerde onderzoeken beoordeeld om de directe kosten van epilepsie (kosten die gemaakt worden om een ziekte te behandelen) en hun verdelingspatroon te 
kunnen vergelijken. Tien onderzoeken naar de kosten van epilepsie werden hiervoor geselecteerd. Het percentage van de nationale uitgaven in de gezondheidszorg op het gebied van epilepsie varieerde tussen $0.12-1.12 \%$ of $0.12-1.05 \%$, afhankelijk van het soort conversie factor. De conversie factoren waren de wisselkoers en de kooppariteiten. Een kooppariteit is gelijk aan het bedrag dat nodig is om een identieke set goederen en voorzieningen in verschillende landen te kunnen kopen. Daarnaast bleek dat in deze onderzoeken de schatting van de directe kosten van epilepsie gebaseerd was op een verschillend aantal kostenposten (bijvoorbeeld kosten van medicamenten, ziekenhuiskosten, transportkosten van en naar het ziekenhuis). Hoe groter het aantal kostenposten hoe kleiner het aandeel van de ziekenhuiskosten en van de kosten van medicamenten was aan de totale kosten van epilepsie.

In hoofdstuk 8 wordt een onderzoek naar de kosten van epilepsie in drie verschillende populaties van patiënten met epilepsie beschreven (huisartspraktijken, academisch ziekenhuis, en epilepsiecentrum). De kosten werden berekend enerzijds prospectief voor drie maanden door middel van een kostendagboek en anderzijds retrospectief voor eveneens drie maanden met een vragenlijst. Hierbij werd ook een vragenlijst over de kwaliteit van het leven gebruikt om meer inzicht te verkrijgen in de ziektelast ten gevolge van epilepsie. 116 patiënten met epilepsie namen deel aan dit onderzoek en er werd geconstateerd dat de gemiddelde kosten per maand varieerden van 52.1 tot $357.6 €$. Patiënten uit de huisartspraktijken, voor wie een relatief gunstig beloop van hun epilepsie verondersteld kon worden, hadden lagere directe kosten, besteedden minder tijd aan het zoeken of ondergaan van een bepaalde behandeling, en rapporteerden lagere aanvalsfrequenties en minder ernstige typen aanvallen dan de patiënten afkomstig uit de twee andere patiëntengroepen. Patiënten uit het epilepsiecentrum daarentegen, die doorgaans een onzekere of een slechte prognose van epilepsie hebben, rapporteerden de grootste veranderingen in productiviteit en in werkloosheid cijfers, en scoorden ook het laagst op de vragenlijsten over de kwaliteit van het leven. In dit onderzoek waren de schattingen van de directe kosten van epilepsie hoger dan in andere onderzoeken in Nederland die uitsluitend een retrospectieve opzet hadden.

In hoofdstuk 9 worden de resultaten van de onderzoeken besproken en enkele toekomst perspectieven weergegeven. Het prospectief onderzoek onder de algemene bevolking uit dit proefschrift resulteerde in een cohort van patiënten met epileptische en niet epileptische niet organische aanvallen (NEA). Bij dit onderzoek werden ook een aantal diagnostische factoren gevonden waarmee patiënten met NEA sneller door de behandelend arts herkend kunnen worden.

Een langdurige follow-up en een vergroting van beide cohorten kan meer inzicht leveren in de prognose van epilepsie, de hiermee samenhangende mortaliteit en morbiditeit, en de lange termijn prognose voor de patiënten met NEA. Een vergroting van het cohort patiënten met NEA kan ook bijdragen aan het vaststellen van de risico factoren die een rol spelen in het ontstaan en persisteren van dit type aanvallen en in het herkennen van verschillende basale kenmerken van deze groep patiënten. Hierdoor is het mogelijk om een aantal diagnostische factoren te definiëren waarmee patiënten met NEA kunnen worden onderscheiden van patiènten met epileptische aanvallen.

Met betrekking tot het onderzoek van de kosten van epilepsie, is de schatting van de directe prospectieve kosten gebaseerd op een kostendagboek. Geconcludeerd werd dat meer onderzoek nodig is om de waarde van dit kostendagboek te kunnen evalueren. Dit kostendagboek kan ook toegepast worden in andere economische evaluatie onderzoeken (bijvoorbeeld kosten-effectiviteit, kosten-utiliteit) zodat de kosten van verschillende interventies op het gebied van epilepsie berekend kunnen worden. Middels kostendagboeken kunnen ook de kosten van andere aandoeningen berekend worden, waardoor economische 
vergelijkingen tussen de verschillende ziekten mogelijk worden. Dit laatste zou dan uiteindelijk de weg openen om op een verantwoorde wijze de voor de gezondheidszorg beschikbare gelden op een effectieve en eerlijke wijze te verdelen. 
118 | Samenvatting 


\section{Acknowledgements}

This manuscript offers an impression of the scientific work that has been done during the last four years and still has to be done. During the past four years I met a lot of people who helped me to complete this manuscript. At this point, I would like to thank some of them more specifically:

-Patients: I am really grateful for your cooperation and enthusiasm.

-Prof. Dr. André Knottnerus: Your advices and kind words were of great value to me.

-Prof. Dr. J. Troost: I am very grateful for the interest and confidence you showed in my work.

-Dr. Marc de Krom: I enjoyed working with you and I appreciate the fact that you always kept your door open for me, even for a small talk.

-Dr. Tiny van Merode: Thank you for your valuable suggestions which often offered a different view on certain subjects.

-Fons Kessels: It was inspiring to work with you and I learned a lot during our meetings. -Jan Lodder: I own you many thanks for the patience you showed while working through all the incident cases.

-Dr. André Ament and Dr. Silvia Evers: I enjoyed working with you and your advices and suggestions were of great importance to me. Now, thanks to you, I know a lot more about economic evaluation studies.

-Mascha Twellaar: Your assistance meant a lot to me. Without your thorough work, I am sure we wouldn't have included as many patients as we did.

-I would also like to thank the co-workers of MEMIC for the data processing.

-Furthermore, I like to express my gratitude to all neurologists, my colleagues, the nurses of the department of Neurology, the co-workers of the outpatient department of Neurology, of the department of Clinical Neurofysiology (head: Prof. Spaans), of the department of Neuroradiology (head Prof. Wilmink), and of the secretary of Neurology, who in their specific way helped me with this study.

-Finally, I would like to thank all my friends and family for their kind support. Especially, I am grateful for my parents for their invaluable support through all the years. As for you Vincent, I can only say: I am glad I met you. 


\section{Curriculum vitae}

Irene Kotsopoulos was born on February 11, in 1971 in Apeldoorn. After graduating from high school in Larisa (Greece) she decided to study medicine in Nijmegen. In November 1996 she completed her medical training and became a resident at the department of Neurology in the St Maartens Gasthuis hospital in Venlo. In 1998 she moved southwards and started with a study on epilepsy at the department of Neurology of the Maastricht University Hospital. Since October 2001 she is in training as a resident at the department of Neurology of the Maastricht University Hospital (head Prof. Dr. J. Troost). 



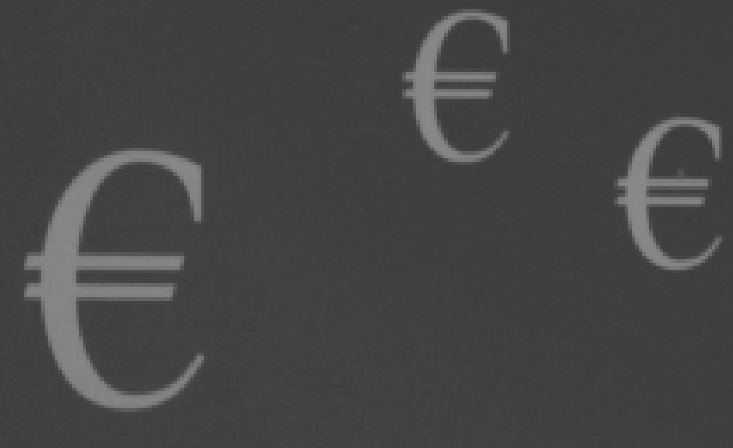

$€$ 